$\frac{225}{m-3}+5$

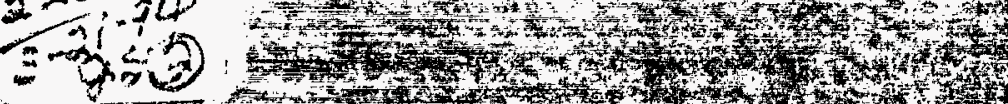

a

2010

ENGINEERING AND SCIENCE ACCOMPLISHMENTS

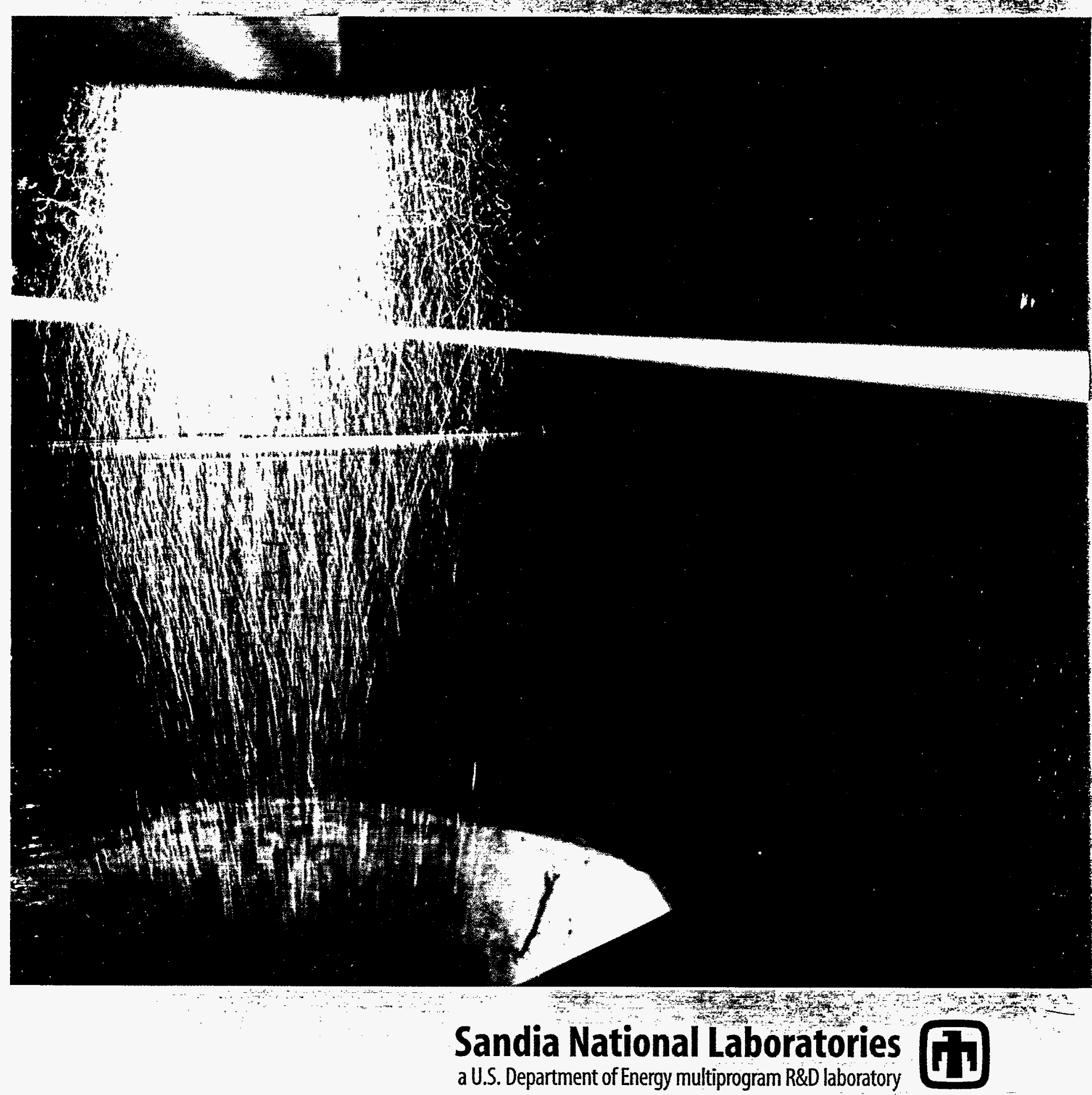




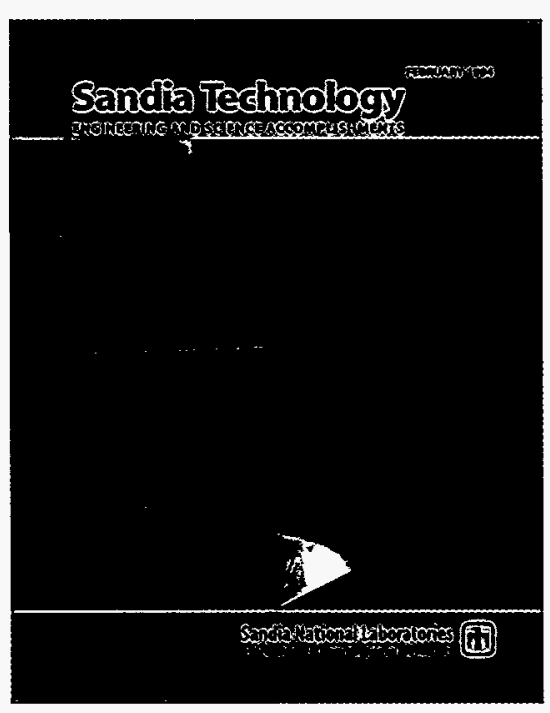

This report was prepared as an account of work sponsored by an agency of the United States Government. Neither the United States Government nor any agency thereof, nor any of their employees, makes any warranty, express or implied, or assumes any legal liability or responsibility for the accuracy, completeness, or usefulness of any information, apparatus, product, or process disclosed, or represents that its use would not infringe privately owned rights. Reference herein to any specific commercial product, process, or senvice by trade name, trademark, manufacturer, or otherwise, does not necessarily constitute or imply its endorsement, recommendation, or favoring by the United States Government, or any agency thereof. The views and opinions expressed herein do not necessarily state or reflect those of the United States Government or any agency thereof.

This work performed at Sandia National Laboratories is supported by the U.S. Department of Energy under contract DE-AC04-94AL85000.
On the cover:

Sandia's Multifuel Combustor allows simulation of combustion conditions in a commercial furnace or boiler. It can be used to test a wide variety of fuels, such as natural gas, oil, pulverized coal and solid or liquid biomass.

\section{A Note on Acronyms}

In an effort to make this document easy to read, acronyms are generally avoided. When unfamiliar acronyms must be used, they are explained in the proximate text. Acronyms that occur freely in popular or news publicationsacronyms such as DOE, DoD, EPA, and NASAoccur in the document without explanation. 


\section{DISCLAIMER}

This report was prepared as an account of work sponsored by an agency of the United States Government. Neither the United States Government nor any agency thereof, nor any of their employees, make any warranty, express or implied, or assumes any legal liability or responsibility for the accuracy, completeness, or usefulness of any information, apparatus, product, or process disclosed, or represents that its use would not infiringe privately owned rights. Reference herein to any specific commercial product, process, or service by trade name, trademark, manufacturer, or otherwise does not necessarily constitute or imply its endorsement, recommendation, or favoring by the United States Government or any agency thereof. The views and opinions of authors expressed herein do not necessarily state or reflect those of the United States Government or any agency thereof. 


\section{DISCLAIMER}

Portions of this document may be illegible electronic image products. Images are produced from the best available original document. 


\section{President's Message}

Sandia began a new era on Oct. 1, 1993, when Martin Marietta Corp. took over management of the Labs from AT\&T, the company that had managed Sandia for more than 40 years. Like AT\&T, Martin will continue to meet the challenge issued by President Truman in 1949 to provide "exceptional service in the national interest." Under Martin's leadership, Sandia will continue to go beyond the call of duty in fulfilling its mission as a multiprogram laboratory of the Department of Energy.

The future holds a formidable challenge for Sandia and all the national laboratories. In today's post-Cold War era of shrinking military budgets and nuclear disarmament, Sandia's role will change. This change is already evident in our increased responsibilities in the areas of nuclear dismantlement and treaty monitoring in the former Soviet Union and elsewhere. The future is also evident in our growing efforts to build partnerships with American industry to transfer new technologies to the private sector for peaceful application. This economic cooperation will help maintain America's competitiveness and economic leadership around the world.

The challenge we face as a Department of Energy laboratory is to implement these changes without eroding the unique capabilities that enable the national laboratories to respond quickly and effectively to strategic uncertainties. It is our job to plan and manage the future of the labs very carefully, and we share this responsibility with the Energy Department.

At Sandia, one of the ways we are preparing for the future is by pursuing strategic initiatives that will address the large-scale technology problems facing industry and the nation: advanced manufacturing technology, electronics, information and computational technology, transportation technology and infrastructure, environmental technology, energy technology, biomedical systems engineering, and post-Cold War defense imperatives. Sandia is making important contributions in these areas, helping to strengthen U.S. economic competitiveness and security.

In this 1994 issue of Sandia Technology, you will have an opportunity to read about some of our work in these initiatives. I hope you will find this information timely and useful.

Al Narath
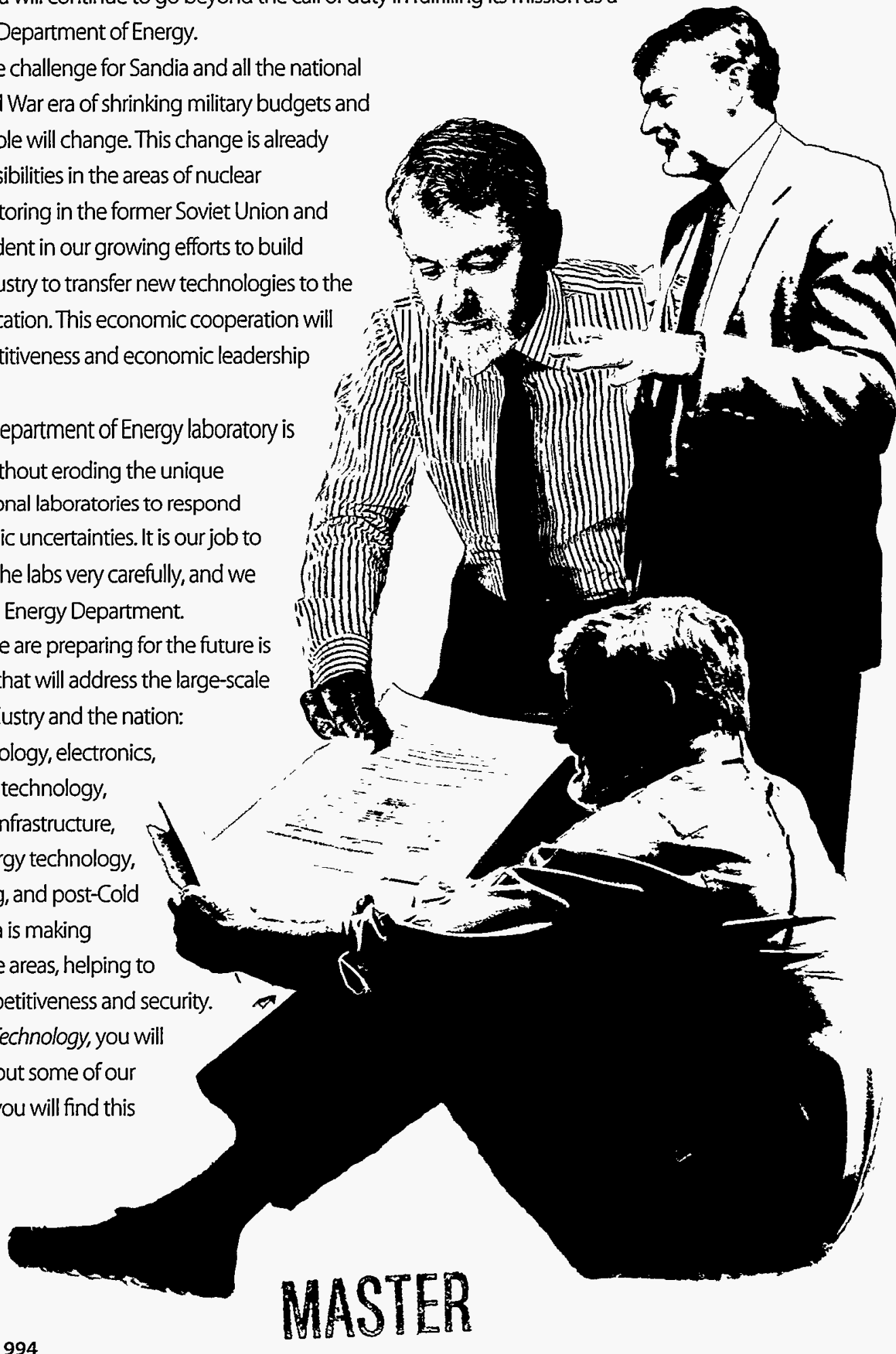


\section{Contents}

Sandia Technology

Engineering and Science Accomplishments

Advanced Manufacturing - Sandia technology helps keep U.S. industry in the lead.

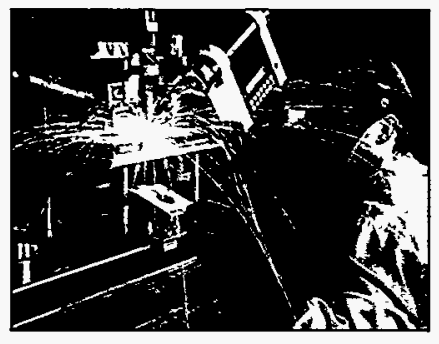

Information components are focus of new center

NCAICM will develop manufacturing tools for electronics plants and

processes for making displays and other components

Booming business

Electric igniter can inflate air bags or excavate rock

Industrial-strength fibers

Sol-gel processes, once used for car mirrors, have many manufacturing applications

Microelectronics - Sandia's unique facilities transform research advances into manufacturable products.

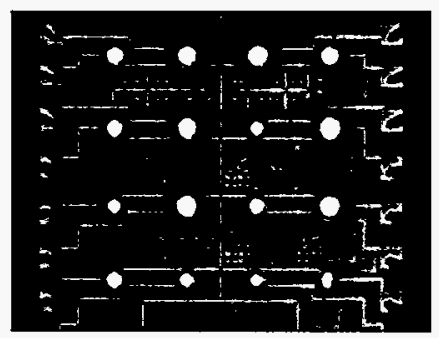

The $1^{\text {st }}$ practical visible microlaser

Revolutionary laser-on-a-chip has host of new applications

Detecting chemical emissions

Tiny quartz microsensor identifies airborne pollutants

Quartz, silicon, and microsensors

Combined technologies open new fields for miniature sensors

Energy - Sandia's energy programs focus on strengthening industrial growth and political decisionmaking.

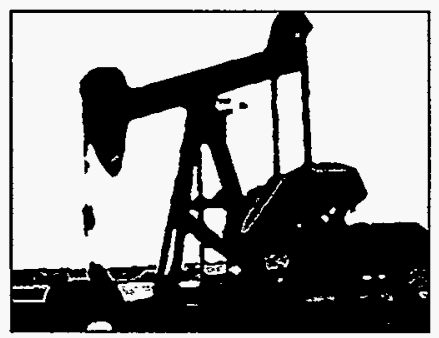

Sustaining domestic oil production

Computer model predicts cleanup of wax in wells

Cleaner coal power

Sandia helps solve ash-related problems in coal-fired boilers

Containing the 'China Syndrome'

Sandia scientists boil water from inside out and upside down

Environment - Sandia is a leader in environmentally conscious manufacturing and hazardous waste reduction.

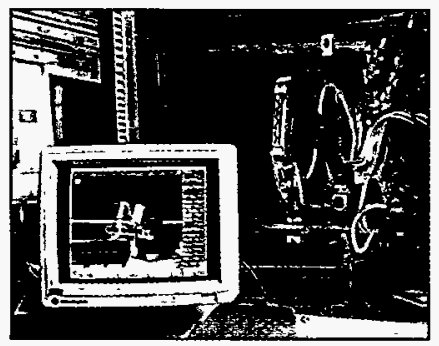

Robotic cleanup

For humans handling radioactive waste, video control is better than being there ......30

Recycling made easy

Sandia-designed system sorts plastics automatically

Toxic waste

Government, academia, and business become partners in landfill cleanup .34 
Health Care - New biomedical technologies help reduce cost and improve quality of health care.

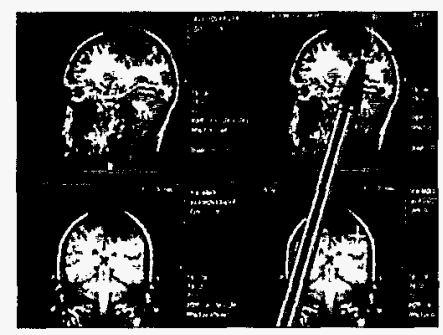

A delicate operation

Massively parallel computing could help guide brain surgery

A better fit

Joint project with the University of Texas focuses on design of prosthetic devices ....40

Shining a laser for burn surgery

Biomedical technology transfer agreement will help

reduce trauma of treatment for severe burn victims

Information \& Computation - Sandia aims to help make the Information Age a reality.

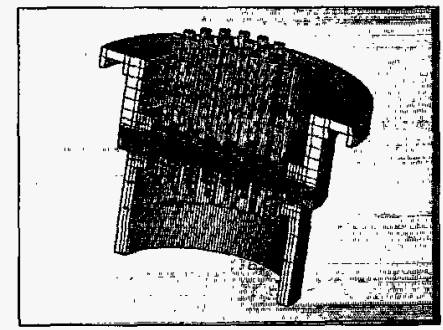

Meshing 3-d surfaces for quicker design

New "paving" algorithm speeds product analysis

Industry ties

From high-speed computing to business networking,

Sandia improves electronic communications

\section{Protecting information}

From medical histories to credit card accounts,

Sandia is helping safeguard confidential data

Transportation - This new initiative at the Labs will help improve transportation, safety, efficiency, and economy.

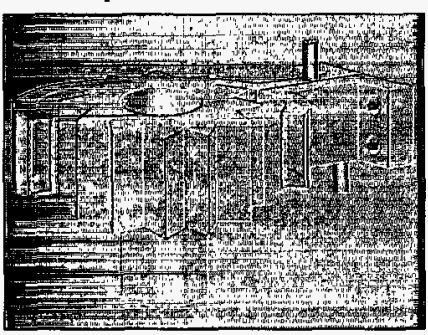

GM CRADAs open avenue for Sandia's technology

Sandia and GM look at several technologies to lessen environmental

impact and improve manufacturing processes

Good vibrations

Active control eliminates noise or unwanted motion

Safer transportation

Satellite-based information systems provide more than cable television

Nonproliferation - Dismantlement and arms control are major areas of emphasis at Sandia.

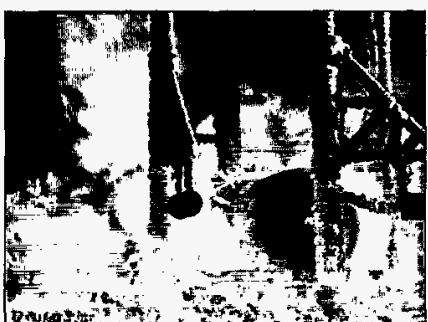

With kid gloves

Protective containers help prevent dismantlement disaster

Porous metals cross old barriers

Lightweight materials may have many applications

Old enemies, new partners

Working with the FSU to ensure nuclear safety

Awards and Patents - Talented, dedicated employees are the backbone of Sandia's success.

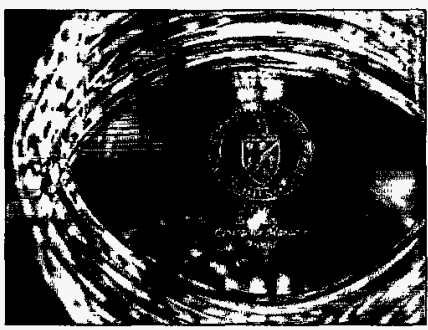

Awards .70

Patents 


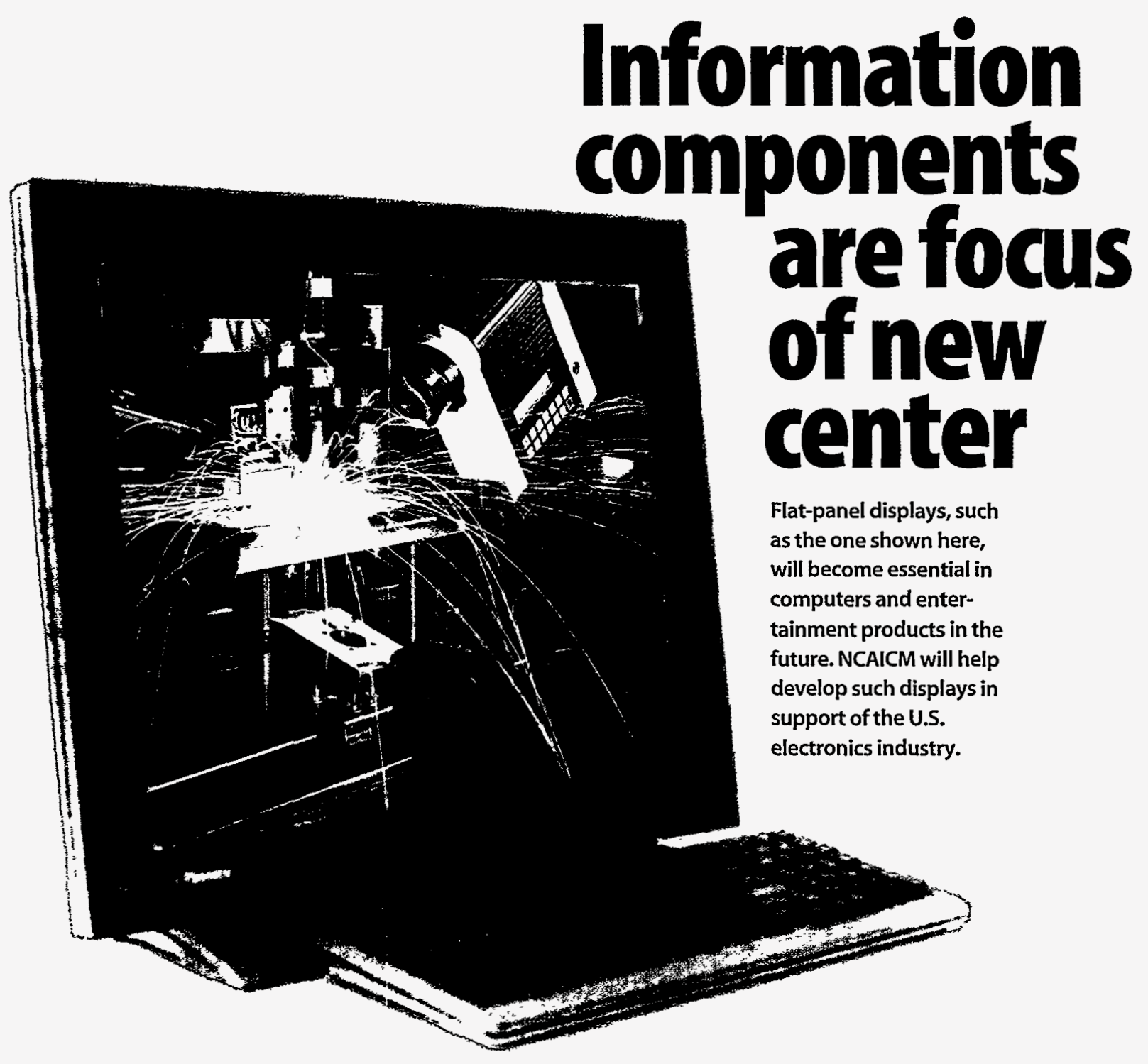




\section{Booming business}

\section{Electric igniter can inflate air bags or excavate rock}

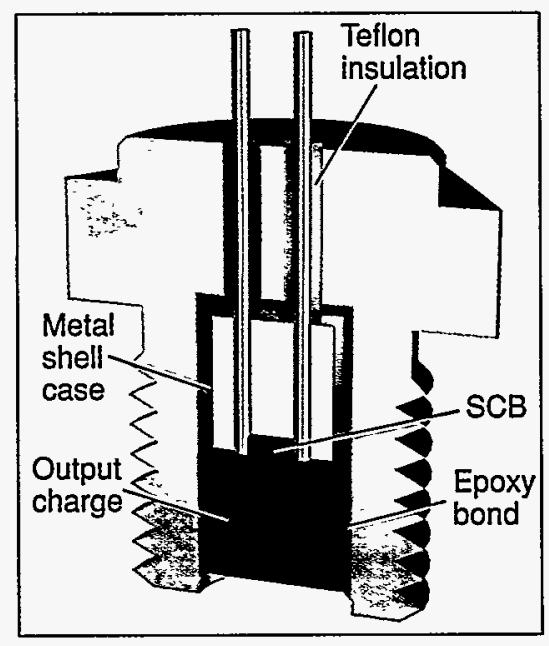

This cross section of a semiconductor bridge device shows the explosive output charge pressed against the polysilicon SCB chip. ig John, the legendary miner of song who saved his buddies' lives by holdDing up a collapsing beam, might not have been buried 600 feet under if mining had been done then like it is today.

In the old days, a miner would step back from an explosive, light a fuze, and duck to avoid flying debris. Later, electrically fired blasting caps attached to long cables became the norm. Nowadays, not only mining, but automobile air bag inflation, explosive bolts, oil well drilling, special effects, satellite deployment, and building demolition can be accomplished with an electric igniter developed at Sandia. Also known as a semiconductor bridge, the device sits on a microelectronic chip smaller than the letters on a penny. The SCB is quicker, more reliable, more precise, and safer than conventional hot wires used to set off explosives.

The SCB was invented at Sandia, and marketing studies done by graduate business students at the University of New Mexico concluded that the product had profit potential. The students made it the focus of an entrepreneurial course; ultimately, UNM's Technology Innovation Center and Sandia's Technology Transfer Department helped form SCB Technologies Inc., a company whose principal stockholders are UNM and New Mexico Tech. SCB then licensed the technology to Thiokol Corp. in Maryland for use in rock blasting, mining, and vehicle airbags and is negotiating more applications with other firms.

So how might the small and humble SCB have saved Big John? Through greater accuracy and less vibration.

"The primary advantage of SCB is precision timing. Precisely timed explosions result in less ground shock, which means fewer complaints from surrounding communities. The shock waves can be phased to cancel each other and minimize ground tremor," says Sandia scientist Bob Bickes, who invented the SCB with now retired Sandian AI Schwarz about 10 years ago. Since then, many research groups at Sandia have continued to improve and refine SCBs.

Miners may use several hundred such initiation devices at once. If the detonations are timed to go off at just the right moment in several different places, the rock breaks in a predictable pattern - forming, for example, an archshaped tunnel through a mountain.

Precisely timed explosions also result in very uniform rubblization - the fragmented rock has fewer oversized particles, making it easier to process and less likely to damage rock-crushing machinery.

This level of precision requires microsecond accuracy. Conventional hot wires ignite explosives within a few milliseconds when they are heated by an 
electrical current. SCB ignitions take place in microseconds, 1,000 times quicker and therefore more predictable than hot wires.

The SCB is essentially a polysilicon circuit that vaporizes into a plasma-a minute cloud of ionized silicon atoms - when an electric current passes through it. This hot gas has sufficient energy to initiate an explosive by percolating into a powderbed and setting it off. The process requires less than onetenth the energy needed for conventional hot-wire ignition, and can save medium- to large-scale mining operations hundreds of thousands of dollars a year, estimates Bickes.

But the SCB's use is not limited to explosives. In the case of air bags, for example, entirely different energetic materials are used that do not detonate, but burn rapidly and then ignite a propellant, causing the air bag to inflate.

SCBs can also be combined with sophisticated circuitry, essentially becoming part of a "smart" system. "SCBs can be used to initiate a precisely timed sequence of events," says Bickes, "such as a seatbelt that tightens just before an air bag inflates."

In fact, an SCB can ignite less sensitive materials than those presently used in automobiles. Because they require less energy, they can operate multiple air bags without overtaxing car batteries. SCBs are also resistant to severe environments such as heat and vibration that an air bag must typically withstand.

Formore information, call Bob Bickes

Explosive Components

(505) 844-0423

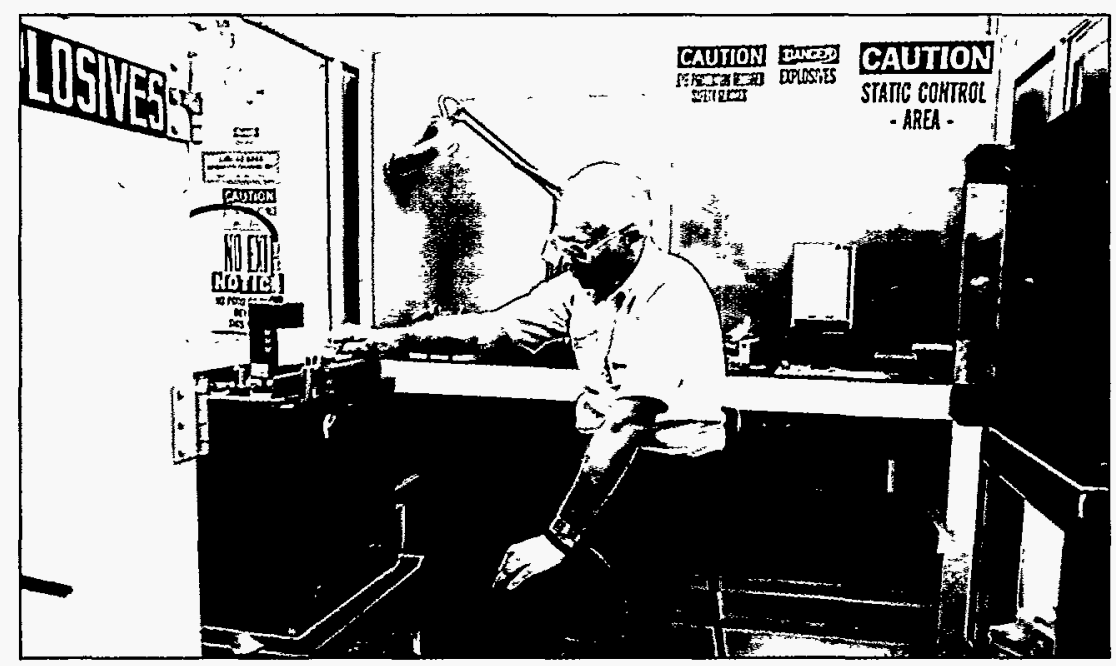

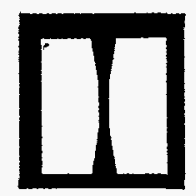

The microelectronic chip that holds Sandia's semiconductor bridge is smaller than the letters on a penny.

Scientist Bob Bickes, coinventor of the semiconductor bridge, checks the performance of one of the devices in a special test lab. 


\section{Industrial-strength fibers}

\section{Sol-gel processes, once used for car mirrors, have many manufacturing applications}

In the 1950s, automakers used sol-gel (solution-gelation) processes to protect rear-view mirrors for automobiles.

The mirror base was dipped in a liquid containing a colloidal suspension of titanium dioxide particles - the sol-gel. When the mirror was removed from the liquid, it was dried and baked, leaving behind a thin, reflective layer on the mirror as the solvent evaporated.

Today, advanced materials research at Sandia is expanding sol-gel technology to improve the performance of such diverse items as antireflective and antiscratch coatings, bullet-resistant textiles, lightweight and high-strength metal matrix composites for engine parts, biological and chemical sensors, and even microfilters for water or wine.

Computer modeling at Sandia is improving the understanding of the physics of sol-gel processes. Sandia researchers have long used computer modeling to design protective coatings for weapons and antireflective coatings for solar energy collectors. Their research has led to sophisticated models that have a variety of potential industrial applications. This expertise is available to industry to help optimize and control coating processes, such as simulating the physics of dip coating in sol-gels for making sensors, membranes, and coatings, or simulating the extrusion and drying of individual sol-gel fibers.

"Modeling sol-gel film and fiber formation processes has led to unique and exciting challenges in numerical computation," says Sandia researcher Randy Schunk. "Meeting these challenges has opened up many new opportunities in the simulation of manufacturing processes."

For example, $3 \mathrm{M}$, a leading manufacturer of special materials, is utilizing Sandia's computer model predictions to aid in the spinning of inorganic fibers from sol-gel to reinforce metals such as aluminum or titanium. These metal matrix composites can be used to produce strong, lightweight parts for aircraft, bicycle frames, or cars.

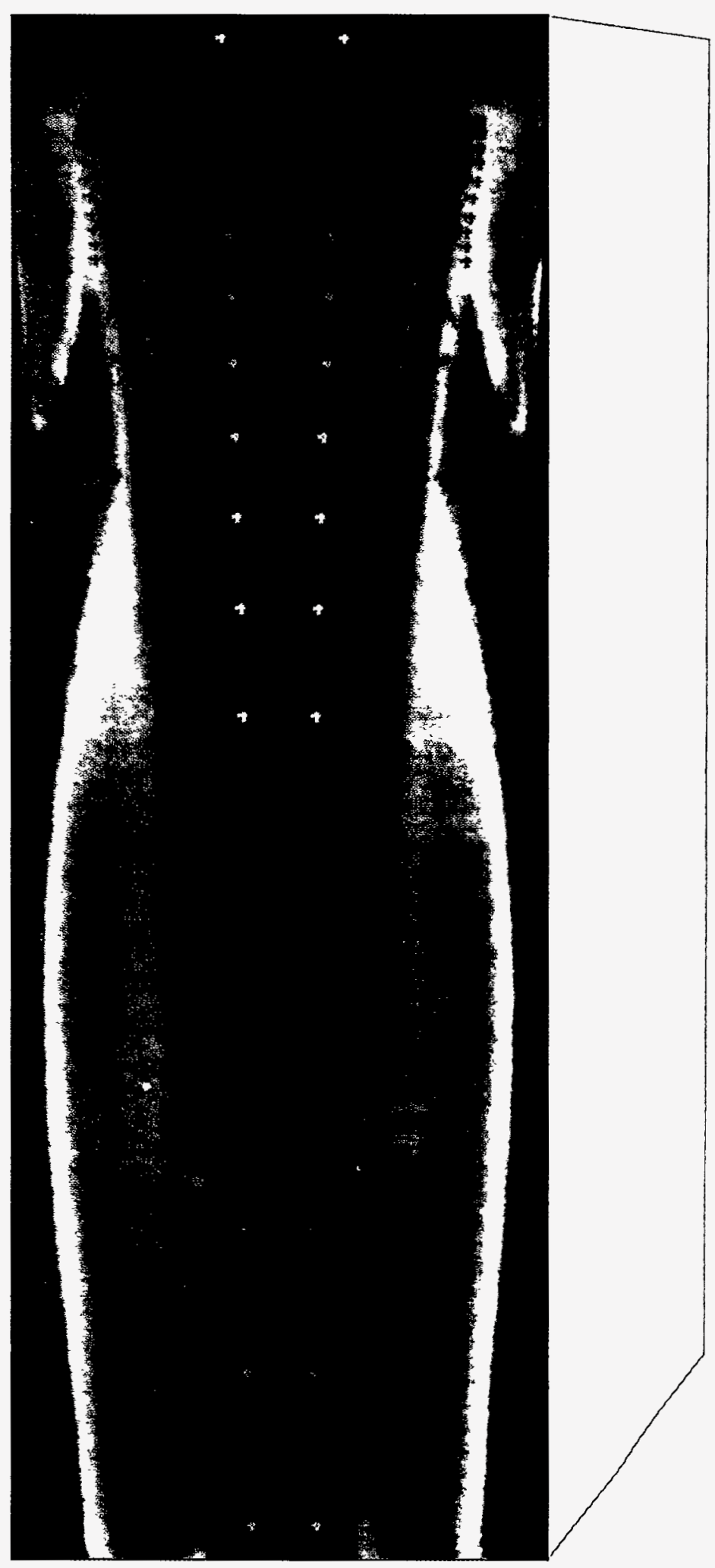




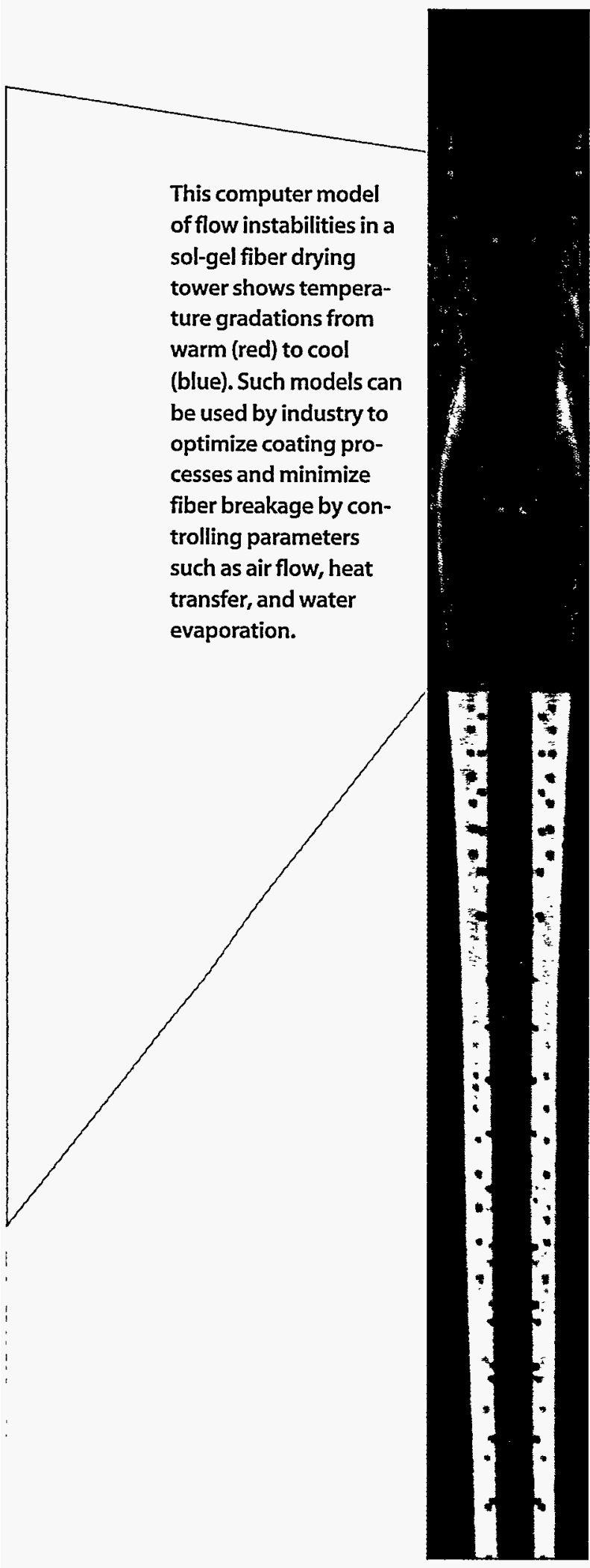

To produce the fibers, $3 \mathrm{M}$ extrudes a sol-gel through tiny holes into a drying tower. As the fibers fall in the tower, moist, heated air is blown in to help evaporate the excess liquid, leaving behind the thin but very tough sol-gel fibers. The computer models help identify tower operating conditions that optimize fiber properties and minimize fiber tangling and breaking by predicting the parameters, such as air flow, heat transfer, and the evaporation rate of water, needed to produce a particular kind of fiber from a sol-gel, notes researcher Greg Evans, at Sandia's California facility.

Materials made by sol-gel processing can have a variety of properties, depending on how they are deposited and treated. If allowed time to react, sol-gel particulates may agglomerate-become denser and form branched, long-chain polymers. The porosity of the polymers is thus directly controlled by the speed of the reaction and drying. If the sol-gel is heated, the polymer chains form a hard, glassy film useful as a surface protectant or antireflectant.

Using computer models, manufacturers can tailor sol-gels to have specific microstructural properties, such as a certain density, pore size, thickness, or surface area. Sol-gels can be used to make industrial filters or sensors with molecular voids of just the right size to detect or capture specific pollutants in air or water.

Sol-gel processes are often more cost-effective and environmentally benign than more conventional methods of producing lightweight, strong composites, such as chemical vapor deposition, evaporation, or spraying. Solvents in the sol-gel process can be recovered and recycled, and sol-gels can be used to treat many kinds of surfaces or to produce stand-alone fibers. 因

Formore information, call Randy Schunk Computational Fluid Dynamics (505) 844-5992

AlHurd Ceramic Processing Science (505) $845-8629$

Greg Evans ComputationalMechanics (510) 294-2795 

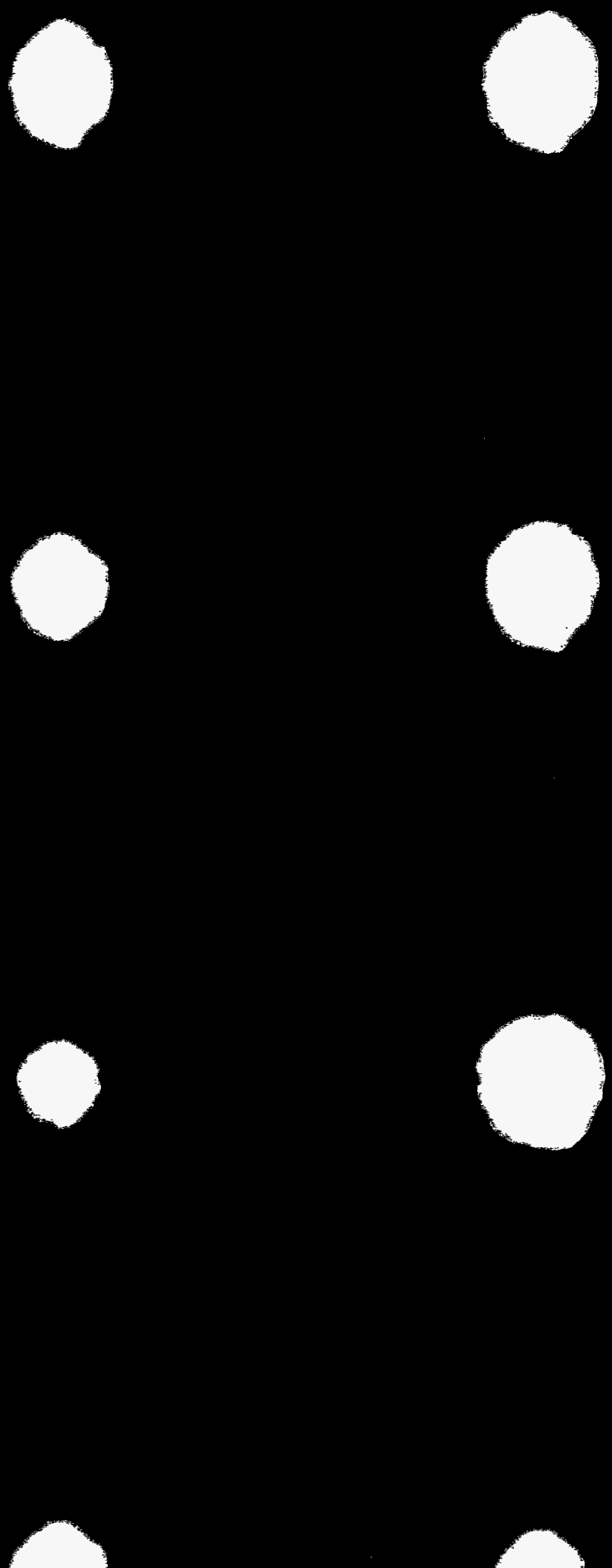

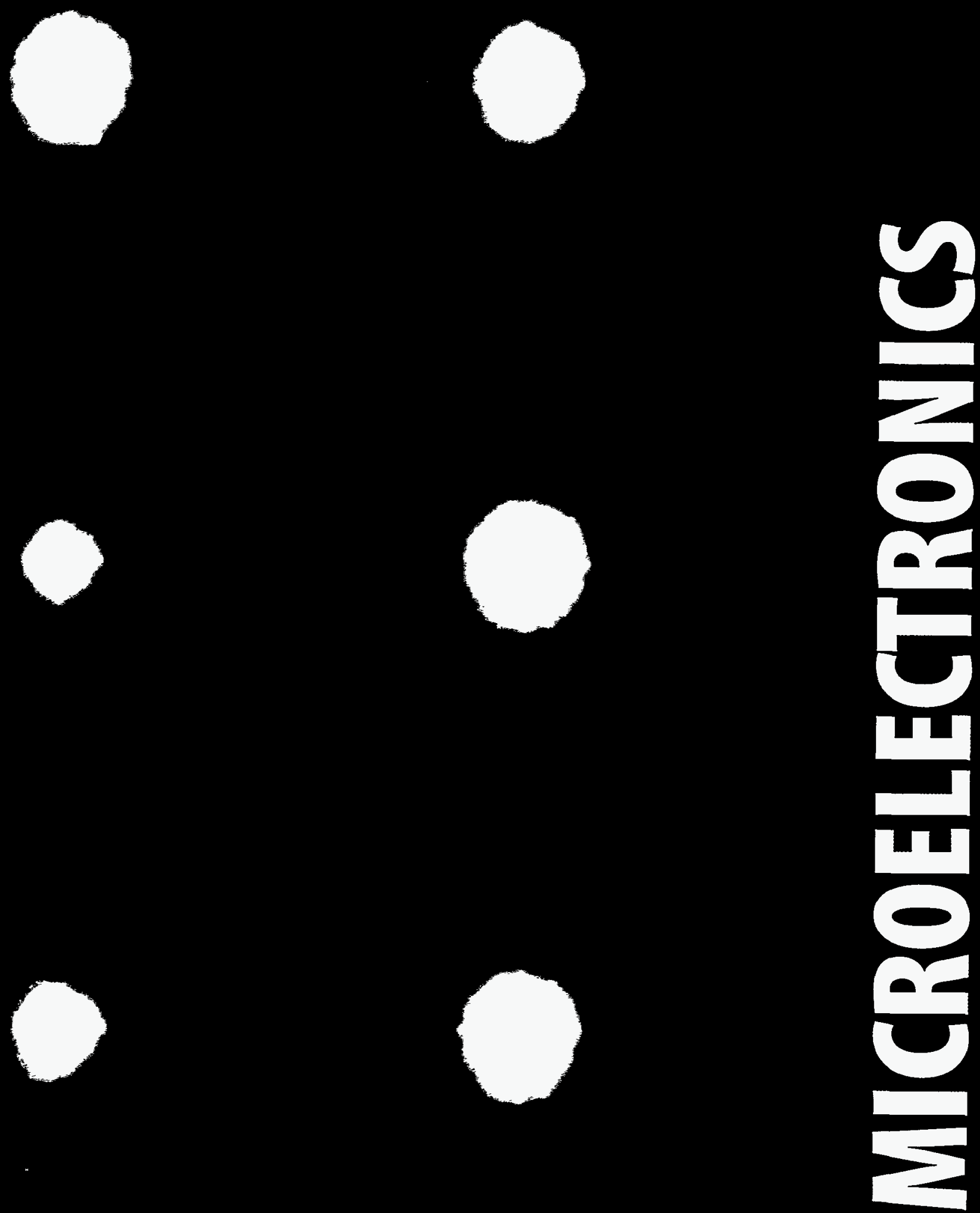

$>1$

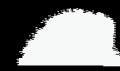




\section{the 1st practical visible microlaser}

Revolutionary laser-on-a-chip has host of new applications

Electrically excited, pulsed VCSEL arrays Jewell, AT\&T Bell Labs

First VCSEL Iga, Japan

VCSEL development Sandia (right side) and others (left side). As the timeline shows,

Sandia has been a primary contributor to VCSEL research and development. Background color corresponds to the part of the spectrum in which VCSELs have emitted visible light.
Continuous-wave, electrically excited visible VCSEL Schneider et al.

Electrically excited, pulsed visible VCSEL

Lott and Schneider

Mirror and process improvements (infrared VCSEL)

Lear and Chalmers

Visible VCSEL

Schneider et al.

Formore information, call Adelbert Owyoung PhotonicsResearch (505) $844-5481$

Richard Schneider SemiconductorMaterials (505) 844-0668

Room-temperature epitaxial VCSEL

Gourley and Drummond
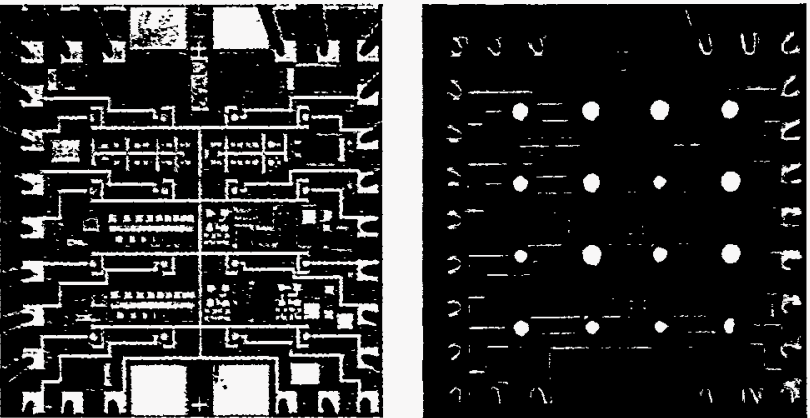

A 4-by-4 array of visible-light-emitting vertical cavity surface-emitting lasers (VCSELs) before and after being electrically pulsed. Since development of this array, Sandia scientists have developed a VCSEL that emits a continuous wave when a constant current is applied. 


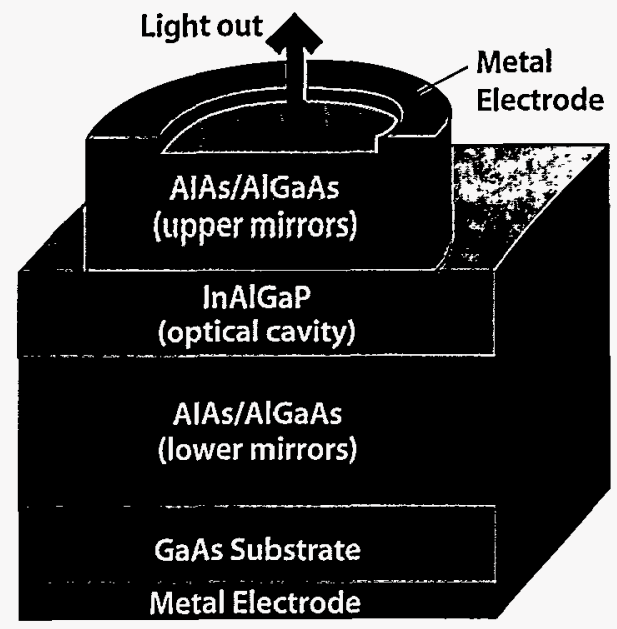

The VCSEL: How it's made, what it looks like, how it works

The VCSEL is built by sequentially layering many different semiconductor materials using growth techniques such as molecular beam epitaxy or metallorganic vapor-phase epitaxy. This process "spray paints" beams of atoms on a semiconductor substrate. By mixing and matching these layers, crystals can be precisely built to optimize electrical and optical properties.

The resulting structure resembles the inside of a sandwich: the center layer is a light-emitting optical cavity; the surrounding layers are aluminum-arsenide/aluminum-gallium-arsenide mirrors. The optical cavity region consists of layers composed of combinations of indium, gallium, aluminum, and phosphorus. Electrical charges approaching from the mirror layers above and below get trapped and recombine in this cavity to emit red light. The mirrors reflect the emitted light, which is amplified in the central layer, to produce the laser beam.
Imagine the following machines in the office of the future:

A digital visual projection display system that fits in the palm of the hand. An inexpensive, high-resolution color laser printer. Speed-of-light optical computer components that don'theat up. Smaller, cheaper bar code scanners.

These and other revolutionary laser-based applications will soon be possible with the help of a tiny microlaser, developed at Sandia and sponsored by the Energy Department's Core Competency Program.

Called a vertical cavity surface-emitting laser (VCSEL, pronounced "vixel"), this tiny laser emits a steady, concentrated, visible beam of 660- to 680-nanometerwavelength light from an aperture 5 to 50 micrometers in diameter-between one-twentieth and one-half the thickness of a strand of human hair. This is the world's first VCSEL that can emit continuous visible light when turned on at room temperature by constant electrical current. The new VCSEL "is ideal for the many applications where focusing to a small spot or coupling to an optical fiber is needed," reports the August 1993 issue of Physics World.

Because the electrically driven VCSEL can be manufactured in closely packed arrays, some observers believe it will have the same effect on computer and communication technologies that the transistor had in the early 1960 s. Today the laser of choice for compact-disc players, laser printers, and fiber-optic communications is the edge emitting semiconductor laser, which emits light sideways from the edge of the semiconductor chip. The VCSEL is not only several hundred times smaller, it emits light perpendicular to the chip's surface. This feature makes it easy to fashion closely packed arrays of lasers the way integrated circuit technology made it possible to fit thousands of transistors on a tiny chip, and also enables economical waferlevel testing.

"It should be possible to put more than 10,000 of these devices on a single two-inch wafer," notes Sandia researcher RickSchneider. As an added advantage, the VCSEL does not require the expensive beam-focusing optics necessary for edgeemitting lasers.

The visible-light VCSEL is the outgrowth of years of research. Following demonstration of the VCSEL concept by researchers at the Tokyo Institute of Technology in 1979, Sandia researchers Paul Gourley and Tim 'Drummond developed the first roomtemperature, optically pumped VCSEL in 1986. After AT\&T inventor Jack Jewell designed the first electrically driven VCSEL array in 1989, RickSchneider and others developed the first VCSEL that emitted visible light in 1991 . Since then, Sandia has continued to improve the VCSEL, increasing its electrical efficiency and manufacturability.

Sandia's most recent achievement is continuous-wave operation of visible-light VCSEL s at room temperature. “This means the device can be operated without cooling; and from a direct current source, eliminating the need for expensive current pulse generation electronics," notes Jim Lott, an Air Force officer and student at the University of New Mexico who helped develop the new VCSEL while on assignment at Sandia. "These developments have captured the interest of many major optoelectronics companies," observes Schneider. Sandia is now exploring working agreements with several manufacturers to develop VCSEL applications. 团 


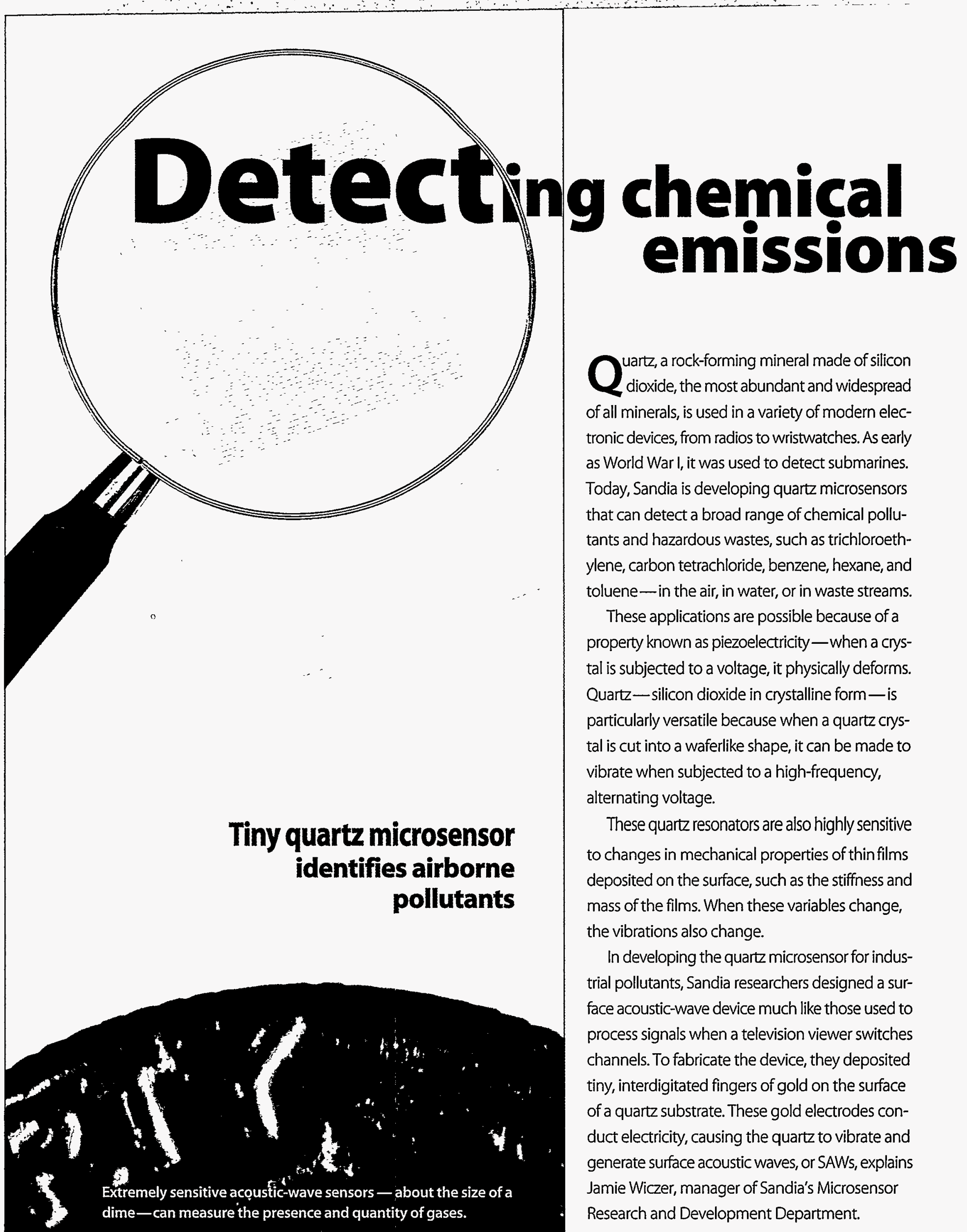


Surface acoustic waves are similar to Rayleigh waves in an earthquake; they propagate only on the surface, not through the bulk of a material. On a quartz wafer, their peak amplitude may be on the order of 10 nanometers 10 billionths of a meter. But because of the acute sensitivity of the quartz device, a change in weight amounting to only nanograms (billionths of a gram) is enough to change the perturbations in the surface acoustic waves.

The individual microsensors, which are actually small pieces of crystalline quartz coated with special films, are connected to microcircuits that can be attached to a laptop computer and plugged into the cigarette lighter of a car. These features make the sensor system very portable for working in the field - for example, to detect chemical emissions at a waste site or a manufacturing plant.

Sandia recently tested the quartz microsensors at AlliedSignal Kansas City to monitor emissions from solventspraying operations used to clean printed circuit boards, says chemical engineer and project leader Greg Frye. The work was sponsored by Sandia's Environmentally Conscious Manufacturing program, a high-priority effort of the Department of Energy. Sandia researchers detected trichloroethylene emitted into the atmosphere on the order of 2,000 parts per million.

Chemists then recommended switching to d-limonene, a much safer substitute for TCE. Workers who use

Sandia Technology • February 1994 spray guns to clean the circuit boards also began using laptop computers to get constant readings of TCE emissions. They soon discovered that they could control emissions to a large degree based on how they pointed the spray gun and how they mixed air and solvent in the gun.

In the end, the Sandia-AlliedSignal team reduced emissions from 2,000 ppm to $40-50 \mathrm{ppm}$, a factor of 40 reduction.

The acoustic sensor is one of several classes of microsensors developed at Sandia. A semiconducting silicon sensor designed at Sandia detects hydrogen and other gases, and has been tested for use on NASA's space shuttle fueling system. A fiber-optic sensor to measure martian soil properties has been developed in a joint Sandia-Jet Propulsion Laboratory program and will be on board a U.S.-Russian Mars probe to be launched from Russia in October 1994. 因
For more information, call

James Wiczer

Microsensor Research \& Development (505) 844-5672

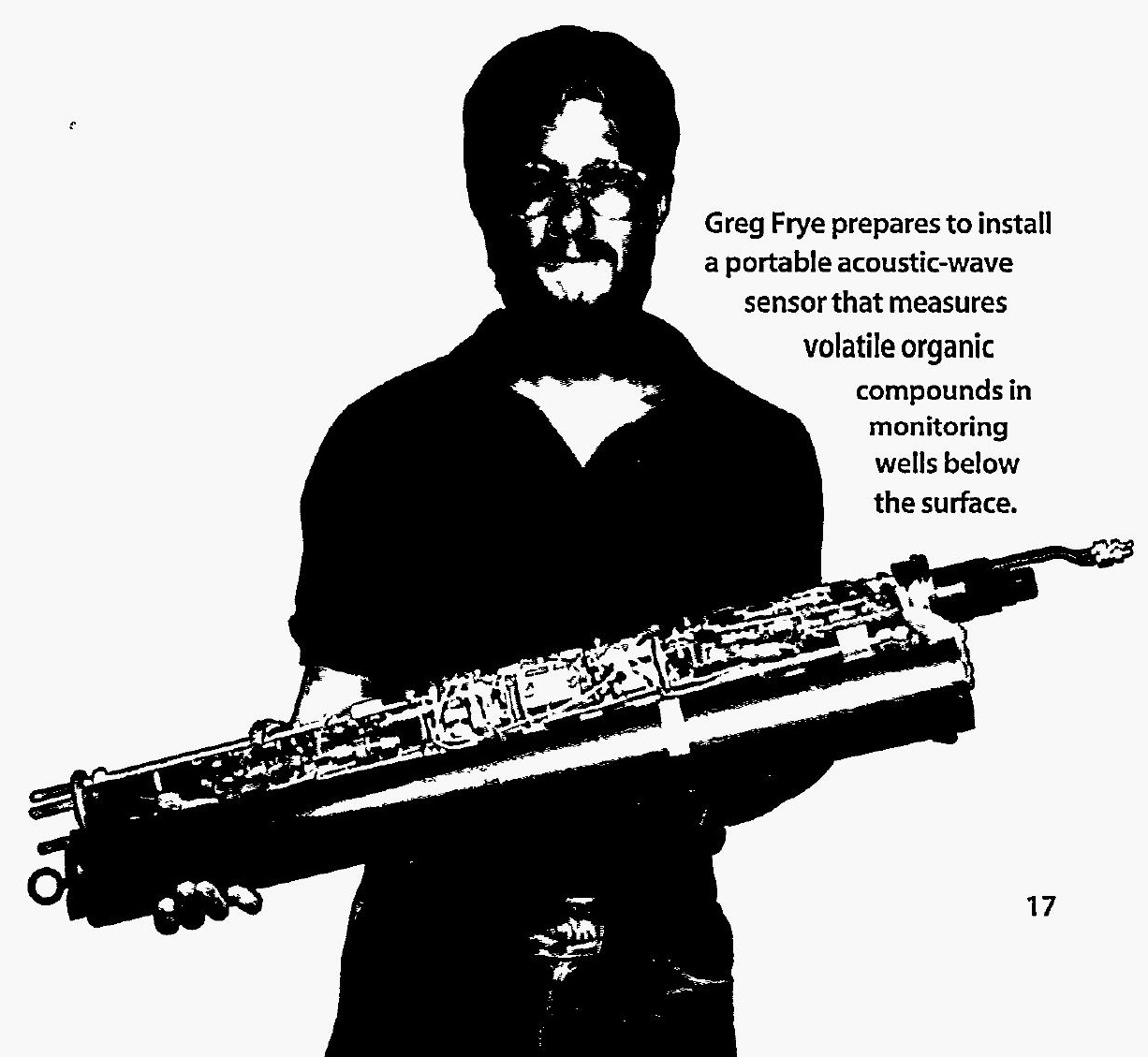

Greg Frye prepares to install portable acoustic-wave vor that measures ile organic compounds in monitoring wells below the surface. 


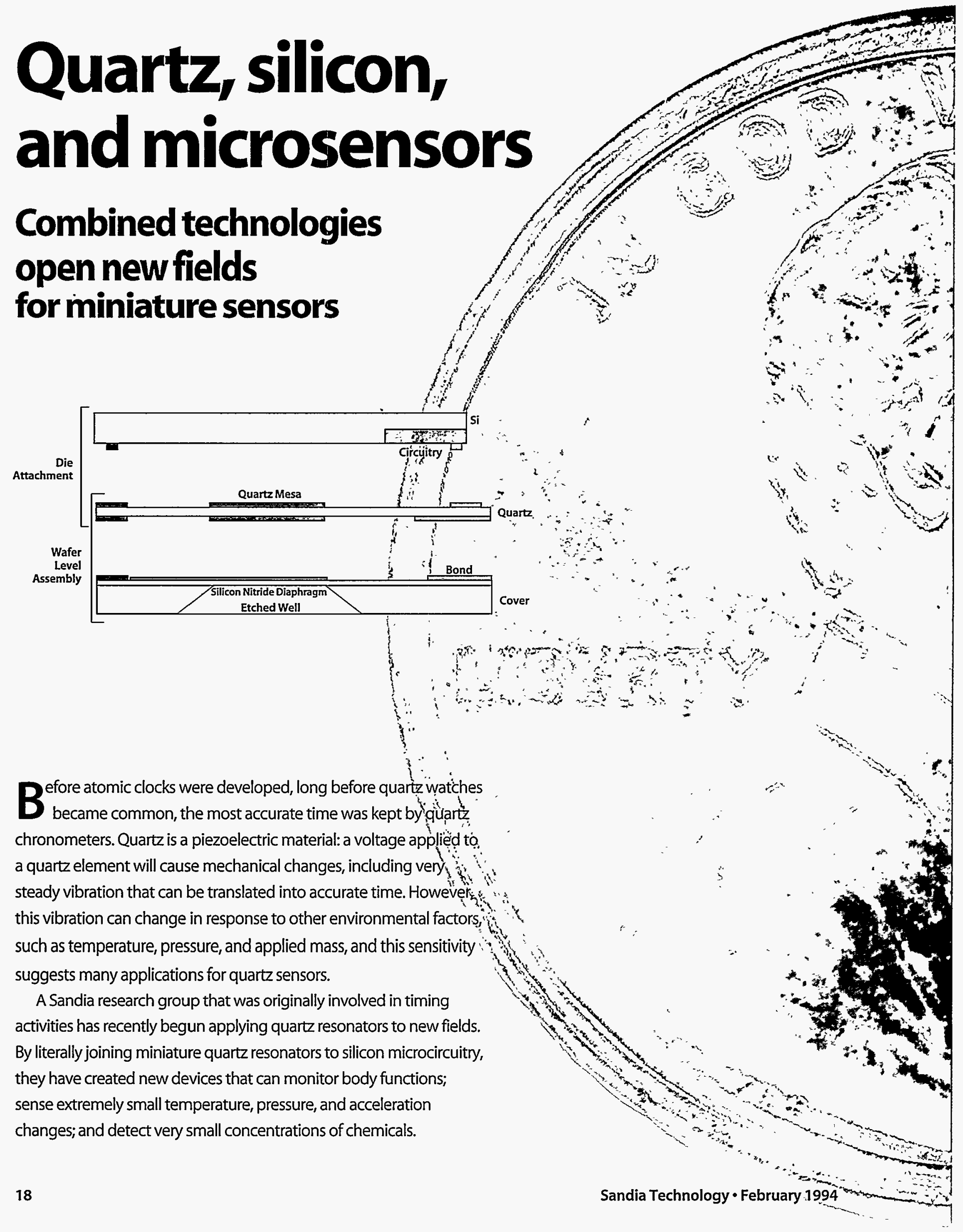




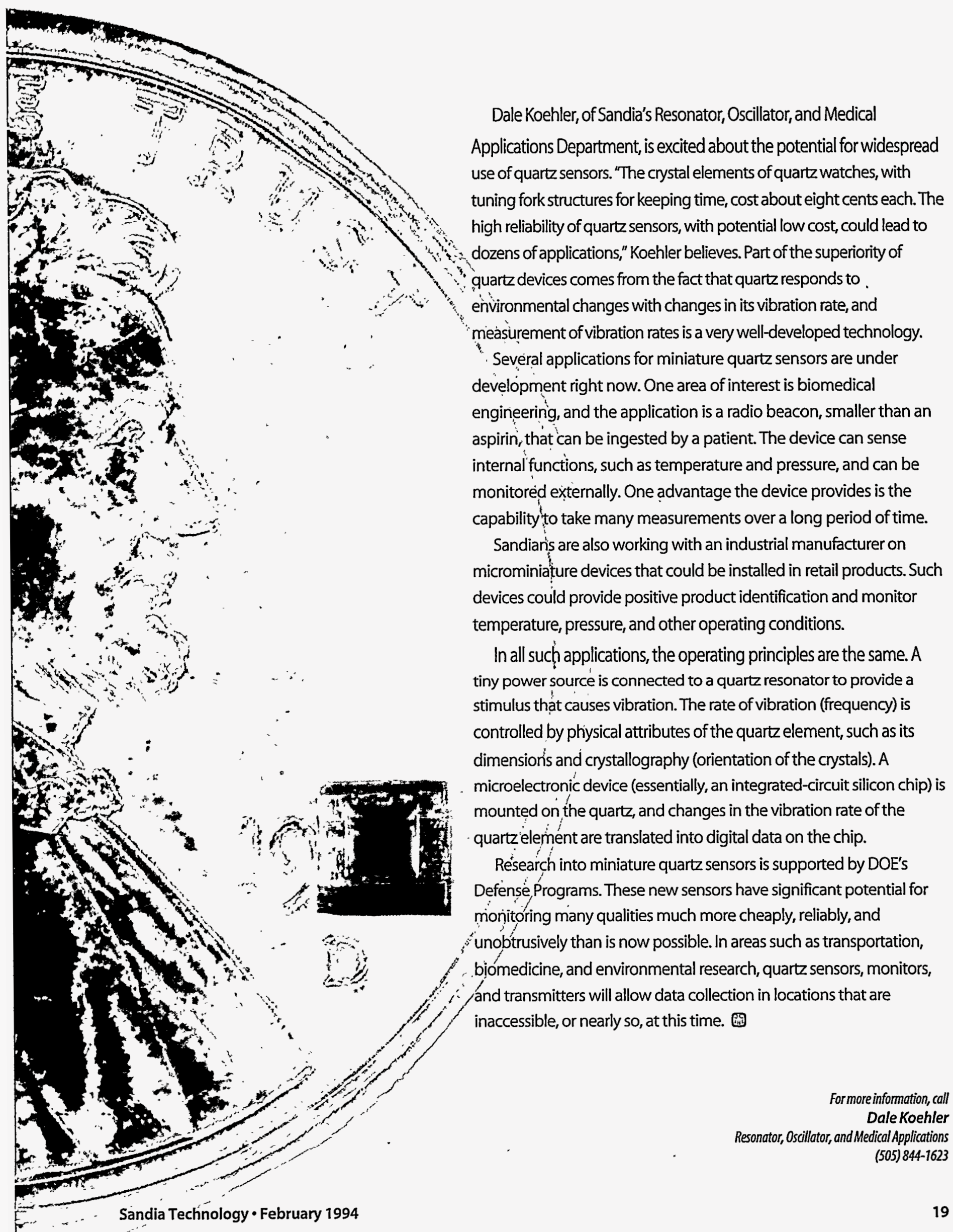




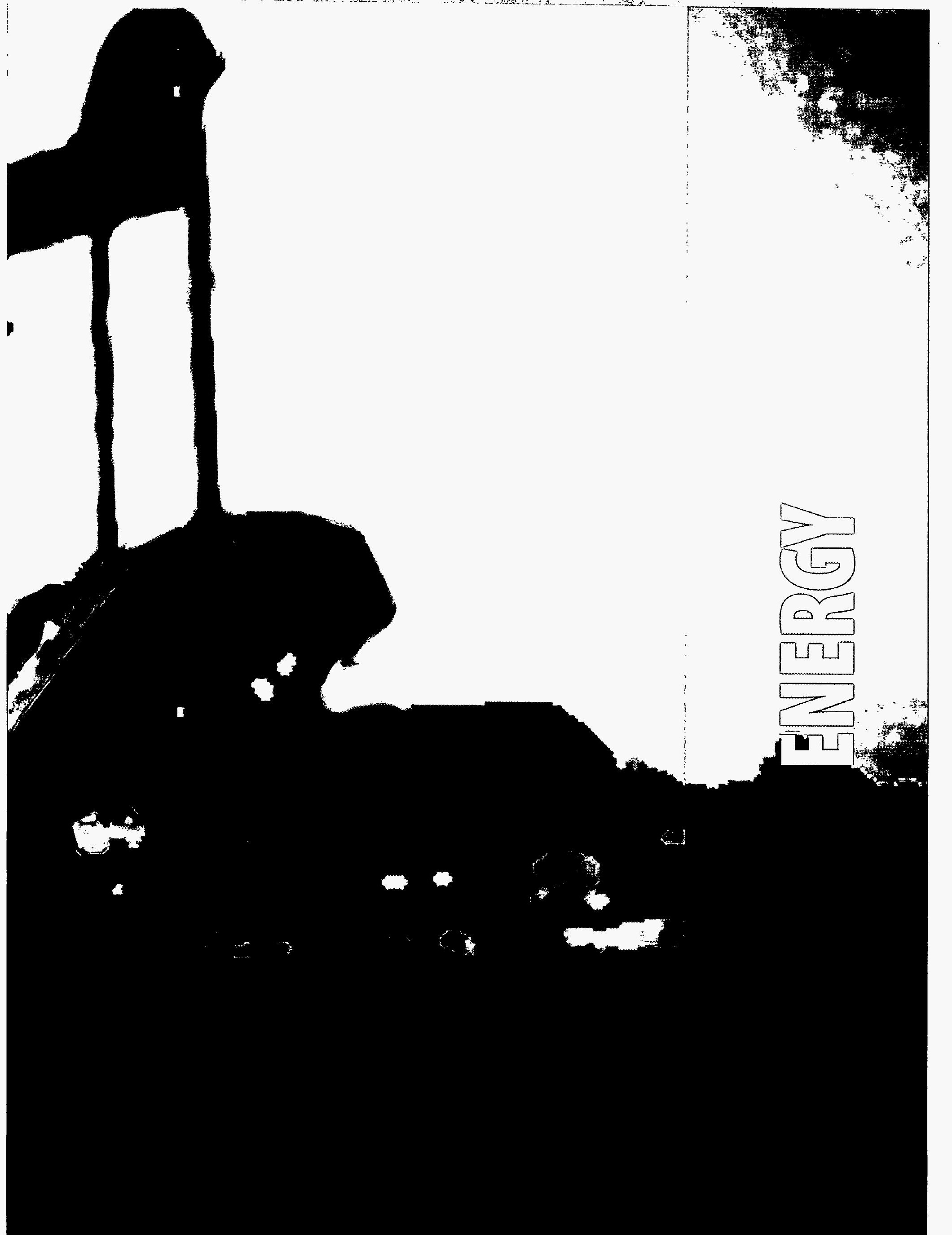




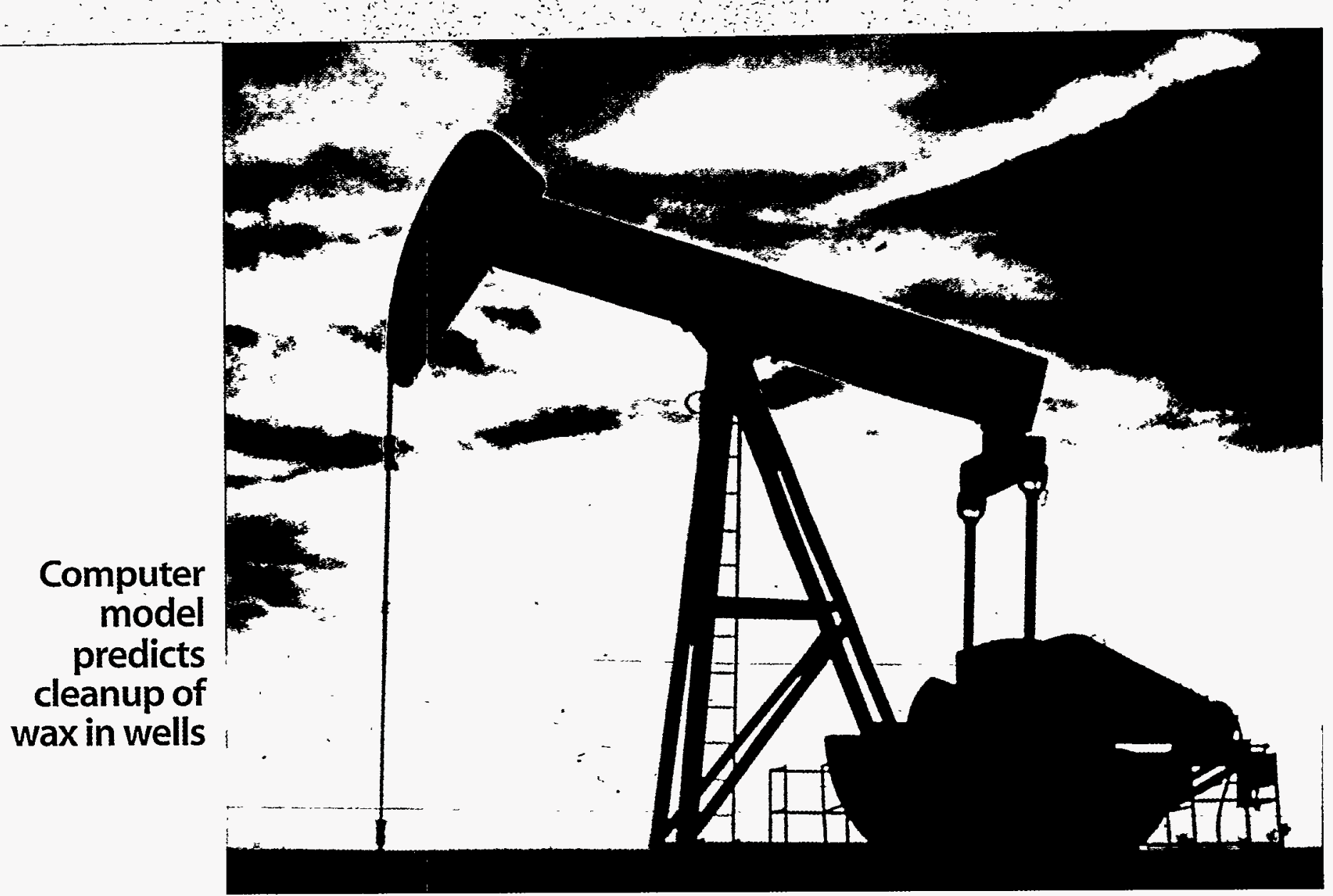

\section{Sustaining domestic} production

M any of the fuels we use - gasoline, natural gas, propane, butane, diesel fuel, automotive oil, even paraffin in candle wax-are petroleum by-products.

Unfortunately, paraffin, or wax, can be a problem in about one-third of all oil wells in the U.S., where it is dissolved in underground oil deposits. As the oil nears the surface, it cools and the paraffin solidifies. Eventually, the solidified paraffin can clog the well and the pumping machinery. This increases operating costs and is especially bothersome in stripper wells that produce
fewer than 10 barrels per day.
Traditionally, oil producers have tried to solve the problem by pumping hot oil or hot water into the well casing to melt the paraffin, potentially causing it to flow back down the well. However, new research conducted by scientists at Sandia and Petrolite, a chemical company, shows that this practice, known as hot oiling, may not always be effective. In fact, because this technique forces more paraffin back into the rock, the paraffin may accumulate and damage the oil-bearing formation.

Based on this research, the Sandia-industry team has developed a list of good practices and special software to help oil producers choose the best treatment for paraffin buildup. Every oil well is different, says Chip Mansure, of Sandia's Geothermal Research Department.

"We developed a software program, called the 'Hot Oiling Spreadsheet,'

For more information, call Chip Mansure Geothermal Research (505) 844-9315 which is available to industry free of charge," says Mansure. "The user enters information such as the size of the well (which indicates the amount of steel), and how hot and how fast the hot-oil truck, which heats the oil to be used in 
the process, will pump hot oil into the casing. The program then predicts where paraffin will be a problem and whether hot oiling will be effective.

"If hot oiling would not be effective, the producer can look at other means of removing the paraffin, such as using chemicals or mechanical devices."

This work is one of many projects sponsored by the Oil Recovery Technology Partnership, an alliance of the Department of Energy, Sandia and Los Alamos national laboratories, and the petroleum industry. The goal of the partnership is to find cost-effective ways to sustain domestic oil production.

Good practices are designed to avoid the problems associated with hot oiling. For example, in a deep well, the large amount of steel in the well casing draws heat away from the hot oil quickly - so quickly, in fact, that by the time the hot oil reaches the bottom of the well, it's cooler than the oil at the bottom. The most effective hot oil jobs, researchers found, are those that deliver the most heat in the shortest time using the least fluid.

Other good practices include:

- The better the quality of the hot oil, the lower the potential for formation damage.

- The well pump should be operating while the hot oiling takes place - otherwise, the wax may have a chance to resolidify, making it even harder.

- The well pressure should be high enough that the oil in the well does not boil, leaving wax and liquid behind to accumulate.

- The volume of oil injected should be limited because stock-tank oil can contain wax crystals, asphaltenes, scale, and corrosion products that can damage the formation.

- The plunger-lift or piston method of oil extraction, an option for some wells, or mechanical scrapers are alternative methods of removing paraffin if hot oiling is determined to be ineffective.

The spreadsheet was developed based on field tests in Oklahoma, Texas, and New Mexico. The software is compatible with most computers.
Paraffin is estimated to be a problem in about one-third of all U.S. oil wells. New software developed by Sandia and Petrolite determines the effectiveness of hot oiling.
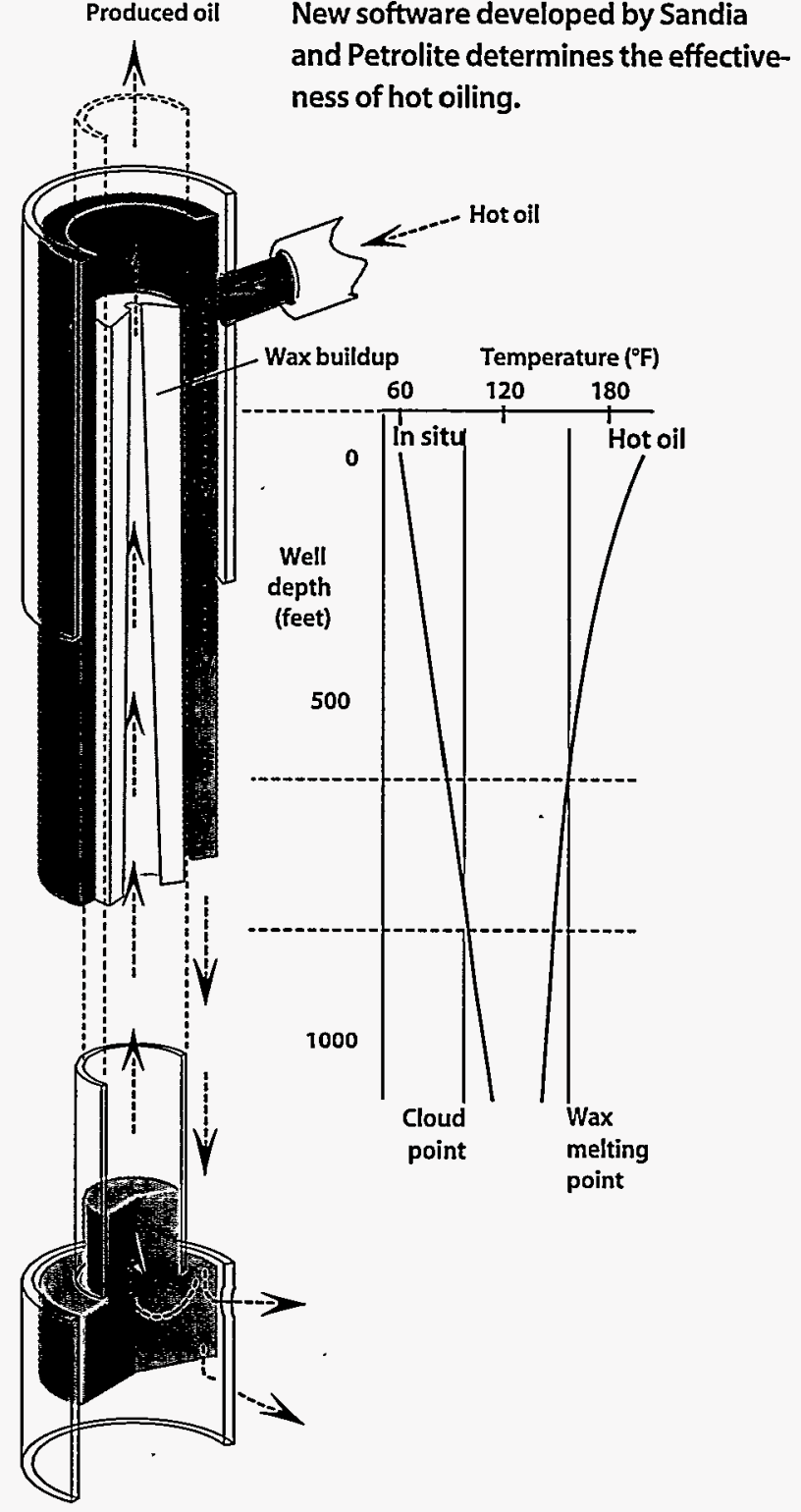

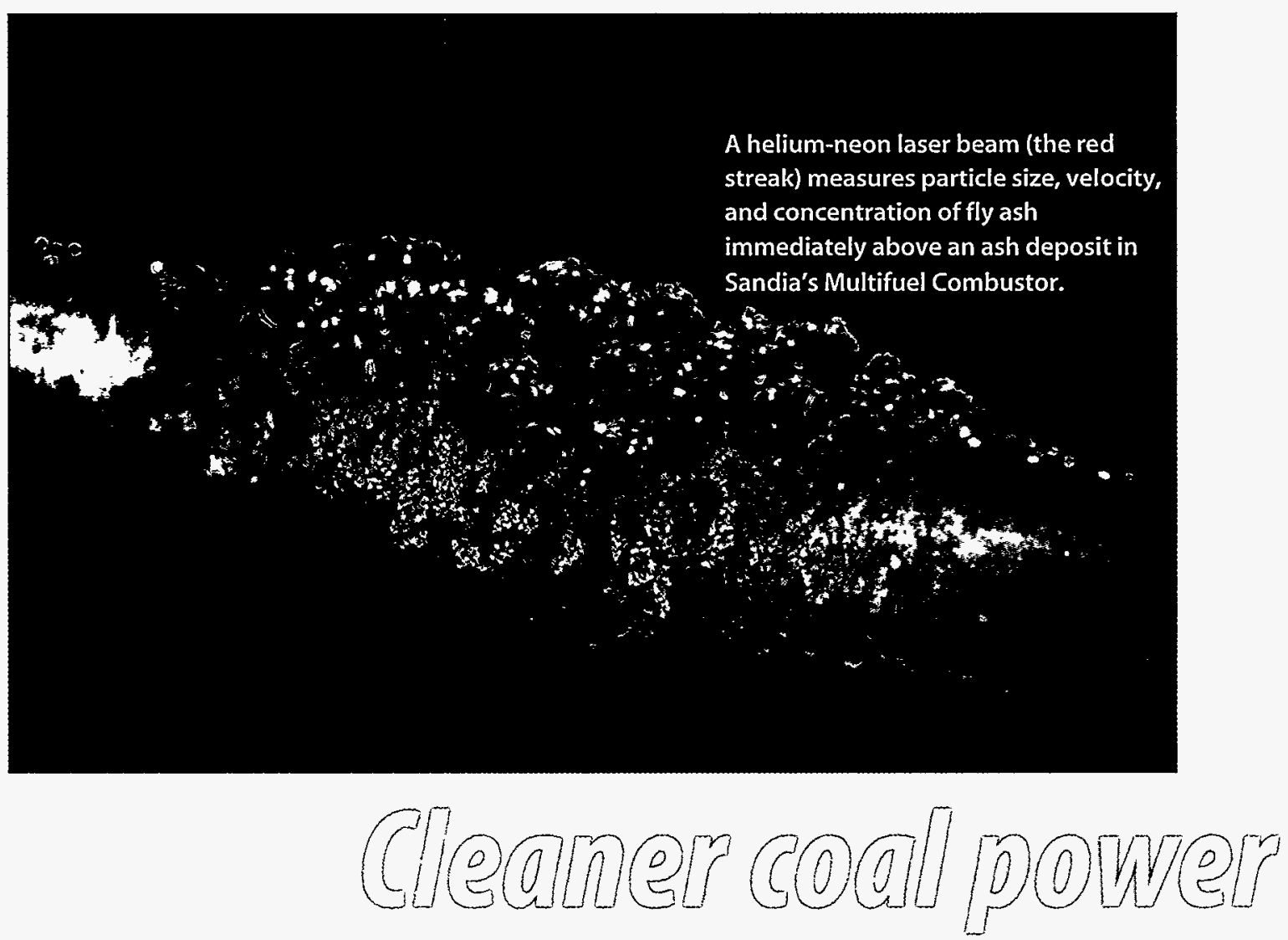

\section{Sandia helps solve ash-related problems in coal-fired boilers}

D espite the proliferation of new energy technologies, coal is a mainstay for electric power generation. More than half the nation's electricity comes from coal, and the U.S. has approximately 31 percent of the world's known recoverable coal reserves, enough to satisfy domestic electricity needs for at least 200 years.

Improving the way coal is burned to produce electricity is of utmost importance to coal-fired utilities such as the Northern Indiana Public Service Company, which recently worked with Sandia to turn a waste stream into a marketable product, save money, and improve the efficiency of its energy operation.

To meet new federal requirements requiring lower sulfur emissions, Indiana's Mitchell Station electric utility began experimenting in 1989 with western coal, which has a lower sulfur content than eastern coal, as an alternative to expensive desulfurization equipment. But worsening ash deposits and continuing problems with unburned carbon led the utility to seek help from Larry Baxter of Sandia's Combustion Research Facility in California. Baxter conducted research sponsored by the Energy Department and identified process improvements that could yield savings of as much as $\$ 1$ million a year, estimates Mitchell Station plant manager Larry Nemcek. 
Although its sulfur content is lower, not as much heat can be extracted from western coal to drive steam turbines. To compensate, NIPSCO tried blending western and eastern coal. This caused more ash to stick to the walls of the boiler and the boiler heater tubes. "By working with Larry Baxter, we discovered that the tenacity of the ash from a coal blend is higher--particularly in blends that are 60 percent western and 40 percent eastern," recalls plant engineer Larry Dora.

Hard-to-remove ash deposits were a problem in the 10-story-high, coal-fired boilers. Inside the radiative portion of the furnace, where the coal burns, a reflective coating on the ash reduced heat absorption, causing higher temperatures and increased ash formation in the convection region, where heated flue gas flows past tubes filled with steam. If left unchecked, openings between the tubes can clog completely with ash and the boiler must be shut down for cleaning. "Ash coating of coal-fired boilers is a serious problem," observes Baxter. "Experts place its cost at $\$ 1$ billion to $\$ 5$ billion a year."

Baxter's predictions that blended coal would make ash removal more difficult were supported by data from Mitchell Station. Baxter and Dora presented the results at the International Joint Power Generation Conference in 1992, where their work was named outstanding paper of the session. Their analysis allowed Mitchell Station engineers to choose the best blend ratio of eastern and western coal.

Another problem in the Mitchell Station boilers was a high unburned carbon content. This not only meant reduced fuel efficiency; it also made the ash impossible to sell as aggregate for concrete, which must have less than 3 percent carbon content. Instead of selling the ash, NIPSCO had to pay for ash disposal.

Sandia's analysis linked the unburned carbon content to the pulverizing process. Because eastern coal is harder than western coal and the two coals are usually blended before being pulverized, eastern coal particles are larger and do not burn as efficiently. Pulverizing the coals separately reduces unburned carbon content.

Baxter continues to work with utilities and fuel suppliers and is using his experience with coal-fired boilers to study ash deposition in biomass combustion.

Formore information, call

Larry Baxter

Combustion Research

(510) 294-2862

Fuels such as natural gas, oil, pulverized coal, and solid or liquid biomass can be tested in Sandia's Multifuel Combustor. The combustor allows simulation of combustion conditions in a commercial furnace or boiler. 
Office of Nuclear Energy continues to support CYBL because of interest from the nuclear power industry in the U.S. and other countries, notes Sandia researcher Scott Slezak.

CYBL consists of two stainless steel test tanks weighing approximately 50 tons. The large outer stainless steel vessel simulates a reactor cavity. The smaller stainless steel inner tank simulates the reactor pressure vessel. The entire assembly is housed in a three-story building.

During a simulation, 800 quart lamps, each able to deliver 6,000 watts of heat, are lowered into the inner vessel to simulate the heat from disintegrated fuel rods. "The maximum energy is 40 watts per square centimeter-roughly 400 times the energy you get from the sun for the same-size surface," explains Keri Sobolik, thermal analyst for CYBL's heat lamp array.

Video cameras record the boiling process through viewing ports in the outer vessel. Hundreds of thermocouples embedded in the vessel measure temperature. $A$ computer system collects the data and produces diagrams of heat flux and temperature.

Boiling passes through stages, or regimes, explains Chu. One of these regimes is film boiling. "In the film boiling regime, so much vapor is accumulated along the outer surface of the inner vessel-effectively forming an insulating layer -that the ability to transfer heat could be

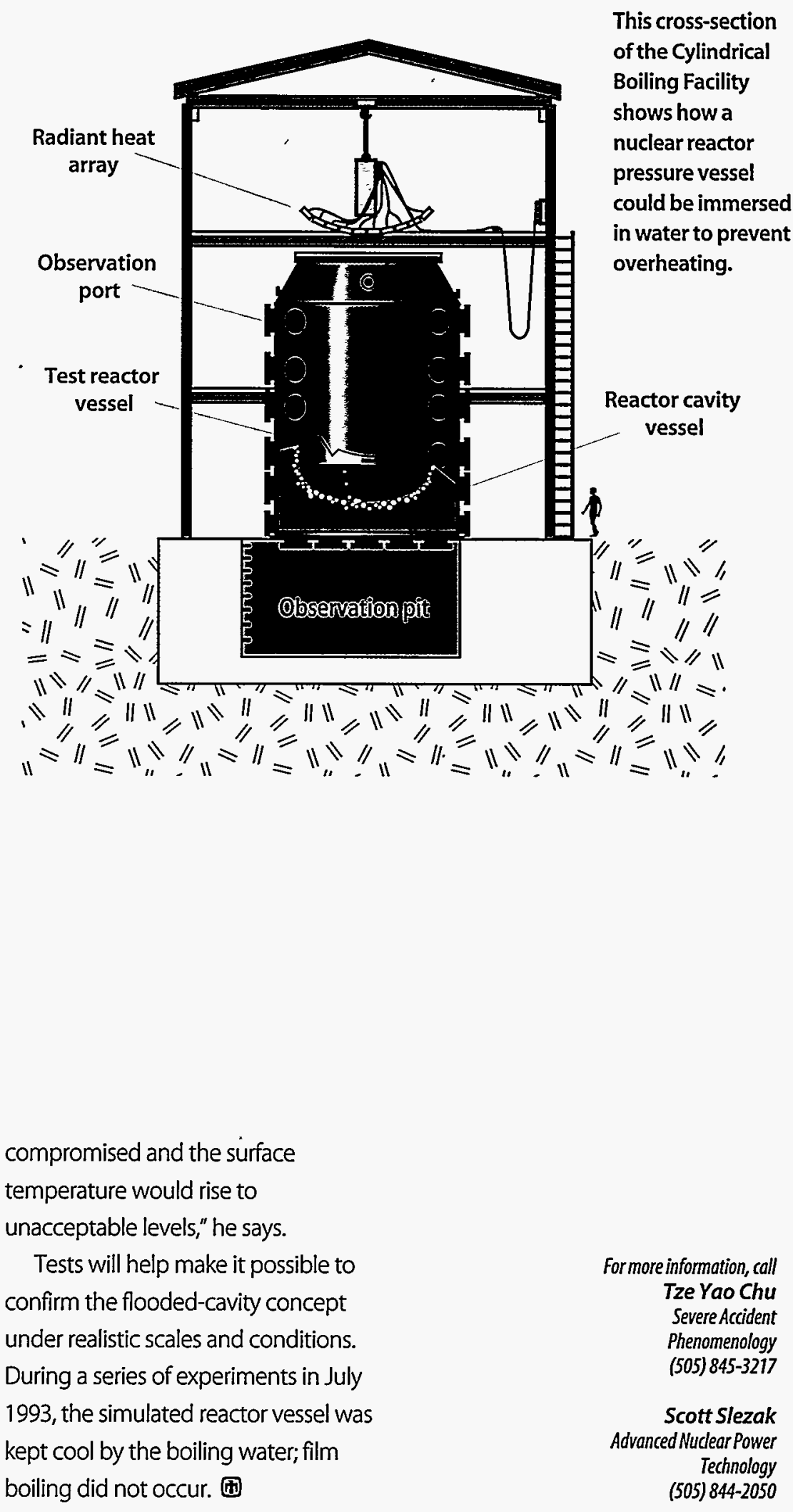




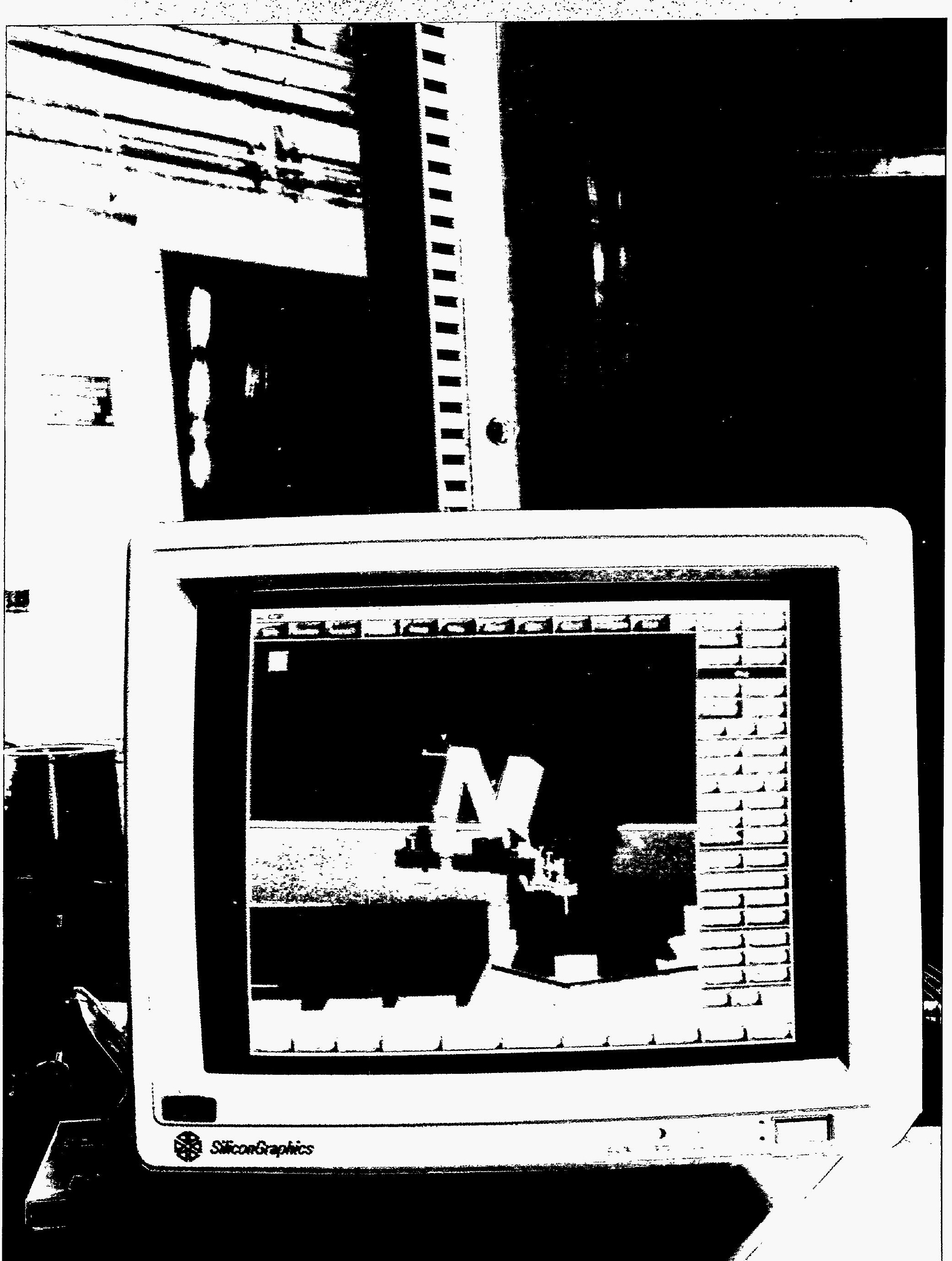




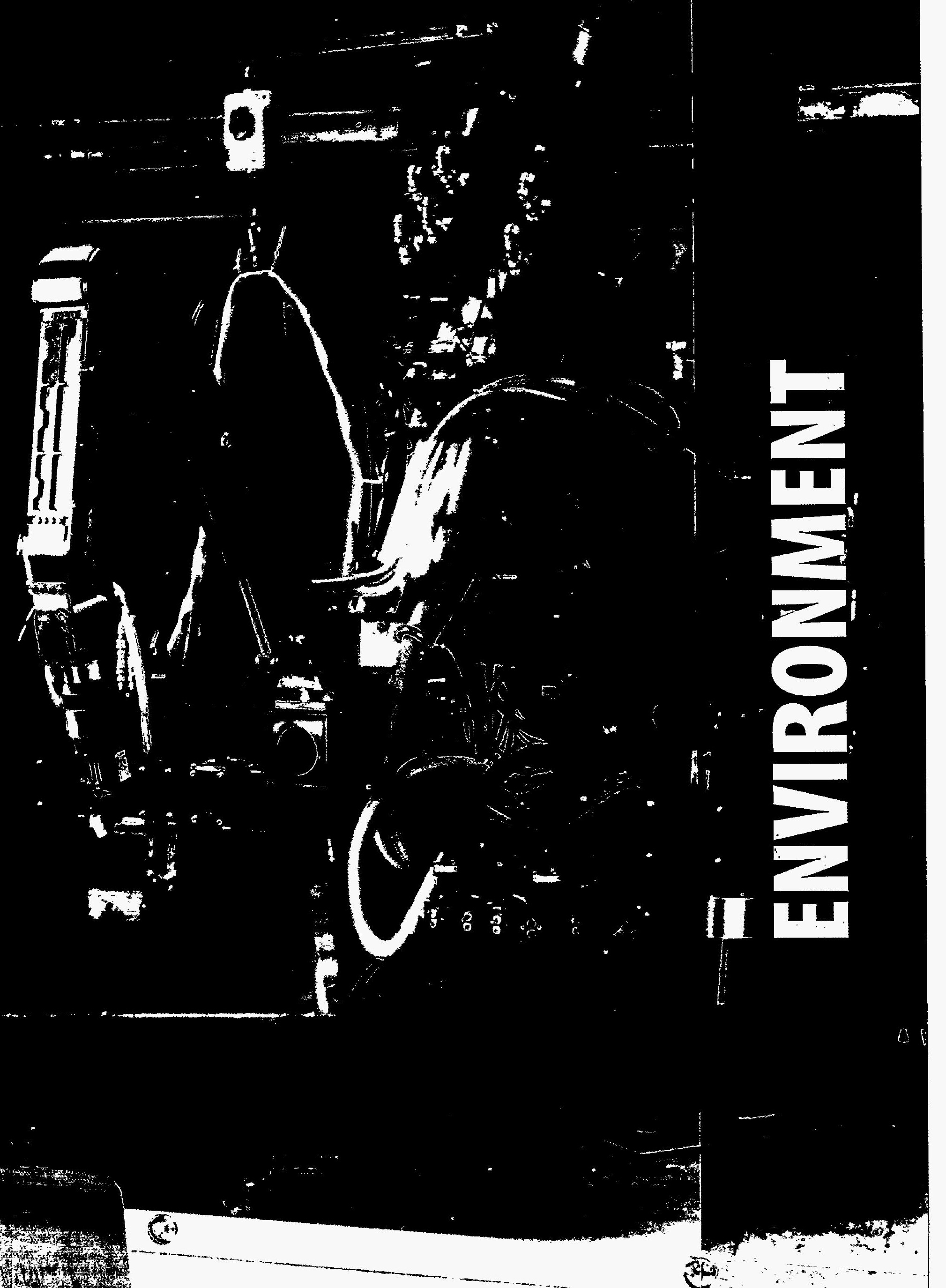



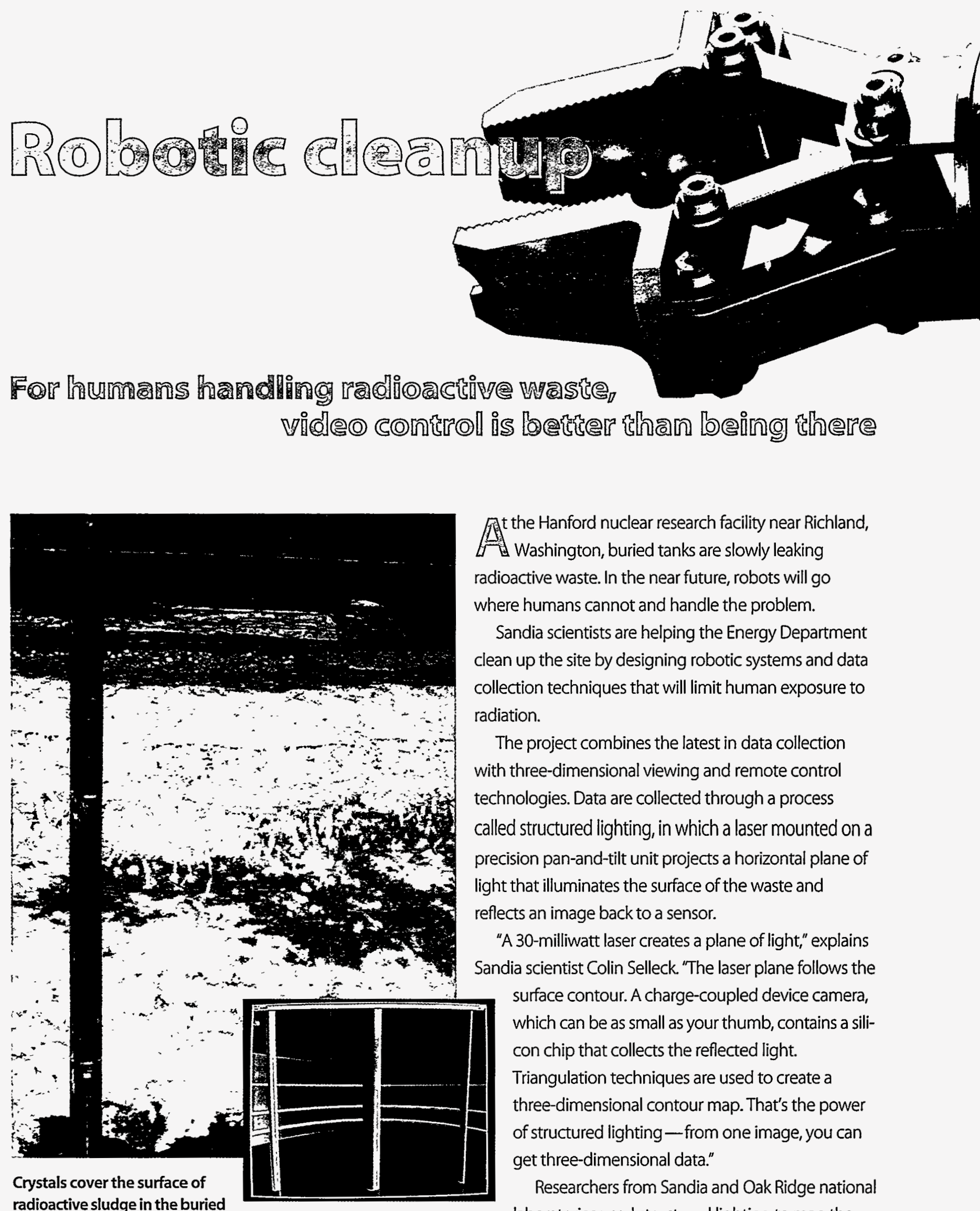

It the Hanford nuclear research facility near Richland, ff Washington, buried tanks are slowly leaking radioactive waste. In the near future, robots will go where humans cannot and handle the problem.

Sandia scientists are helping the Energy Department clean up the site by designing robotic systems and data collection techniques that will limit human exposure to radiation.

The project combines the latest in data collection with three-dimensional viewing and remote control technologies. Data are collected through a process called structured lighting, in which a laser mounted on a precision pan-and-tilt unit projects a horizontal plane of light that illuminates the surface of the waste and reflects an image back to a sensor.

"A 30-milliwatt laser creates a plane of light," explains Sandia scientist Colin Selleck. "The laser plane follows the surface contour. A charge-coupled device camera, which can be as small as your thumb, contains a silicon chip that collects the reflected light. Triangulation techniques are used to create a three-dimensional contour map. That's the power of structured lighting - from one image, you can get three-dimensional data."

Researchers from Sandia and Oak Ridge national the buried laboratories used structured lighting to map the surface of buried waste inside a tank at the Energy lation (inset) shows a computer-generated model of the interior of a tank. Such models will be used to guide a robot during cleanup. Department's Fernald facility. The task took eight 
hours and mapped features as small as 3 inches. In demonstrations conducted by Sandia at Hanford, a robot cut a pipe using only structured lighting and ultrasonic sensors.

Remote control of the robot is possible through a three-dimensional viewing technique known as virtual reality. Combined with user-friendly programming, virtual reality allows a human operator to see and manipulate the robot using a stereo viewer that gives the operator a sense of immersion in the simulated environment and simulates the motions of the robot.

"What virtual reality does is allow you to interact naturally with the computer," notes computer scientist Sharon Stansfield, "without knowing all the computer languages."

To make this interaction possible, researchers construct a threedimensional computer model of a tank interior and combine it with a stereo viewer, control stick, and software that allow a human operator to move the robot around the tank and give it verbal commands.

"As virtual reality - particularly the quick collection and presentation of three-dimensional data - becomes increasingly sophisticated, several users in different places will be able to view the same three-dimensional world," adds researcher Creve Maples.

The Hanford robot will have internal smarts and sensors to prevent collisions with objects inside the tank. Such safeguards will prevent costly or hazardous mistakes, such as a command that might cause the robot to run into a wall.

In addition, the robot will carry a pipe cutter; ultrasonic sensors; a chemical analysis lab for measuring oxygen, hydrogen, and liquid viscosity; and force sensors that will transmit resistive force to the tip of the robotic arm and ultimately to the human operator.

The robot must have a very high strength-to-weight ratio to accommodate the huge underground tanks at Hanford, which measure 75 feet wide and 40 feet tall. Each tank has a 42 -inch-wide opening in the top covered by a removable lid. "We need to fit the robot arm through that hole and still reach across the radius of the tank," notes Sandia researcher Brady Davies. "We do not want to modify the tanks by adding more openings and perhaps creating more leakage problems."

Buried waste in the tanks has four main components: a salt-cakey substance, a peanut-buttery clay or sludge, liquid, and vapor that can sometimes be explosive. Sandia's responsibility is to develop robotic technologies to characterize and remediate the contents of the tanks quickly, safely, and inexpensively. Ultimately, solid wastes will likely be vitrified — hardened into a glass — and stored in barrels or moved to another site. 중
A robotic arm (left) is being tested at Sandia for gripping and removing buried pipes from underground tanks at the Hanford site.

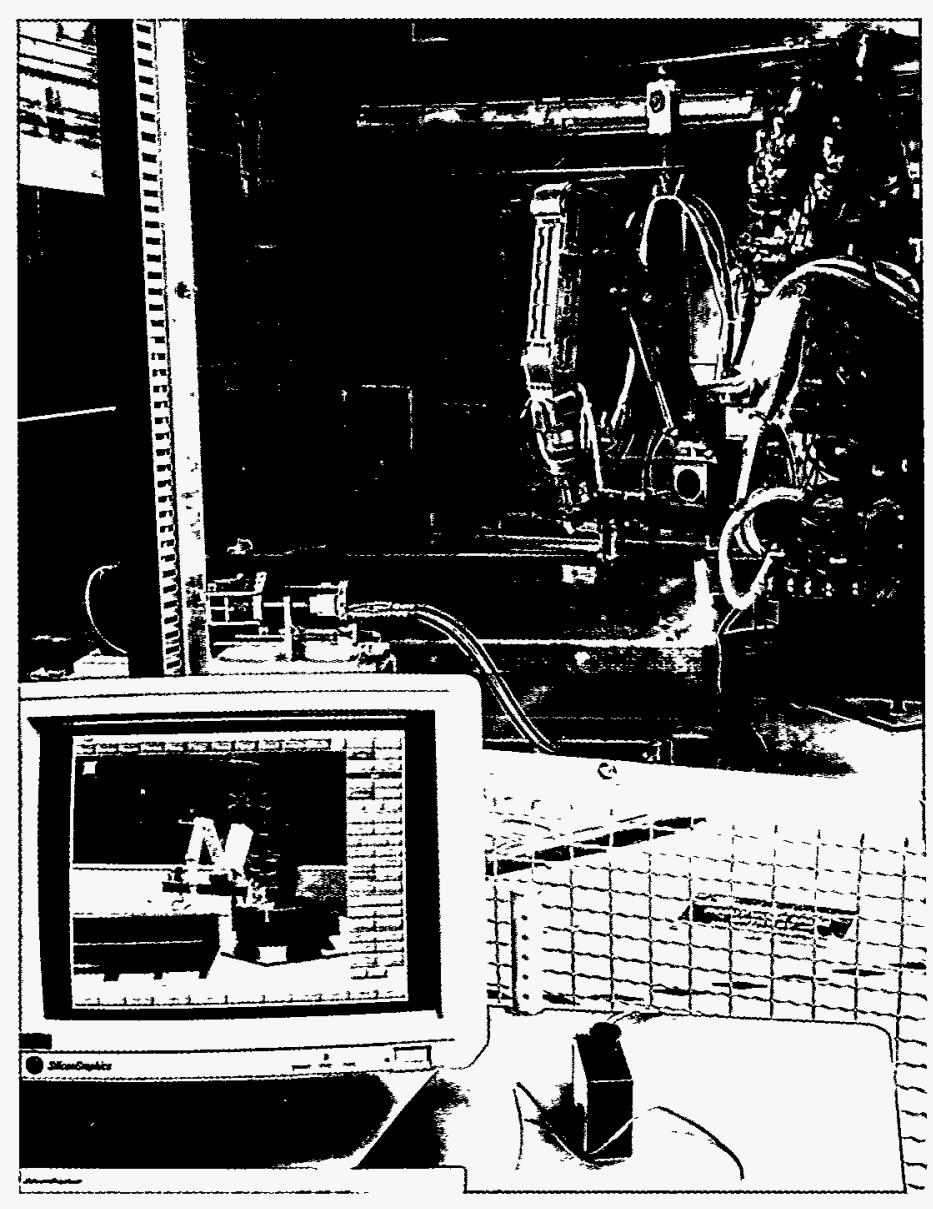

A human operator can view the robot's movements remotely on a computer screen. 


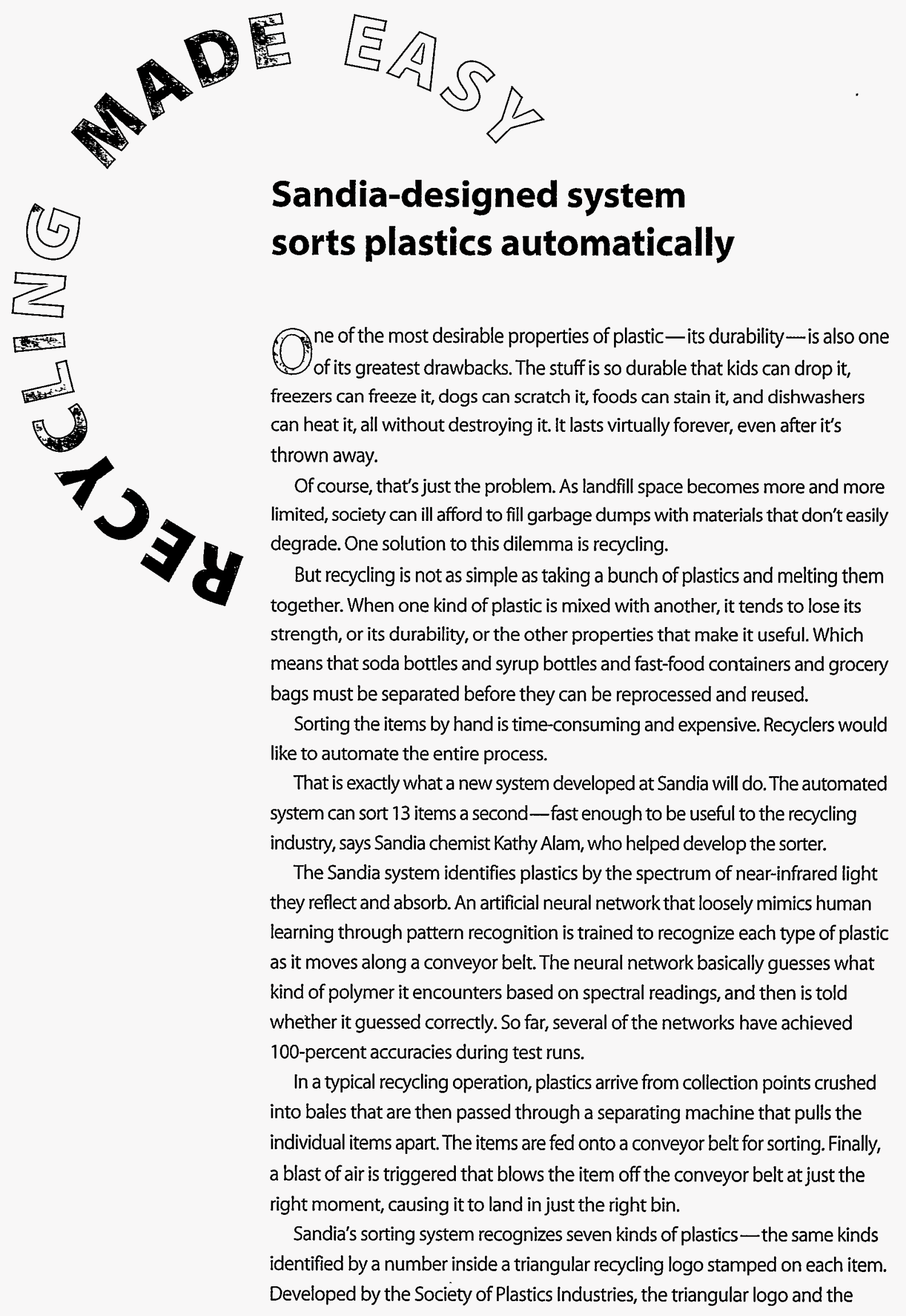




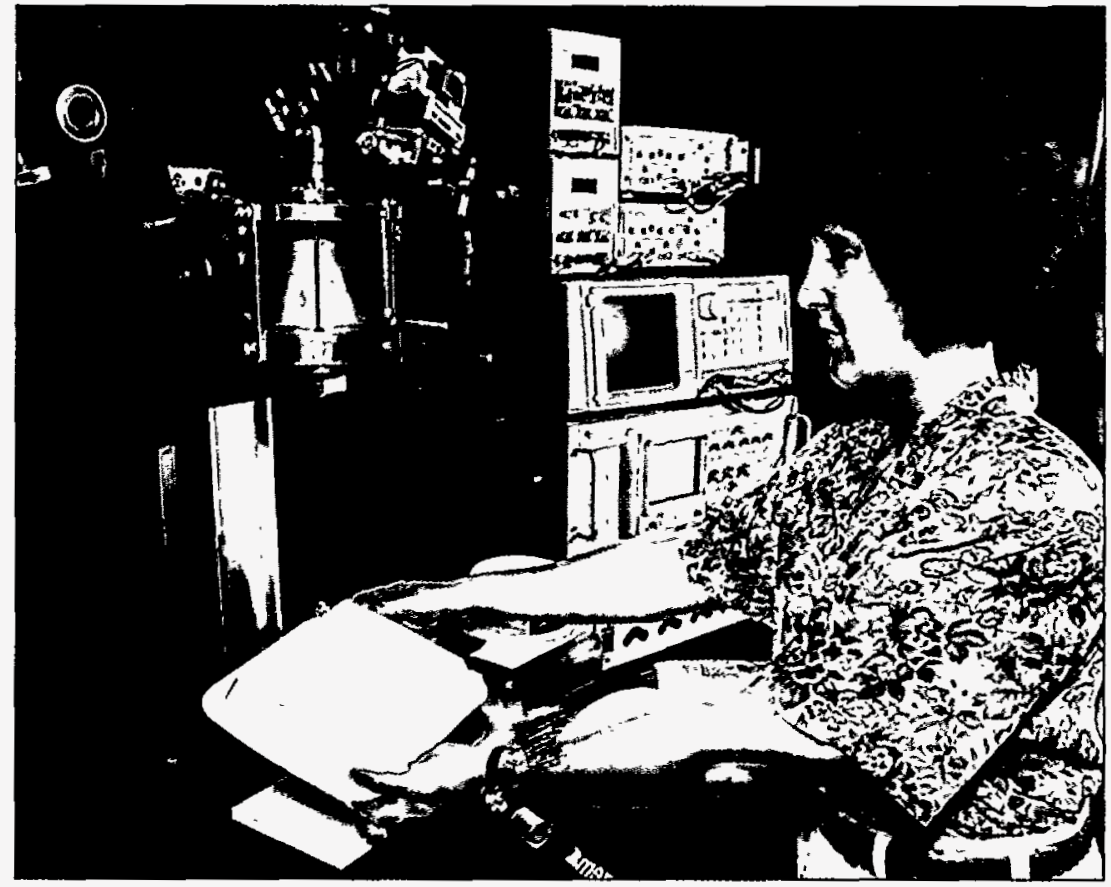

seven-tiered identification system are not mandatory in the U.S., but are observed by many manufacturers on a voluntary basis.

The seven categories refer to seven kinds of resins used in consumer plastics: polyethylene terephthalate (1-PETE), found in soft drink bottles; high-density polyethylene (2-HDPE), found in milk jugs; polyvinyl chloride (3-PVC), found in nonmetal pipes and sometimes shampoo bottles or other items; low-density polyethylene (4-LDPE), the primary constituent in some plastic grocery bags; polypropylene (5-PP), used in syrup bottles; and polystyrene (6-PS), found in fast-food containers, coffee cups, and some yogurt containers. The seventh category is a catchall for everything else.

Though plastics recycling is on the increase, it has not yet caught on in a big way in the U.S. However, it is already mandatory in parts of Europe, explains Alam. Germany, in particular, has passed legislation requiring manufacturers to recycle plastics.

Meanwhile, some U.S. companies are beginning to show an interest in plastics-sorting technologies. Sandia has a license with a manufacturer of recycling equipment that allows the company to use the Sandia-developed sorting technology.

Sandia researchers are also working on identifying and sorting nonconsumer plastics such as carpeting, computer casings, and electronic parts. (Carpeting is often made of nylon or polyethylene.) Ultimately, recycling companies would like to sort about 20 categories of plastic waste, says Alam, including thermoplastics in cars and computers, Plexiglas, Lexan, and nylon.
Sandia researcher Suzanne Stanton demonstrates an automatic sorting machine developed at Sandia for identifying and sorting plastics on a conveyor belt.
Formore information, call Kathy Alam Surface/MolecularSpectro/Gas Analysis (505) $845-9621$

Suzanne Stanton Manufacturing Applications (505) $845-9339$

Greg Hebner Laser, Optics, \& Remote Sensing (505) 844-6831 


\section{Toxic waste}

\section{Government, academia, and business become partners in landfill cleanup}

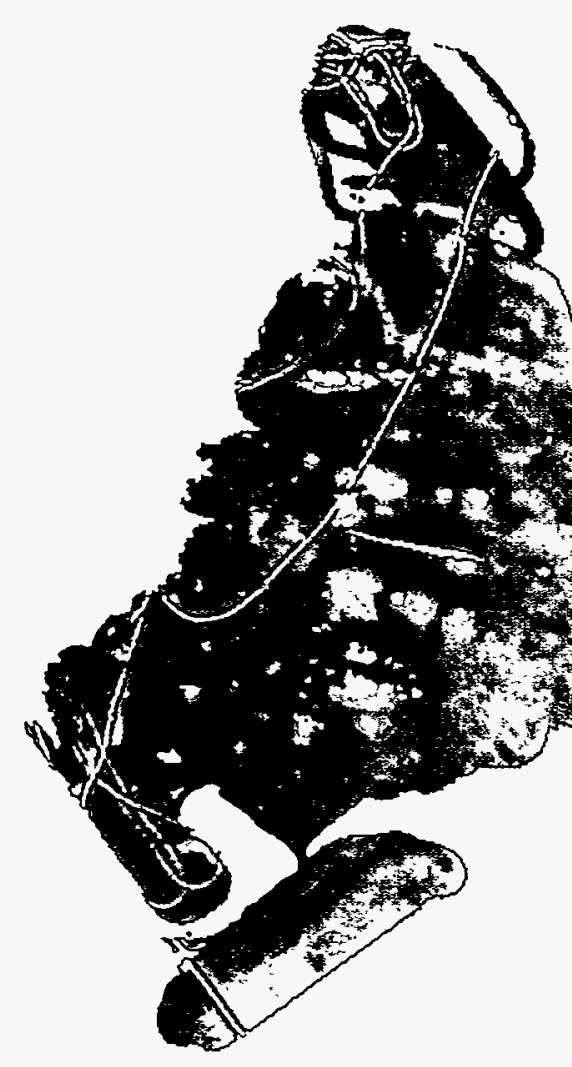

The Surface Towed Ordnance Locator System, originally developed by the Navy to search for buried explosives, can also be used to map magnetic anomalies underground, as in this image of a six-acre landfill.

Drums of radioactive waste, utility lines, fence posts, or anything else made of ferromagnetic metal can be imaged with STOLS, as demonstrated in this map of a hazardous waste landfill and the surrounding area at Sandia. To the right of the color image is a surface photograph of the same area.
$T$ at Sandia, learned of a dune buggy that could tow a trailer carrying seven magnetometers to map buried metal objects.

The dune buggy was part of STOLS - the Surface Towed Ordnance Locator System - developed by the Navy to search for buried explosives.

The vehicle, which can cover more than 10 acres a day, seemed to fit the needs of the Mixed Waste Landfill Integration Demonstration at Sandia National Laboratories. This program is dedicated to demonstrating innovative and costeffective solutions for cleaning up mixed wastes - wastes containing both radioactive and chemical constituents - while integrating the efforts of private industry, educational institutions, and government.

Today, Cochran, Jim McDonald of the Naval Research Laboratory, and GeoCenters Inc. of Boston are working to adapt the system, originally developed to clean up bombing ranges, to help characterize buried hazardous waste sites. Geo-Centers Inc. has commercialized STOLS and is interested in expanding its capabilities to the waste cleanup market.

The next generation of STOLS, called the Multi-Sensored Towed Array Detection System, will use magnetometers to detect buried metals, such as underground toxic waste drums, and sensors to detect radiation and organic vapors in the air. Like the original STOLS, it will also use automated data acquisition and the Global Positioning

System for navigation.

The cleanup of chemical and mixed wastes discarded since the late 1940s at Department of Energy facilities is expected to cost $\$ 150$ billion and may take 30 years. In addition to STOLS, Sandia is assessing a variety of technologies to help reduce the cost of waste cleanup.

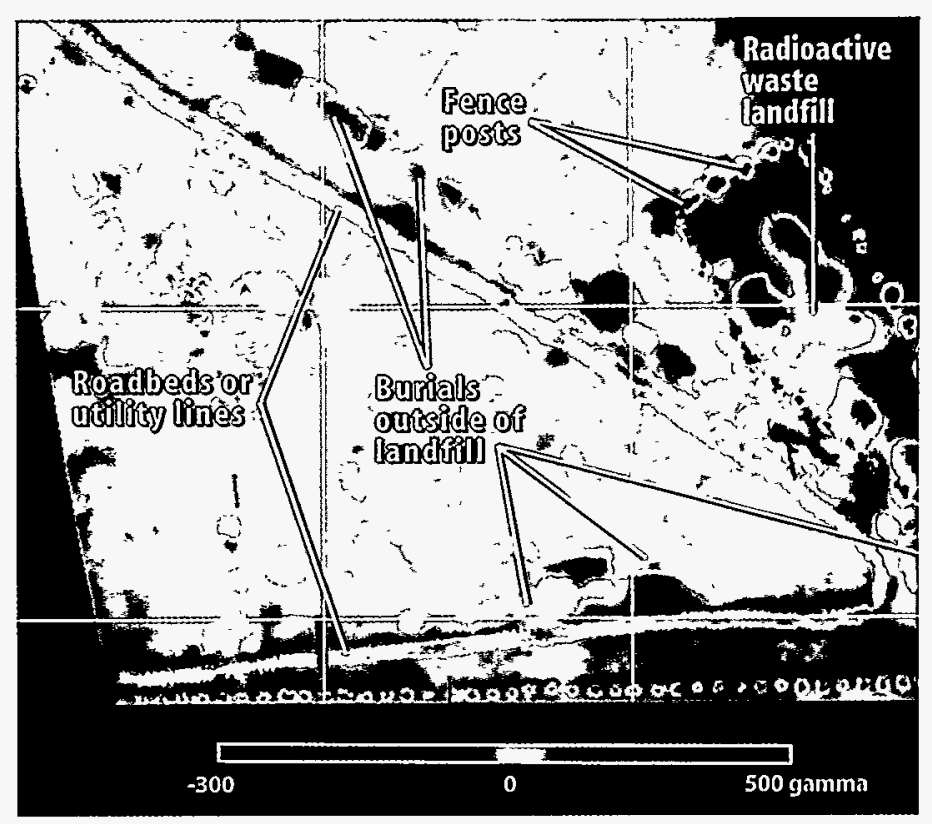




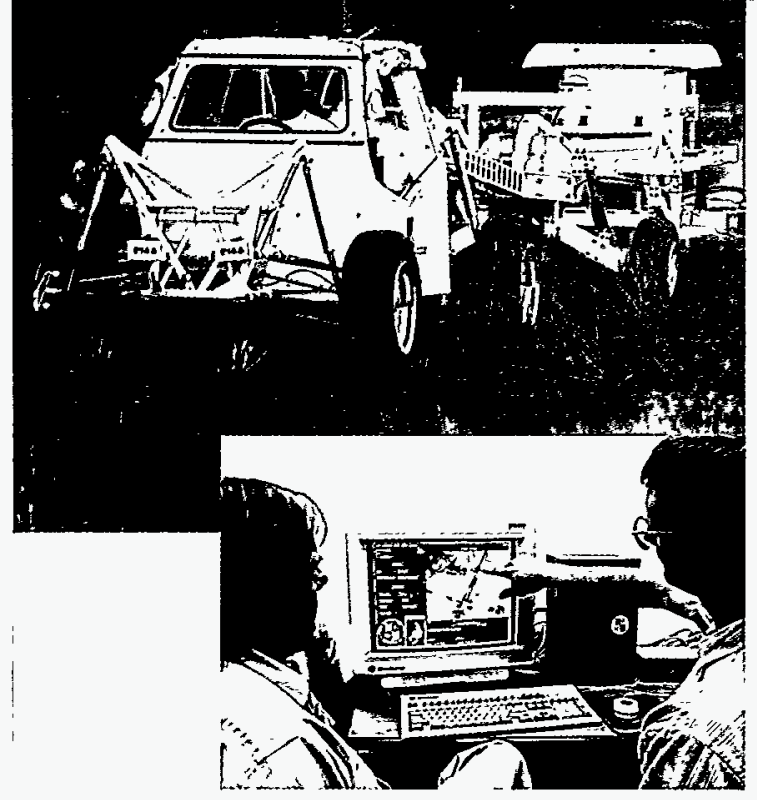

Researchers Jim McDonald (left) and John Cochran study landfill images obtained with STOLS, a system that tows a trailer carrying magnetometers for mapping buried metal objects.

Formore information, call

Tom Burford (MWLID)

Environmental Restoration Technology

(505) $845-9893$

John Cochran (STOLS)

Safety \& Risk Assessment

(505) 848-0475
To characterize the waste and cut costs, MWLID researchers conduct a variety of field tests at one time to produce a complete picture of a contaminated area. New drilling techniques, sampling optimization methods, borehole location optimization, subsurface imaging, membrane liners, and analytical screening tools are some of the technologies being tested.

"The goal is to show how these individual technologies may interact," says Bob Floran, principal investigator of the Landfill Characterization and Monitoring System for MWLID.

After the characterization phase, MWLID will turn to the next phaseremediation. Of particular concern to engineers is the vadose zone - the area beneath a landfill and above groundwater. Fast-moving pollutants can easily contaminate the vadose zone and threaten underlying groundwater.

Researchers are evaluating several emerging remediation technologies, such as electrokinetics to remove metal ions; extraction systems using vacuum and soil heating methods; isolation of contaminants with subsurface liners, barriers, and surface cover systems; stabilization measures to keep waste from migrating; and alteration of soil chemistry to reduce toxicity.

Successful technologies will be available for use by government and industry. "We stress the need to not only develop technologies, but also to have them used to help clean up mixed waste landfills," says Cecelia Williams, principal investigator for MWLID's technology integration and transfer system. Sandia is developing partnerships with state, local, and tribal governments, universities, public organizations, and private industry to broaden knowledge and use of emerging technologies.

In addition to the further development of STOLS, other MWLID technologies that have been commercialized by private industry are the SEAMIST membrane liner that was purchased by Eastman Cherrington Environmental Co. of Houston, and SitePlanner, a sampling methodology available from ConSolve Inc. in Massachusetts.

Other MWLID technologies are nearly market ready. They include PLUME, a system that provides geostatistical routines to optimize the number and location of boreholes and samples for site characterization, and a field analytical screening method known as adsorptive stripping voltammetry, which measures heavy metal concentrations in soils. 固 



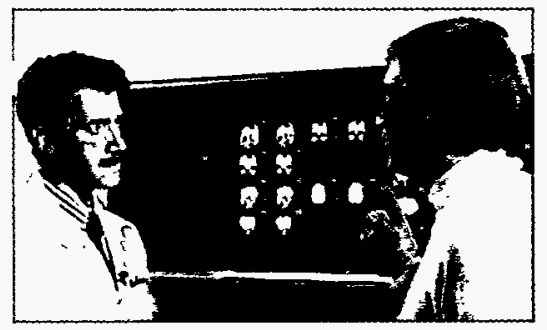

Dr. William Orrison (left) and Carl Diegert view a conventional $X$-ray presentation of brain anatomy and function.

\section{Massively parallel computing could help guide brain surgery}
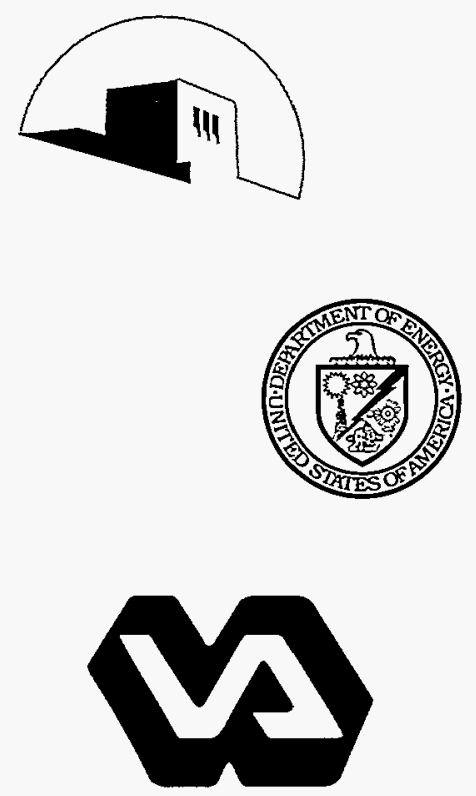

\section{a delicate operation}

W ith every passing year, medical researchers come a little bit closer to unraveling the mysteries of the human brain. Today, Sandia scientists are working with doctors to develop three-dimensional computer imaging techniques that may one day make it easier to successfully complete that most delicate of operations - brain surgery.

"Often in surgery or medical exams, you want to see the data immediately," says Sandia scientist Carl Diegert. "But the medical data set is huge; you have to decide what's important. One of our innovations is that we've extracted and distilled the data from magnetic resonance images so that it can be viewed and used on a conventional computer workstation."

Another innovation is the superimposition of three-dimensional computer models with actual video footage of surgery taking place. This fusion of the two media will eventually help guide doctors through the surgery process, notes Diegert.

To make the vast amount of data from MRI scans more manageable, Sandia computer scientists are developing algorithms that analyze the data and display only what is critical in a three dimensional image. The algorithms sort through the scans and identify necessary features, such as lighter-colored surfaces that might represent blood vessels or a lesion in the brain. Ultimately, scien- tists hope to use this process to assist in real-life surgeries.

Diegert and a Sandia videographer recently witnessed and videotaped a brain operation conducted by $\mathrm{Dr}$. Nevin Baldwin, a neurosurgeon at the Veteran's Affairs Hospital in Albuquerque, New Mexico. Doctors were worried the patient might have a recurring brain tumor, but it turned out to be infected tissue, which Dr. Baldwin removed during the surgery.

Diegert is now working with Drs. John Sanders and William Orrison of the UNM School of Medicine and the VA Medical Center Department of Radiology to use magnetic resonance images from the same patient to build a three-dimensional computer model of the patient's brain. The MRI scans were sent to Diegert over a computer network - -a quick and effective way to share critical information. Diegert will review the threedimensional computer model with the surgeon to see if it would have been helpful during surgery.

"Radiologists typically take half an hour to compute a single threedimensional MRI view of the brain," notes Diegert. "At that rate, it would take a couple of days to prepare complete three-dimensional images of a whole brain. But we can do it much more quickly with massively parallel computing. Our process is 100 to 1,000 times faster." 
Or, as Baldwin says, "When it's the brain, time is of the essence."

Although supercomputers, such as the Intel Paragon model recently installed at Sandia, are quite expensive, in two years they are expected to be more economical for hospitals, leading to a transition to parallel computing.

One of the advantages of MRI scans is that they are relatively easy to adjust to show whatever features or specific surfaces the doctor is interested in viewing, such as arteries or lesions. This is because the very high magnetic field in an MRI machine causes water molecules inside the body to align. When the machine emits a radio signal, the aligned water molecules absorb the signal, tip slightly, and send the signal back. When this signal is returned, it is used to produce an image of the aligned molecules. By changing the parameters slightly, the radiologist can view different images of body tissue. Improvements in automatic data reduction make such large-scale observations clinically useful. 团

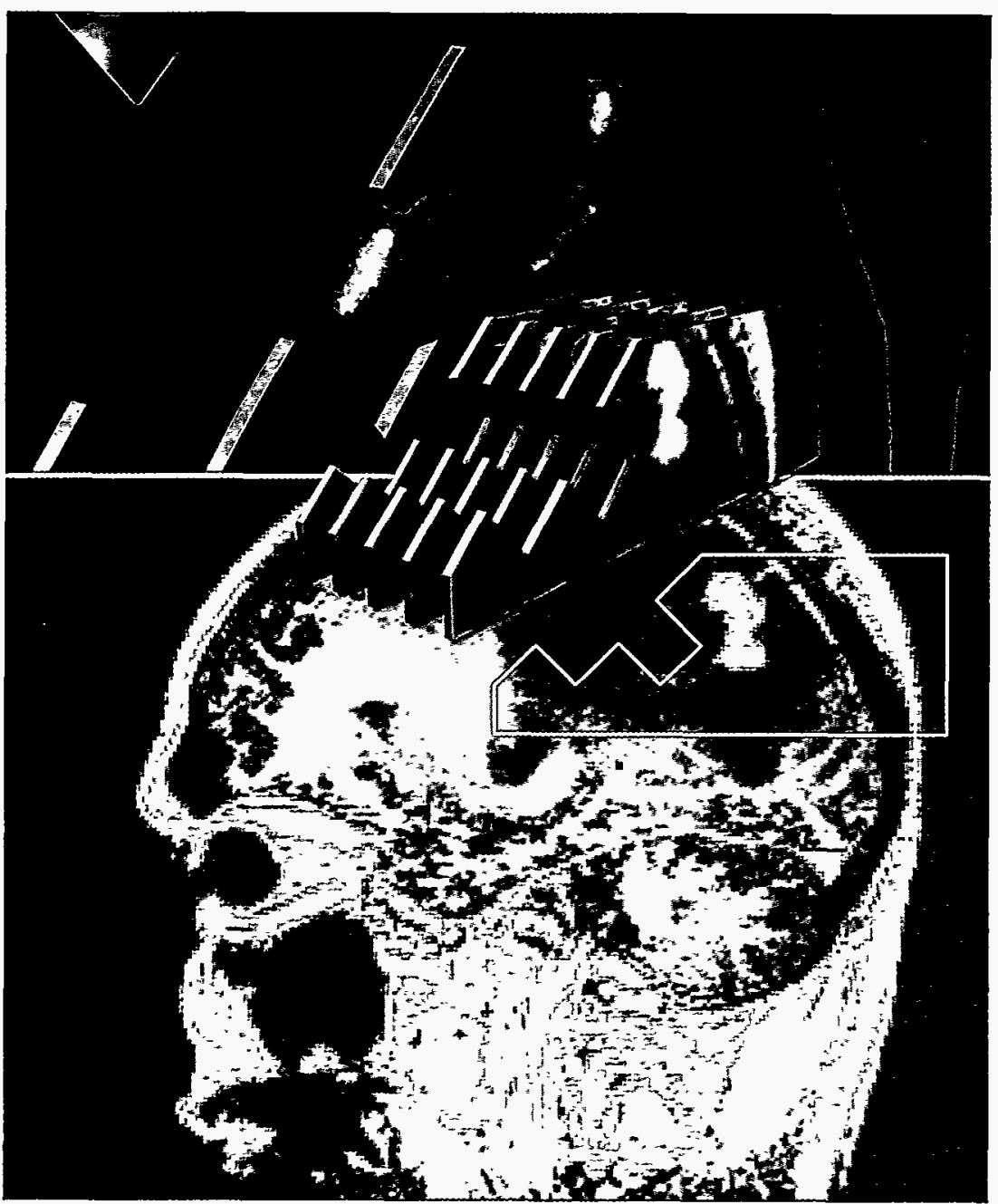

A magnetic source machine that senses the magnetic field generated by neurons in the brain observes brain function.

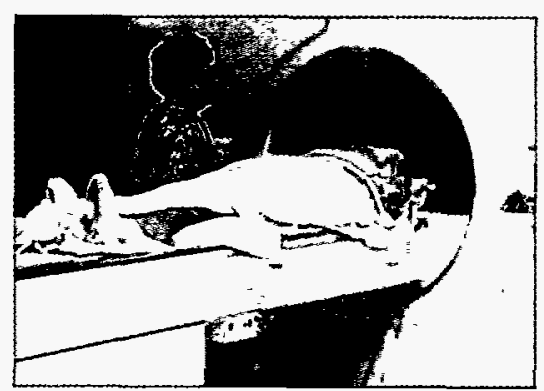

A magnetic resonance machine observes brain anatomy.

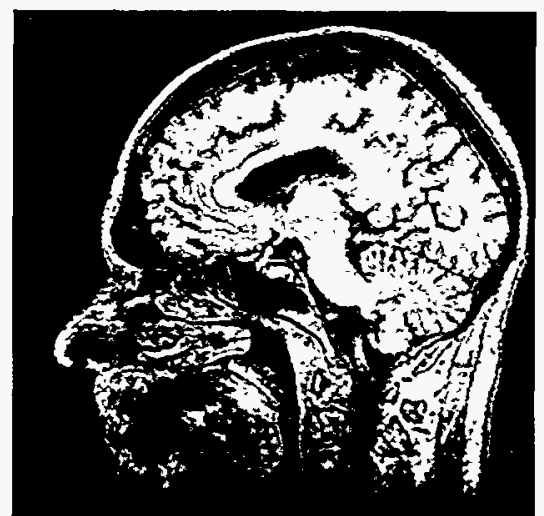

A black-and-white magnetic resonance image shows the brain's anatomy.

Topleft:

In this enlargement, the lesion is shown in green; the surgeon must avoid the area shown in red to prevent motor damage during surgery.

\section{Middle left:}

The extent of the lesion is clearly displayed in a three-dimensional "bread loaf" of slices of the data.

Bottom left:

A color-enhanced magnetic source image shows the lesion in the upper portion of the brain.

Formore information, call Carl Diegert Parallel Computing Science (505) 845-7193 

The Sandia-University of Texas project is focused on below-the-knee amputations. To improve the fit of prosthetics, researchers scan the remaining healthy portion of the leg ultrasonically to produce a three-dimensional model of the skin surface and underlying bone surfaces. "Images generated so far show great potential for using this technique to design better prosthetics," says researcher Scott Strong, whose specialty is image and signal processing.

A circular tub filled with water rotates around the leg while a transducer behind a window in the wall of the tub transmits and receives ultrasonic energy to produce a planar image or cross section of the leg. A scan takes about 20 seconds.

"By keeping the transducer out of the tub, we reduce turbulence in the water that would move the patient's leg and distort the data," notes Morimoto.

Sandia scientists have also developed computer models that predict the surfaces of skin and bone - in other words, the completeness of the data - that the ultrasonic imaging will provide. These models have been extremely accurate in visualizing the data, and have allowed researchers to determine in advance how much data to collect.

Researchers at the University of Texas perform biomechanical adjustments to the ultrasound scan data in a computer-aided design system. This system develops fabrication specifications based on the data and sends them to a computercontrolled machine that fabricates the prosthesis. In time, this technique may become part of an advanced manufacturing process and eliminate the need for hand-crafted prosthetic devices. 因

Formore information, call

Alan Morimoto

Intelligent Systems

(505) 844-0112

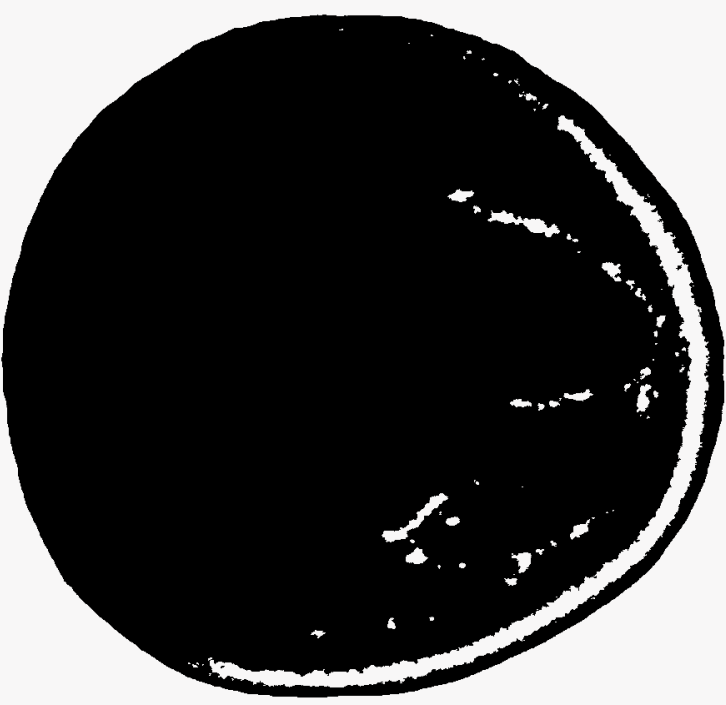

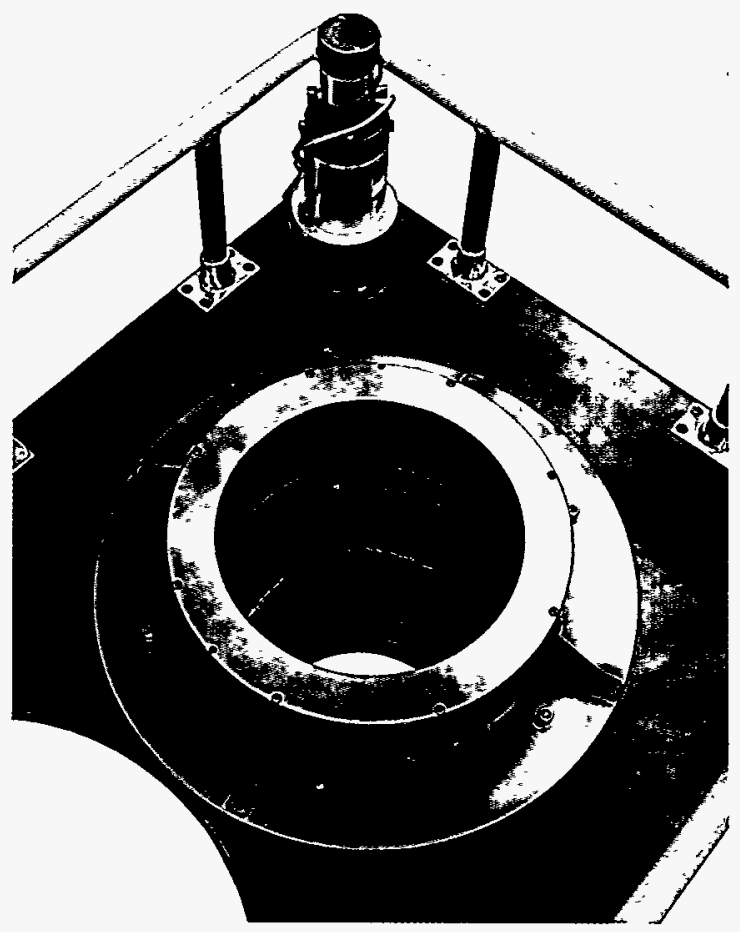

To obtain ultrasound images, a patient inserts the healthy portion of the leg into a circular tub (above) filled with water. 
shining a
laser
for
furn
surgery

\section{Biomedical technology transfer agreement will help reduce trauma of treatment for severe burn victims}

Cor all its wonders, modern

medicine is far from gentle with severe burn patients. Every year, more than 100,000 people in the U.S. suffer severe burns. In some ways, treatment of these burns hasn't progressed much since the days of the Civil War: a surgeon, using a scalpel, "fillets" the patient's skin, removing dead skin until blood - a sign of live skin - is visible.

This procedure requires massive transfusions to replace lost blood, adds to the disfigurement already caused by the burn, and involves slow and extremely painful recovery.

Furthermore, the patient's chances of dying are proportional to the area of skin that is severely burned - the larger the burn, the less likely a recovery. Annually, the total cost of treatment of severe burns is estimated to exceed $\$ 2$ billion.

But help may soon be on the way. Medical researchers at Massachusetts General Hospital and scientists at Sandia National Laboratories are designing a better way to treat severe burns. The goal of their \$13.4-million cooperative project is to reduce patient trauma by using a laser beam to remove burned skin and automated diagnostics to minimize loss of live skin and minimize blood loss, the main cause of death in burn patients. Heavy bleeding often prevents a successful skin graft after the burned skin is removed.

Their joint effort is the first biomedical Cooperative Research and Development Agreement at Sandia.
The program is funded by the Department of Energy.

In the new bum treatment procedure, the laserwill replace the scalpel.

"Doctors at Massachusetts General Hospital, a national leader in burn treatment, figured out somewhat fortuitously that laser ablation, if done correctly, kills only a very thin layer of healthy skin beneath the dead skin," explains materials scientist Ned Godshall, of Sandia's Instrumentation Engineering and Technology Department. This 100micrometer-thin layer of skin is so thin that nutrients from below can still get through it and keep the skin alive. Yet this layer seals the blood and stops the profuse bleeding from preventing a good graft.

"The irony is that you treat a burn victim by burning the victim slightly," he adds.

A new diagnostic system will direct the surgeon-controlled laser to remove as little live skin as possible. In conventional treatment, a surgeon removes layers of skin until blood is visible, because blood only flows through live, healthy skin. Sandia scientists are investigating a variety of ways to distinguish the demarcation line between healthy and dead skin, which often look the same to the naked eye. Researchers will begin by studying the method currently in use at MGH's Wellman Laboratories of Photomedicine, in which doctors inject indocyanine, a green dye that fluoresces when it comes into contact with laser light, into a patient's blood. 
Scientists will also experiment with other sensors, computer modeling, robotic manipulators that can move the laser beam around and turn it on or off as needed, and different wavelengths of light to see how they are reflected or absorbed by dead vs. live tissue. Sandia also brings its expertise in ensuring system safety and reliability to the high-power laser burn debridement project. 团

Indocyanine, a green dye that fluoresces when in contact with laser light, can be injected into a patient's blood to indicate healthy tissue.

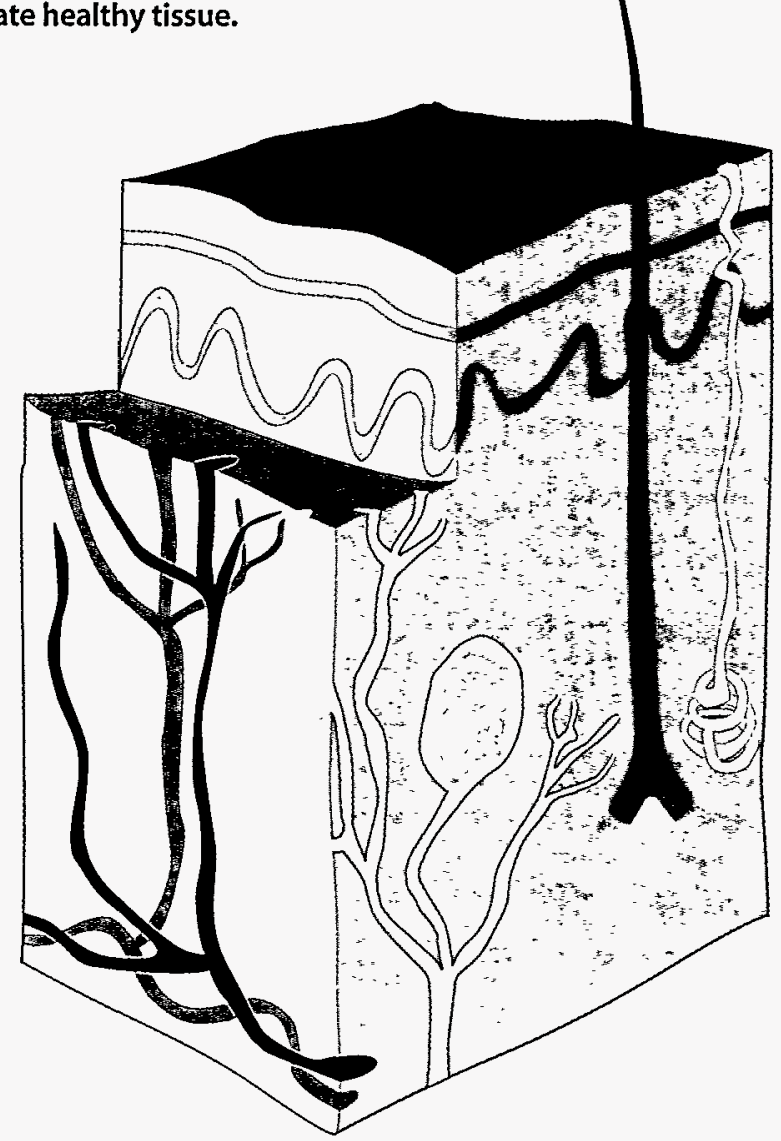

Formore information, call

Ned Godshall Instrumentation Engineering \& Technology

(505) 845-9193

Don Schroeder

Program Development

(505) 845-8409

\section{Blood vessels that carry nutrients to skin are destroyed when tissue is burned. However, Massachusetts General Hospital and Sandia are working} on a new treatment method that uses a high-power laser guided by a sensor instead of a scalpel to remove only burned skin and leave healthy skin intact. 


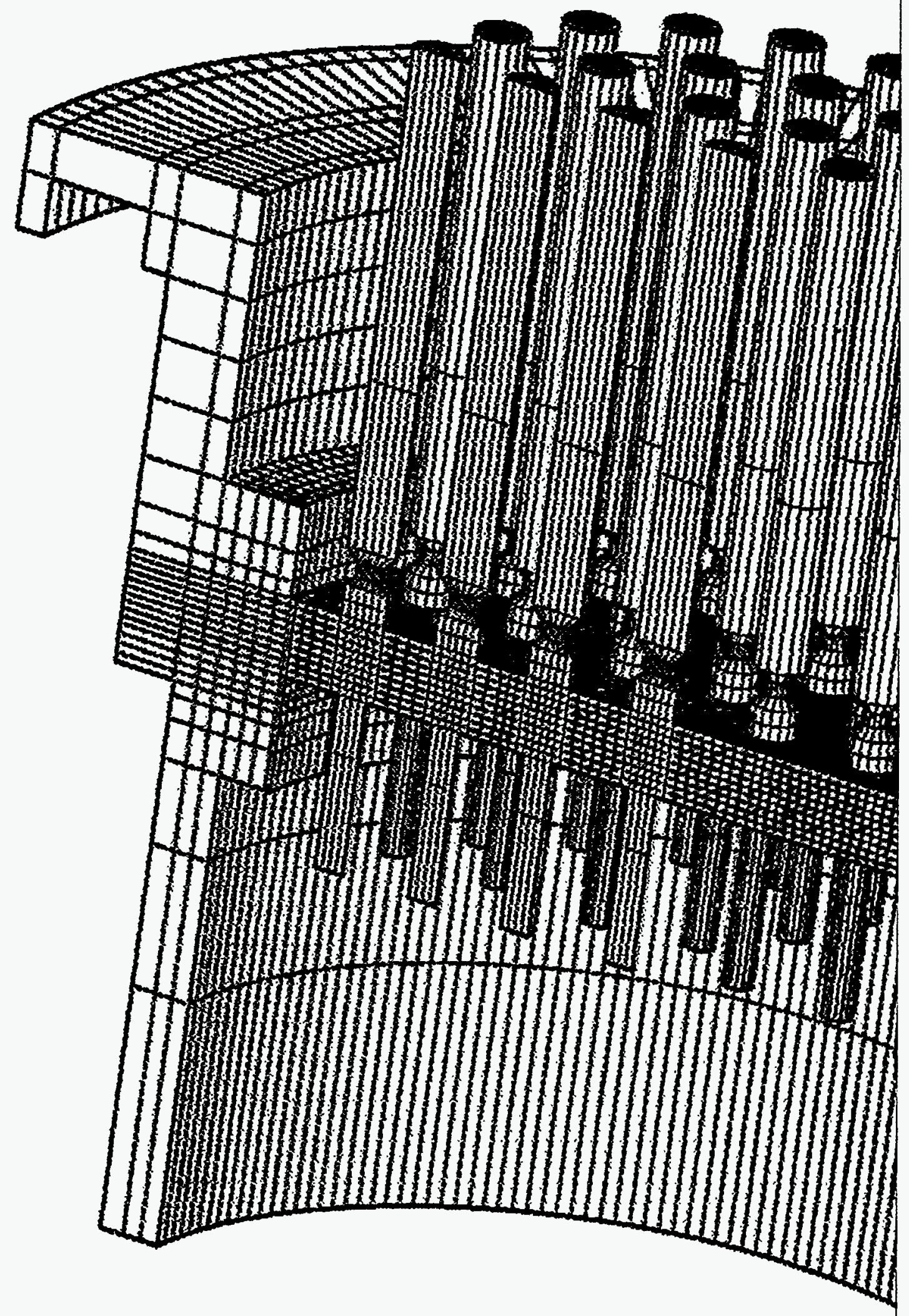




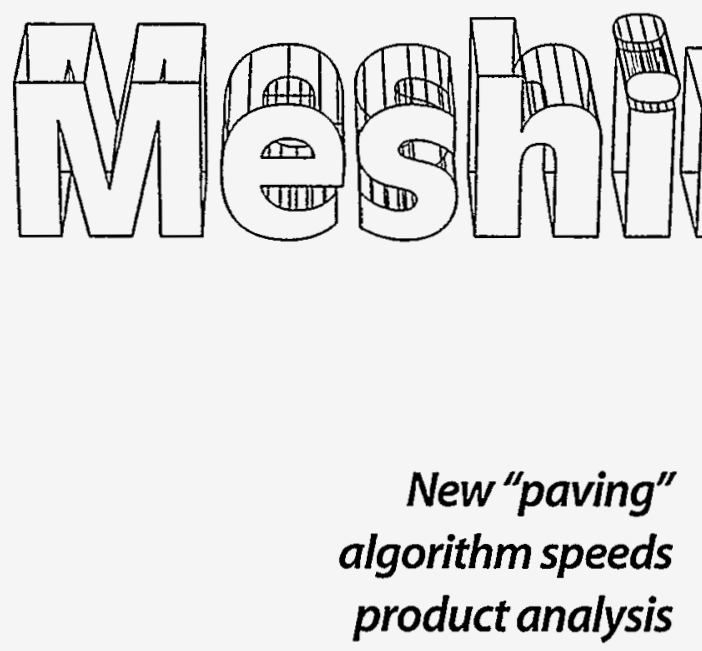

andia simulation experts have developed new algorithms that
dramatically shorten the time required to mesh models of complex geometries and make it much easier to model three-dimensional surfaces. These advances have attracted the attention of U.S. industry and have led to the development of a consortium to commercialize this technology. Ford Motor Company is one member of the group, as are several software and engineering companies.

Mesh generation is the creation of a computer model of a tangible object; the model uses meshes (looking like grids on the computer screen) to represent the surfaces of the object. The intersections of the meshes define points where displacement and stress, for example, may be calculated. "It can take four to six weeks, using typical

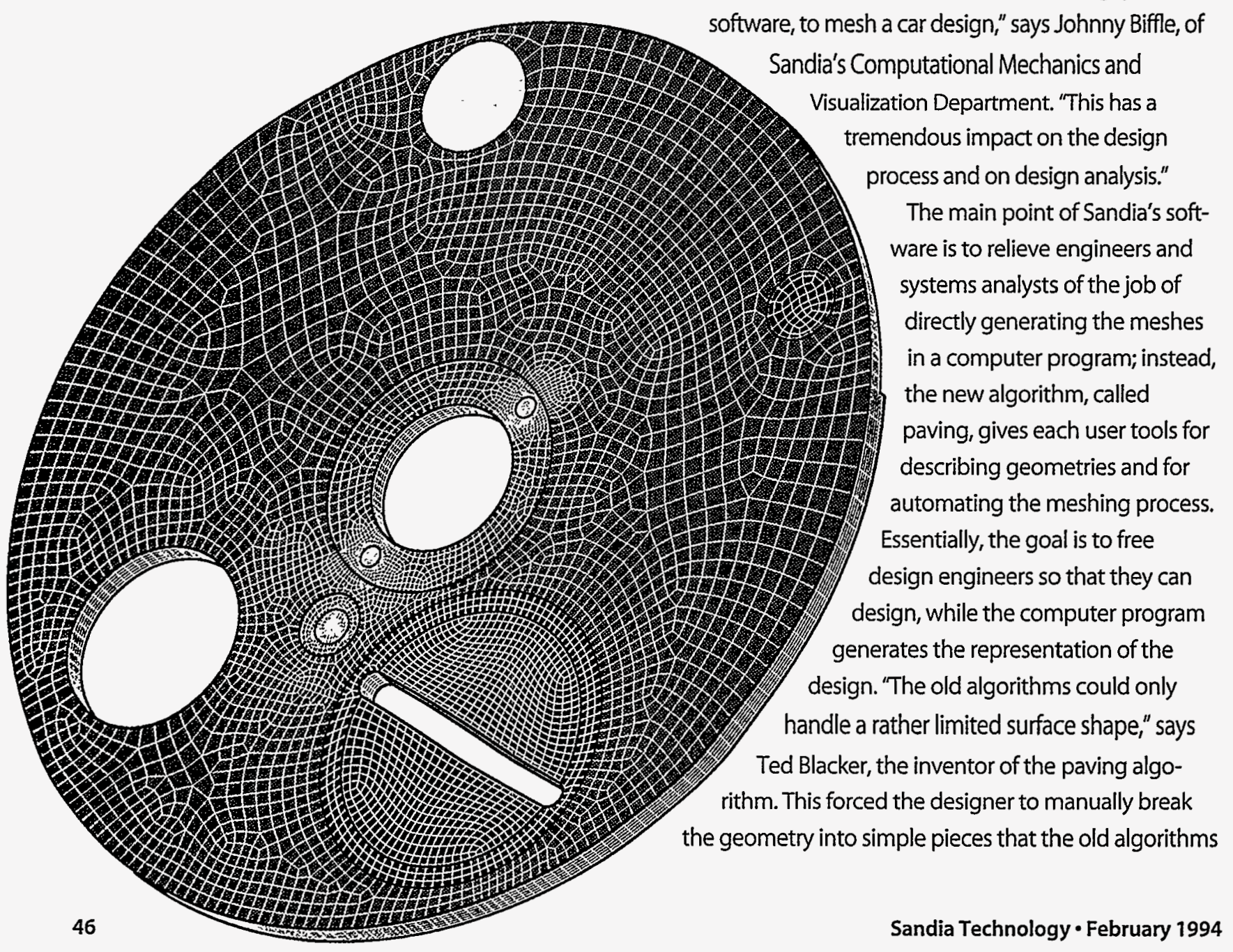


could handle. The new paving algorithm is far more general. "We can now generate mesh on a complex section of an object, such as the entire fender area of an automobile, or even the entire object, thus providing a three-dimensional surface representation automatically," says Blacker. One of the main uses of the mesh representations is in impact analysis, showing changes in shape as external forces crunch objects modeled by meshes on the computer screen.

The new paving algorithm has won a 1993 R\&D 100 award, presented by R\&DMagazine to the most significant technical products of the year. The mesh-generation algorithm originated in Sandia's defense work on safety systems for nuclear weapons. These new applications show how defense expertise, developed under DOE Defense Programs funding, can be applied to industrial needs. "This new software technology can reduce design time, and therefore reduce the time to market of products," notes Biffle. The next step for the Sandia meshing experts is to develop automated meshing for three-dimensional solids, showing how external forces can deform or change materials in a volumetric representation. "Every advance in modeling and simulation technology can help U.S. companies become more competitive," Biffle says. "This work is applicable to any company that uses analysis to improve the design of its products." 园

Formore information, call

Johnny Biffle

(505) 844-5385

Ted Blacker

(505) 844-9785

Computational Mechanics and Visualization

Left, the safing wheel of the stronglink system for a nuclear warhead. Above right, a lightning arrester connector showing the hermetic glass seal in the center of the device. Right, a computer meshing of a wellbore bit in a design project to improve longevity of the bit. In all these projects, the new meshing algorithm provided more rapid design and more accurate simulation than previous methods.
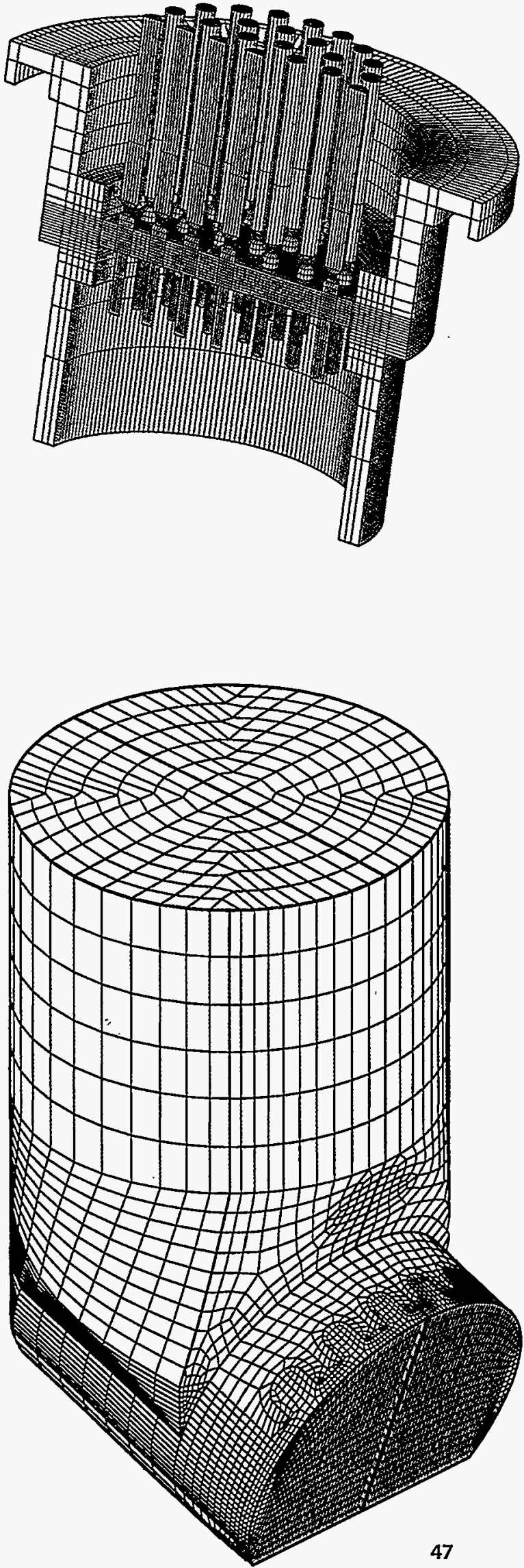


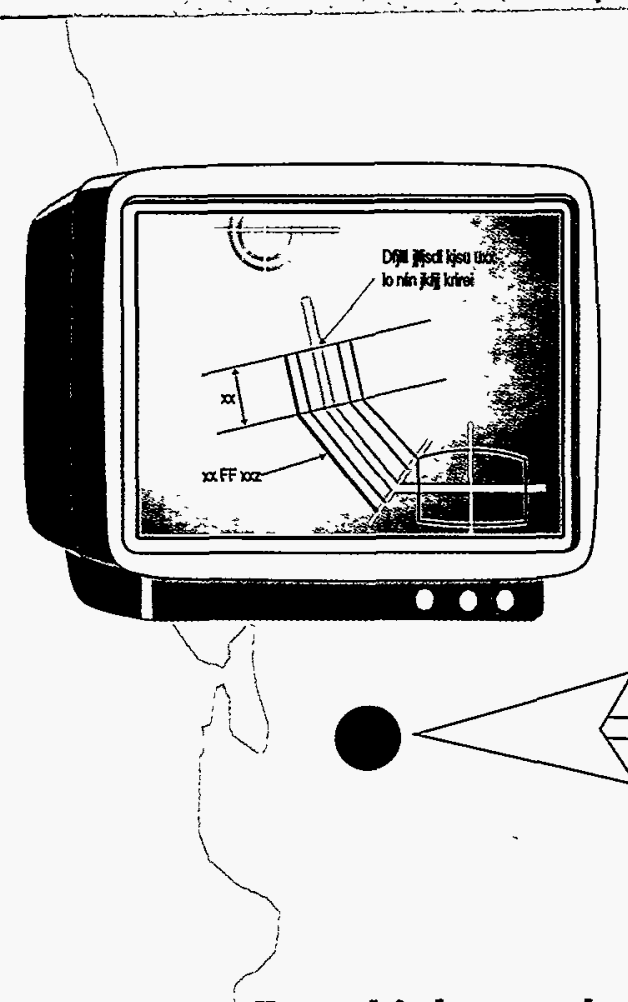

From high-speed computing to business networking, Sandia improves electronic communications

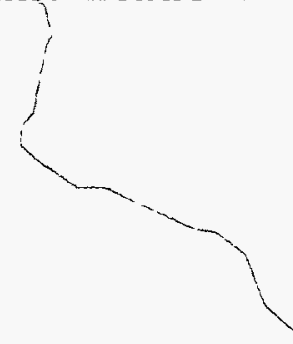

W hether establishing bussiness contacts or solving engineering problems, workers of the future will rely upon knowledge as close as the nearest desktop. By punching the right keys on a computer, scientists and businesspeople will be able to design products in three dimensions, simulate manufacturing processes, or consult data bases of environmental technologies in use around the world.

America's investment in nuclear weapon research at the Energy Department's national laboratories such as Sandia has spawned development of some of the most advanced computing and communications expertise in the world-expertise that is now being shared with the private sector.

One means of sharing such information is TIE-In, Technology Information Environment for Industry, a technology retrieval system at Sandia designed to give industries remote access to the Labs' capabilities and solutions at minimal cost.

"This is a pilot project to use computer and communications technologies to develò a mechanism for providing companies of any size with the ability to use solutions at the Labs," says project leader Jim Ang.

For example, an engineer seeking to improve welding processes for building a machine part can use welding process simulation and design programs. A banker seeking information about security systems can access computer tools for physical security design-without having to be a computer expert or structural engineer.

This is because one of the unique features of the TIE-In system is userfriendly software that guides users through the process of finding intelligent solutions to their particular problems. The system incorporates on-line training and education materials as well as graphical interfaces that show the user in pictures what is described in technical language. Remote access is possible via telephone or Internet connections. 


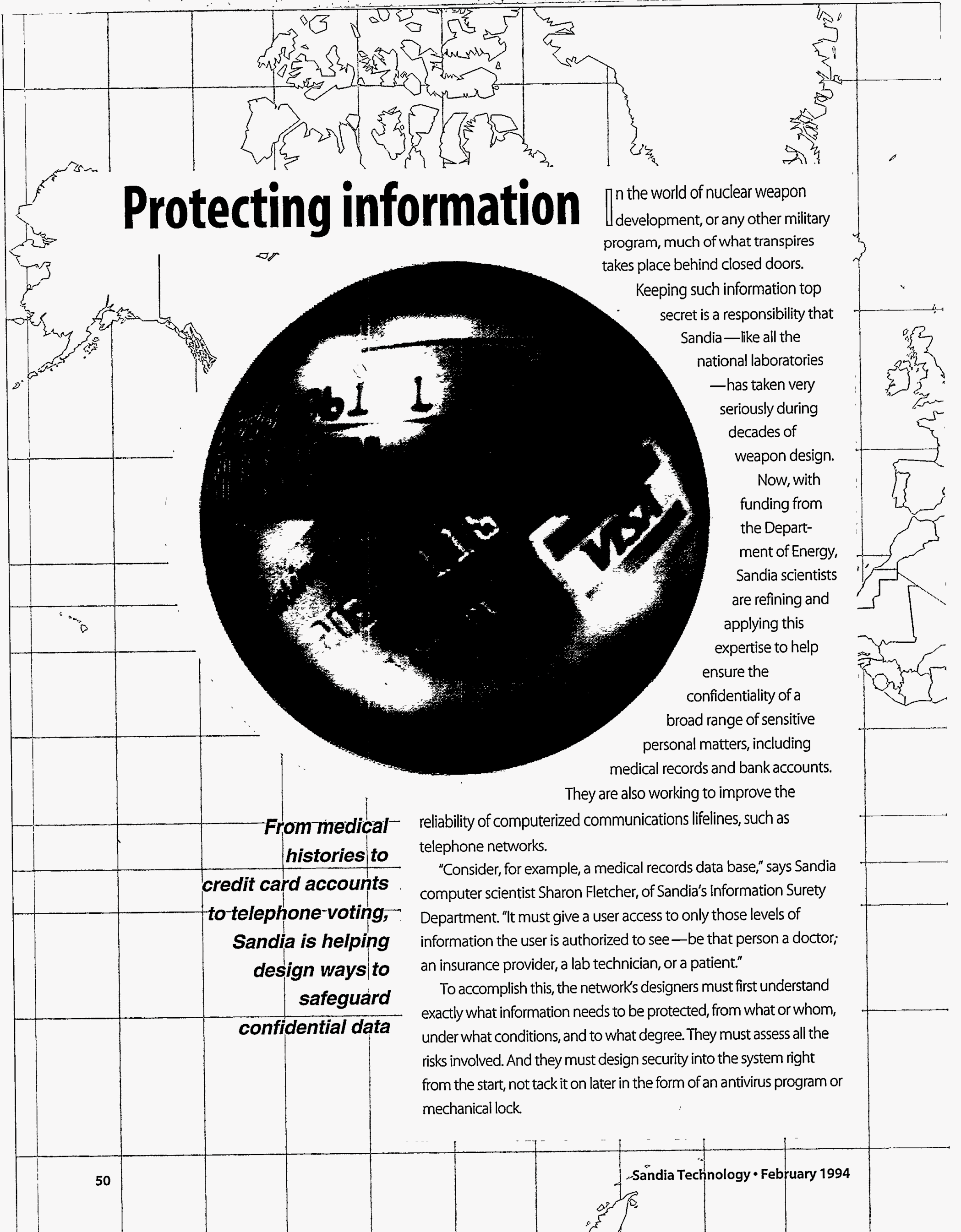




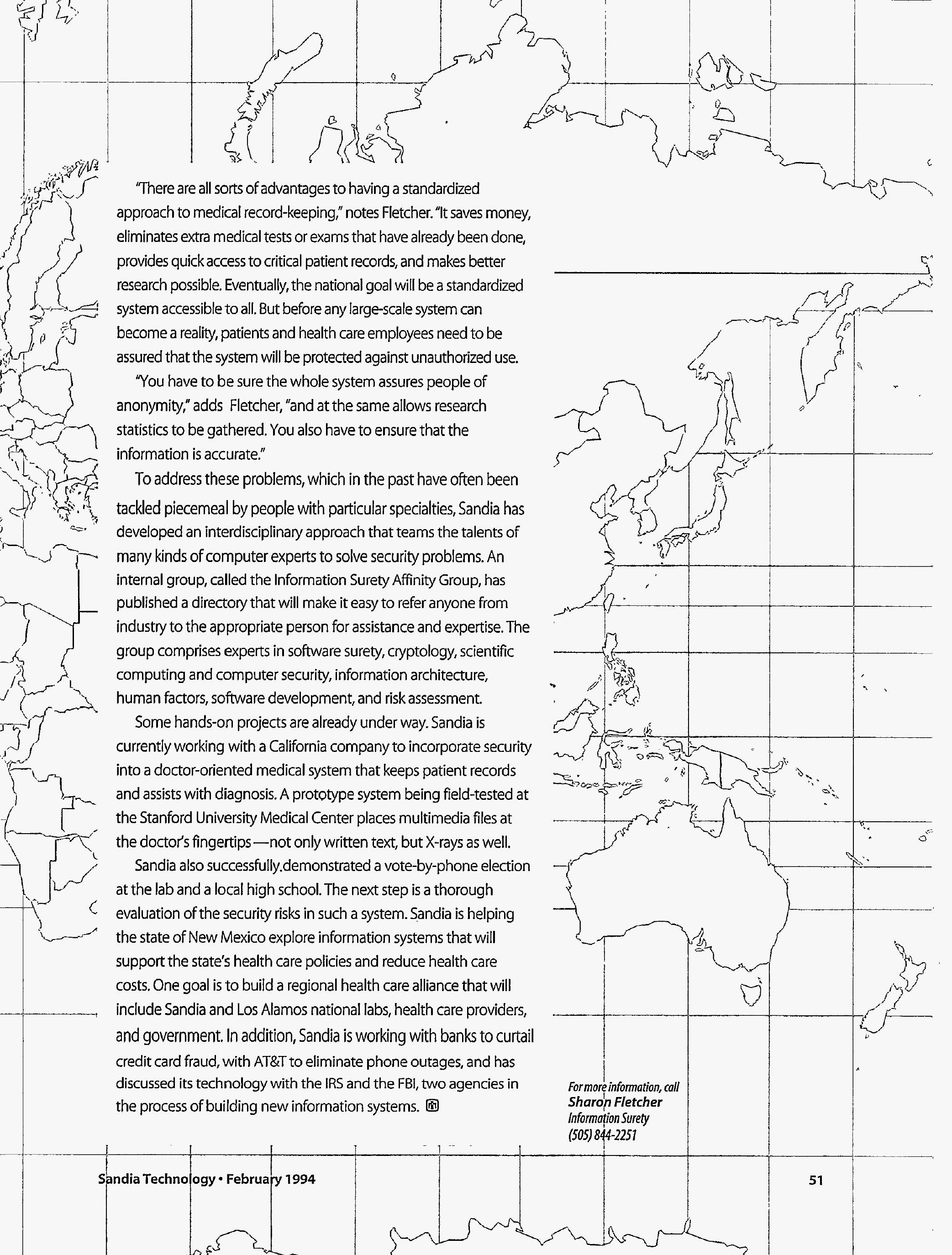




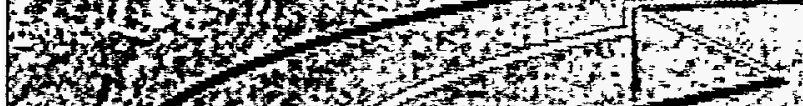

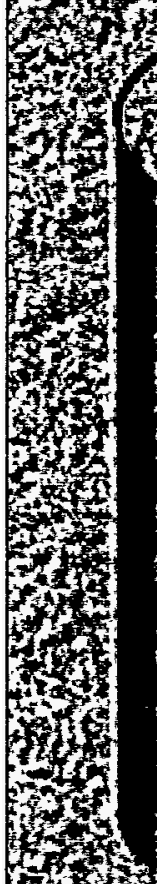

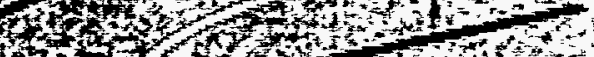

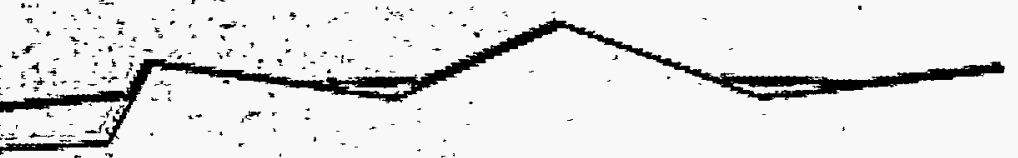

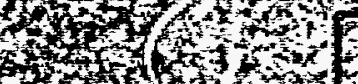

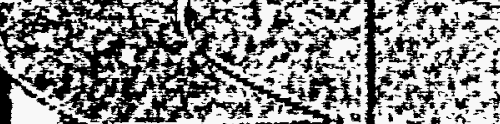

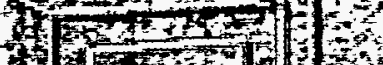

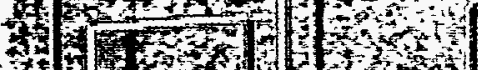

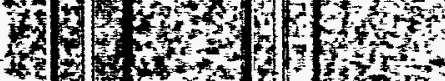

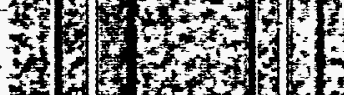

Eiming

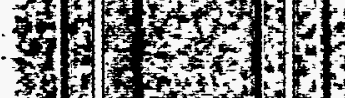

$3^{2}+5$

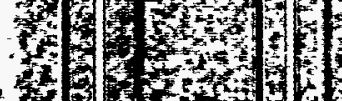

Qtitw

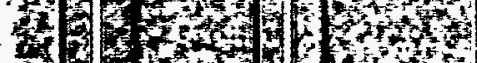

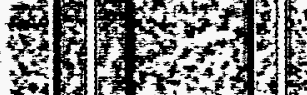

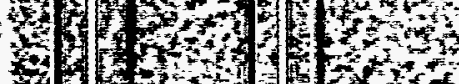

150

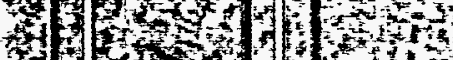

in 030

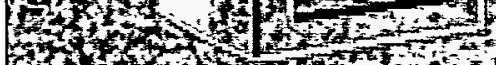

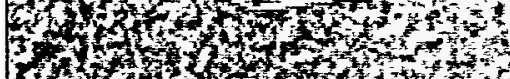

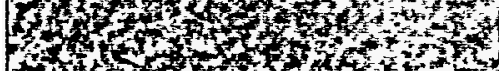

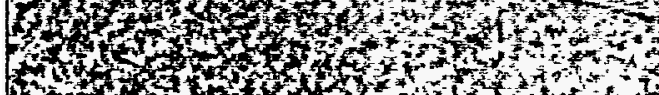

1351010

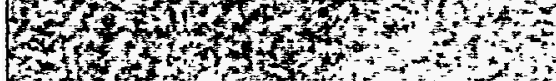

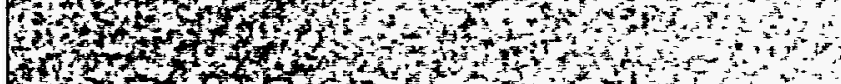

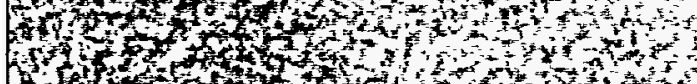

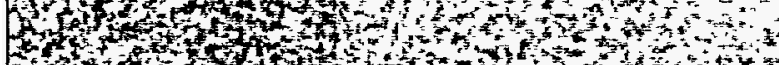

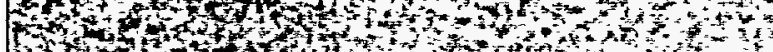

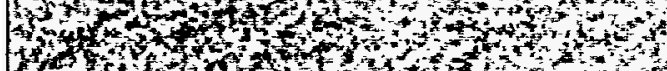

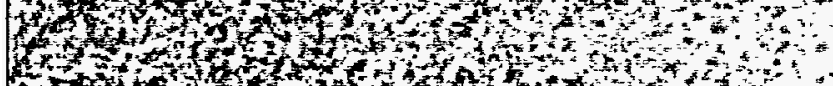

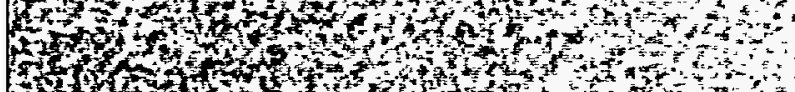

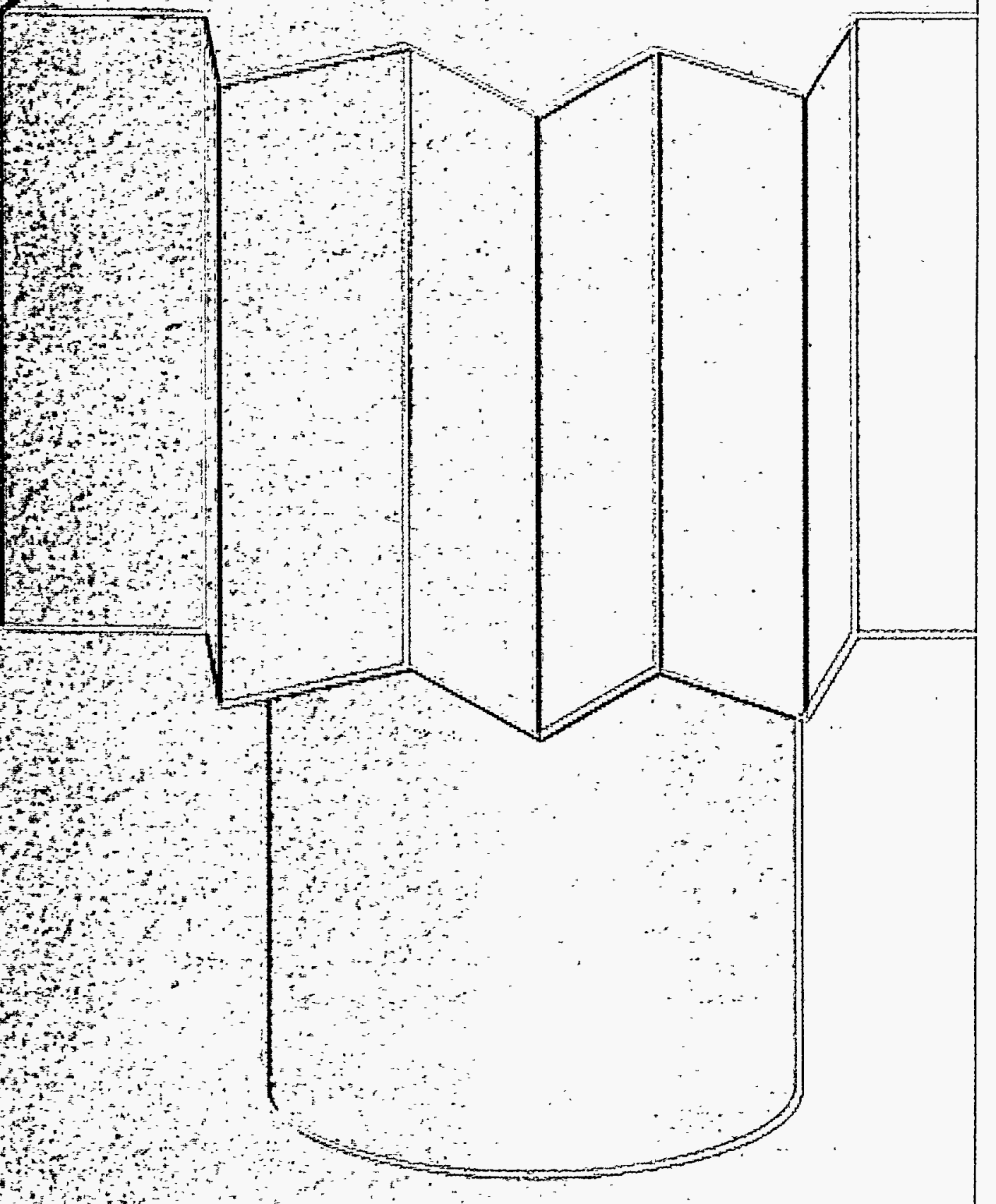

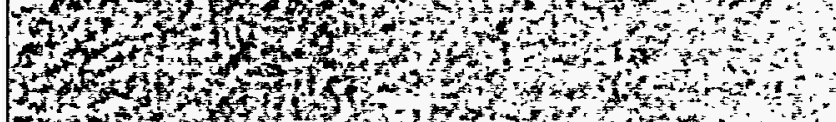

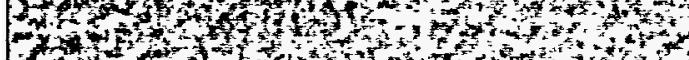

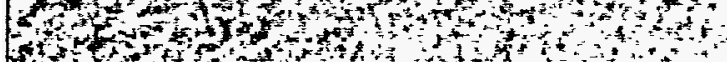

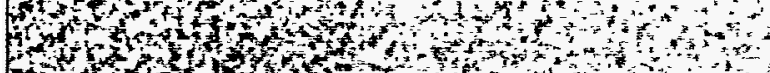

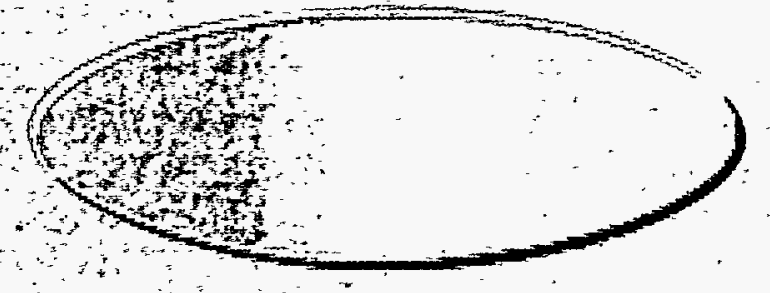






\section{GM CRADAs open avenue for Sandia's technology}

\section{Sandia and GM look at several technologies to lessen environmental impact and improve manufacturing processes}

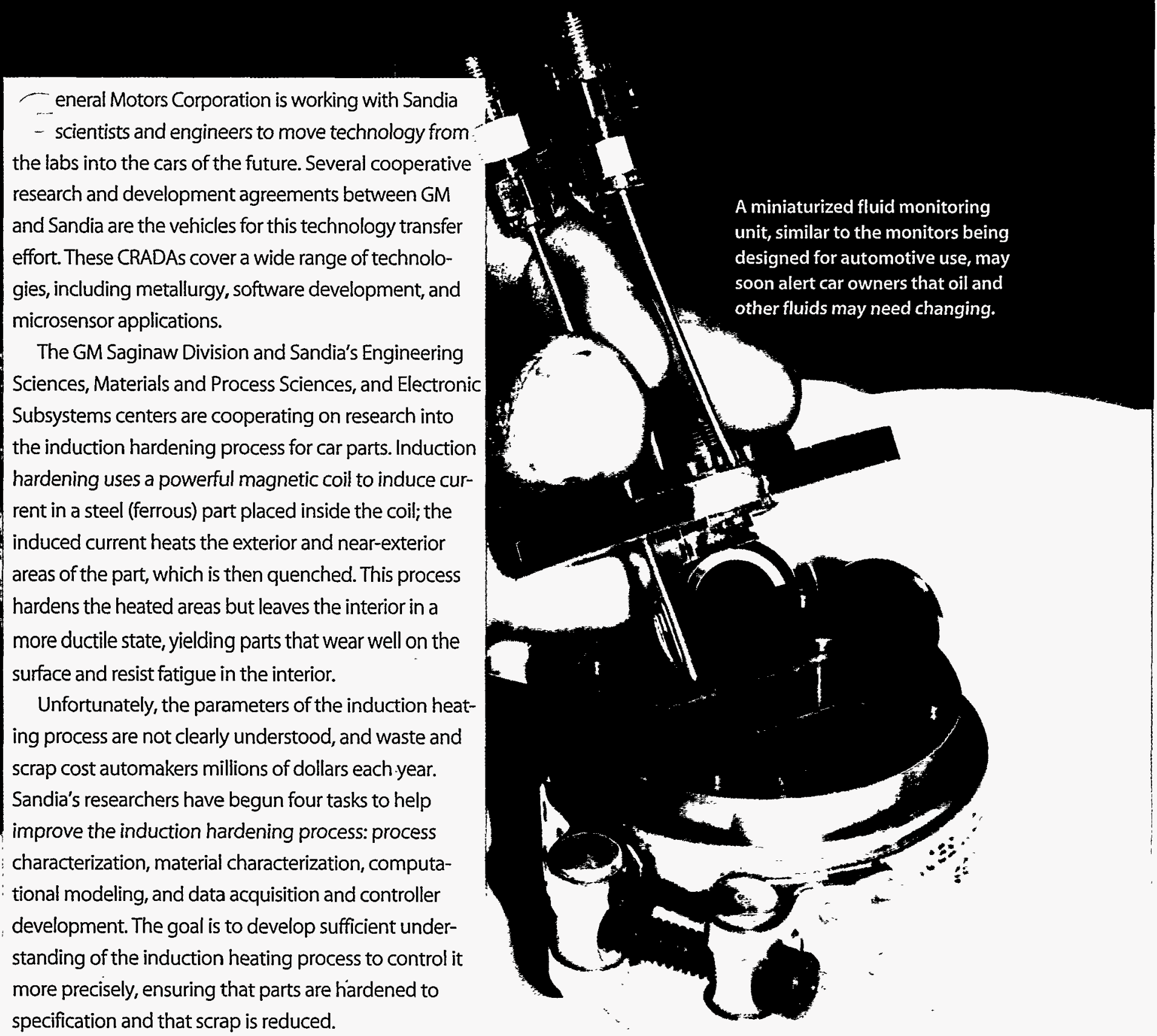




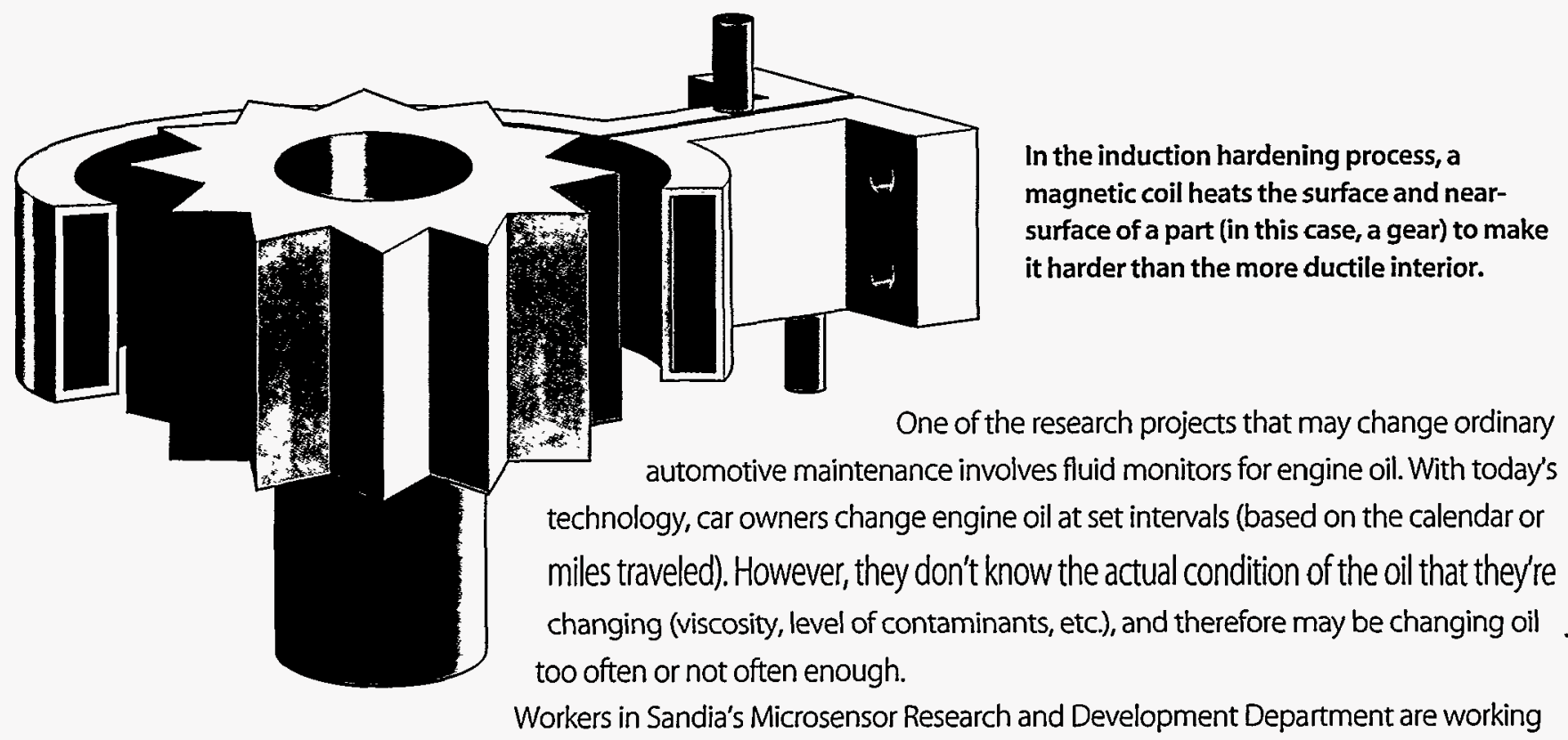

on in-situ monitors that will provide real-time information on oil condition. "We want to catch the oil at the appropriate time in its degradation cycle," says Richard Cernosek, one of the researchers on the project. "We want to know when it needs changing, but not change it so early that we increase environmental wastes." Project workers are adapting a quartz crystal microbalance sensor that measures the change in viscosity and the rate of particulate buildup in fluids. As the technology for monitoring engine oil advances, there may be further uses, such as checking engine coolant and other fluids.

The agreements with General Motors run from two-and-a-half to three years. In addition to the projects on induction hardening and oil monitoring, Sandians will be working on improved aluminum alloys, task analysis software, thermal spray technology, and materials selection software. This last task is a "knowledge-based" application (a software system that is broader-based than an expert system) aimed at making materials choices that are more environmentally aware.

These CRADAs and other agreements with U.S. automakers are moving Sandia into a new arena for transferring technology and expertise to U.S. industry. Sandia will also be an active player in the administration-backed agreement to create the U.S. super car, an 80-mile-per-gallon, environmentally friendly car for the 21 st century. Defense technology at Sandia is now serving the broader goal of national economic competitiveness; helping the domestic auto industry is an important part of that effort. 图

Formore information, call

Russ Skocypec (Induction hardening)

Thermal \& Fluid Engineering

(505) 845-8838

Richard Cernosek (Fluid monitoring)

Microsensor Research \& Development

(505) $845-8818$

Laurence Phillips (Materials selection software)

Strategic Technologies

(505) 844-7332

Mike Maguire (Aluminum alloys)

Physical \& Joining Metallurgy

(505) 845-3705

Randy Brost (Task analysis software)

Intelligent System Principles

(505) 844-1336

Mark Smith (Thermal spray technology)

Ceramic Processing Science

(505) 845-3256

Sandia Technology • February 1994

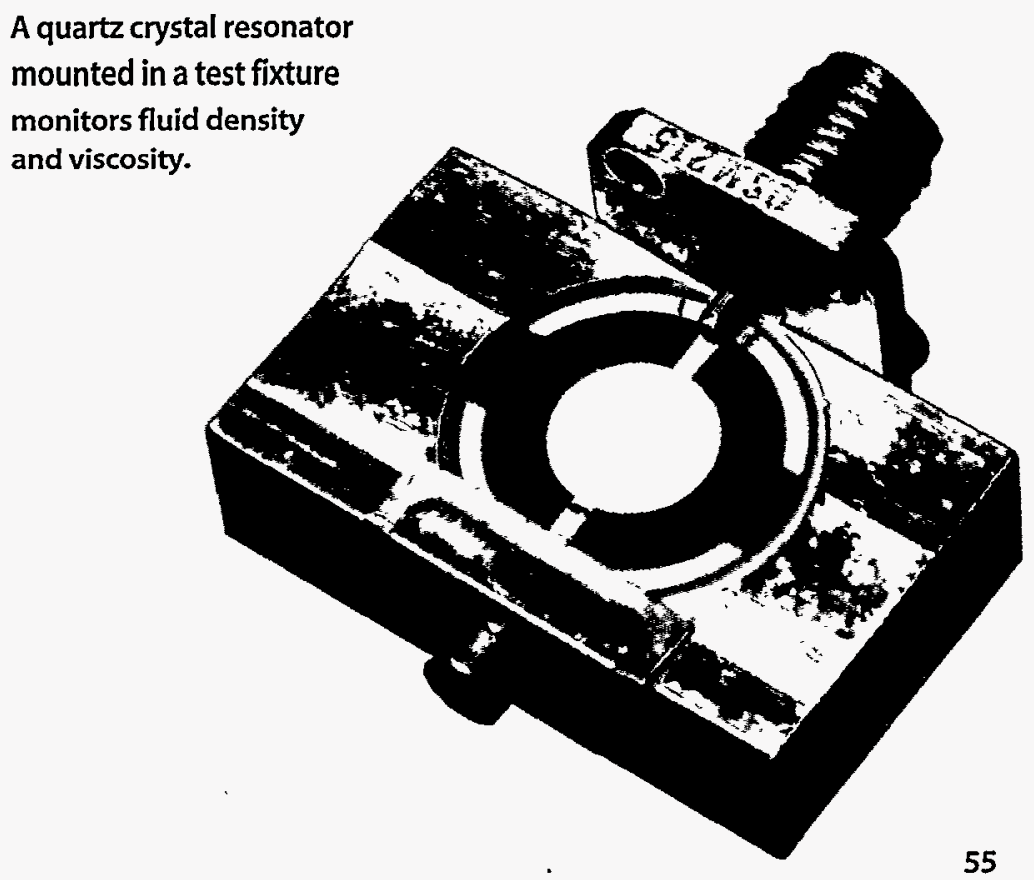

A quartz crystal resonator mounted in a test fixture monitors fluid density and viscosity. 


\section{good VIDAATION}

\section{Active control eliminates noise or unwanted motion}

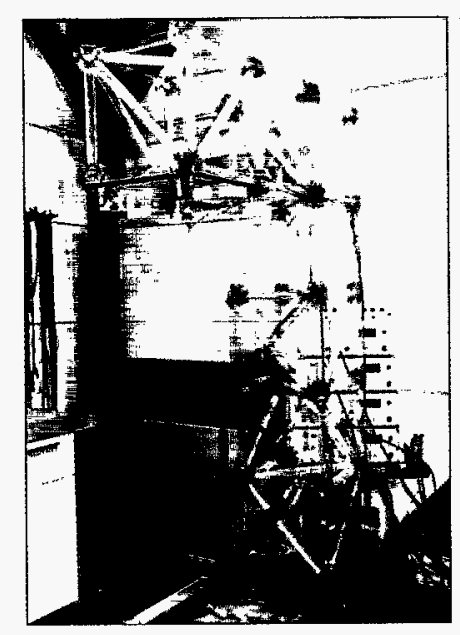

The benefits of vibration control on a structure can be studied and analyzed on a test platform such as this one in the Smart Structures Lab at Sandia.
N oisy trains, vibrating engines, chattering machine tools, trembling microchips on an assembly line-these and other items suffering from excessive noise or motion can be stabilized through a technique known as active vibration control.

Active control differs from conventional passive methods, such as a rubber damper between an engine and a frame. The rubber damper simply absorbs shock and vibration; it does not directly control the motion of the engine. Active control, however, generates a response to counteract the unwanted nojse owibation. Sensors in the active control system measure howmuctuthe engine is vibrating and send the information to a central processor $r_{s}$ which directs actuators to apply forces on the engine and counteract the vibration:

The result: reduced vibration.

Luxury cars sometimes feature active control of interior noise. Sensors inside the car detect noise from the engine, for instance, and put out a signal, through the speaker system to cancel the sound. .

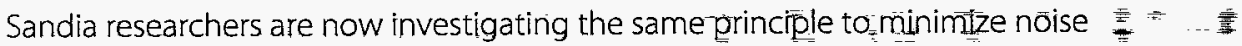
on the Bay Area Rapid Transit system in California, known as BART. The menting individual train cars and studying the resonances and acoustic response of the sounds generated. Eventually, active or passive control may be used to reduce the noise.

Sandia's expertise in this arena comes from work in advanced submarine technology for the Advanced Research Projects Agency, notes Sandia electrical engineer Bert Tise. A structure such as an airplane, spacecraft, or manufacturing device can be fitted with sensors that detect vibration and movement and with actuators that counteract the vibration or motion. Both sensors and actuators feed into a central processor.

The concept of active control has existed since the 1950s, but until the late 1980s, computer power and speed were inadequate to handle the complicated calculations needed to operate such systems.

Active control has many potential applications, such as stabilizing engine mounts, reducing machine tool chatter, grinding precision lenses, or manufacturing integrated circuits and flat-panel displays. 


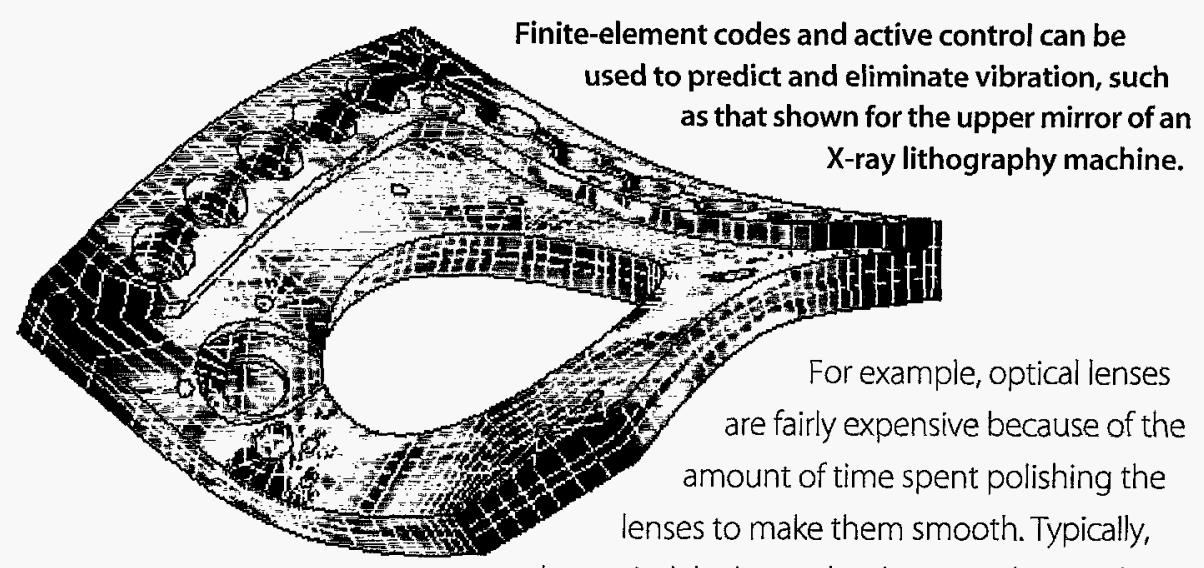

robots grind the lenses, but because the grinding

tool vibrates, the resulting surface is not completely smooth and must be polished manually to its final smoothness after the lens is ground. "If we could stop the grinder from vibrating, the cost of a lens would be lower because it would require less polishing," says Tise.

Another application is photolithography of silicon wafers for integrated circuits. Currently, IC patterns are transferred onto silicon wafers by exposure to an energy source shining through a mask. Each time the wafer is moved between exposures, it vibrates, and the manufacturing process must slow down and wait until the wafer settles. With active control, photolithography would be faster and more stable, perhaps allowitng for even finer, more closely packed circuits in microprocessors.

Sandia is now looking at transferring ARPA's active vibration control and processor technology to industry. One company is planning to repackage the processors to make them smaller. If active control systems become abundant enough to be economical, they might one day be used to quiet industrial coolers or mitigate earthquake shocks in buildings.

A researcher works on a commercial lithography machine, a microcircuit manufacturing device that can benefit from a Sandia-designed system that minimizes vibration.

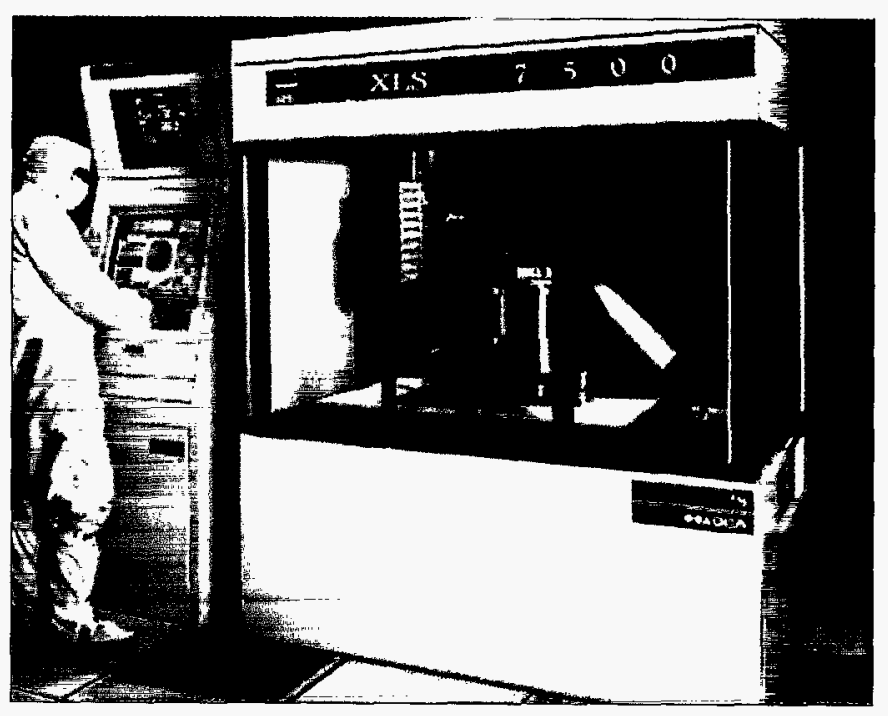




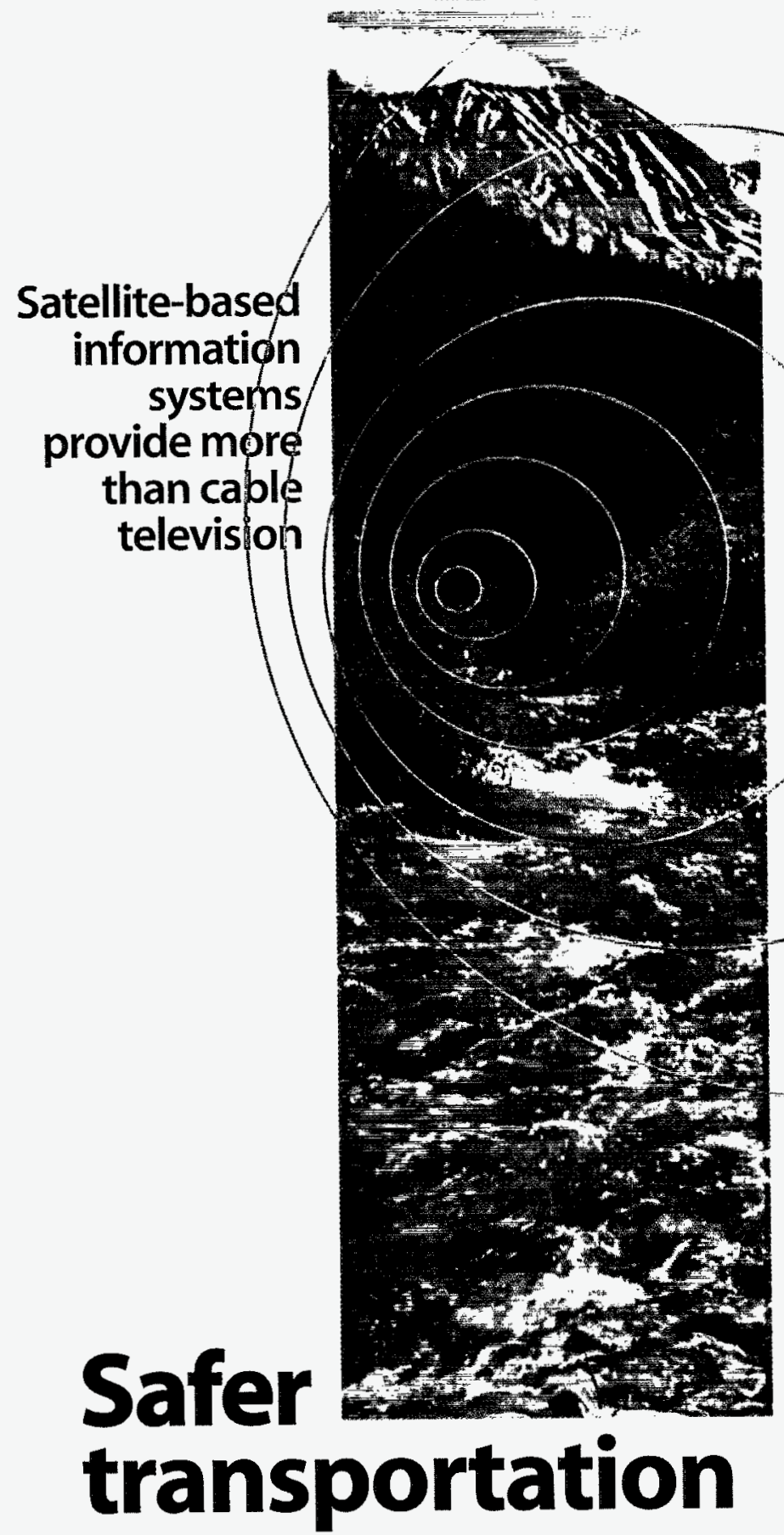

t's not a very likely scenario, but

not unthinkable, either: A school bus carrying 40 children and their teachers runs off a road in a remote part of the state. The wheels are damaged and the bus has to be towed.

Perhaps they are on their way to a game in another region, or returning from a nature hike. Depending on how remote their
Sandia researchers are helping develop a transportation management system keyed to Geographic Information System's, a technology thạt uses satellite signals to pinpoifht a vehicle's location. Autómobiles may orie day be equipped with sensors and transmitters that caín give their condjifion and locationin an acsident. 


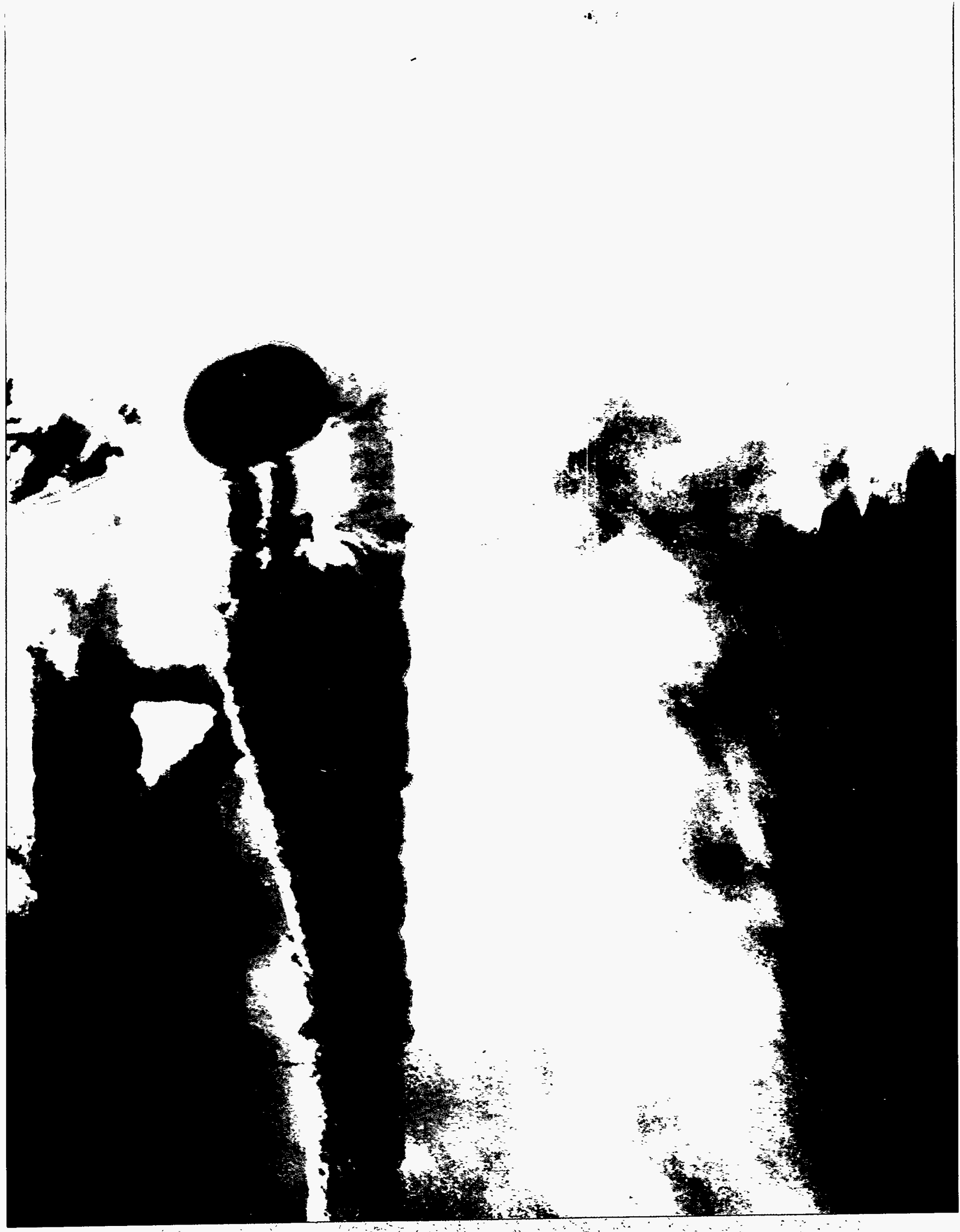




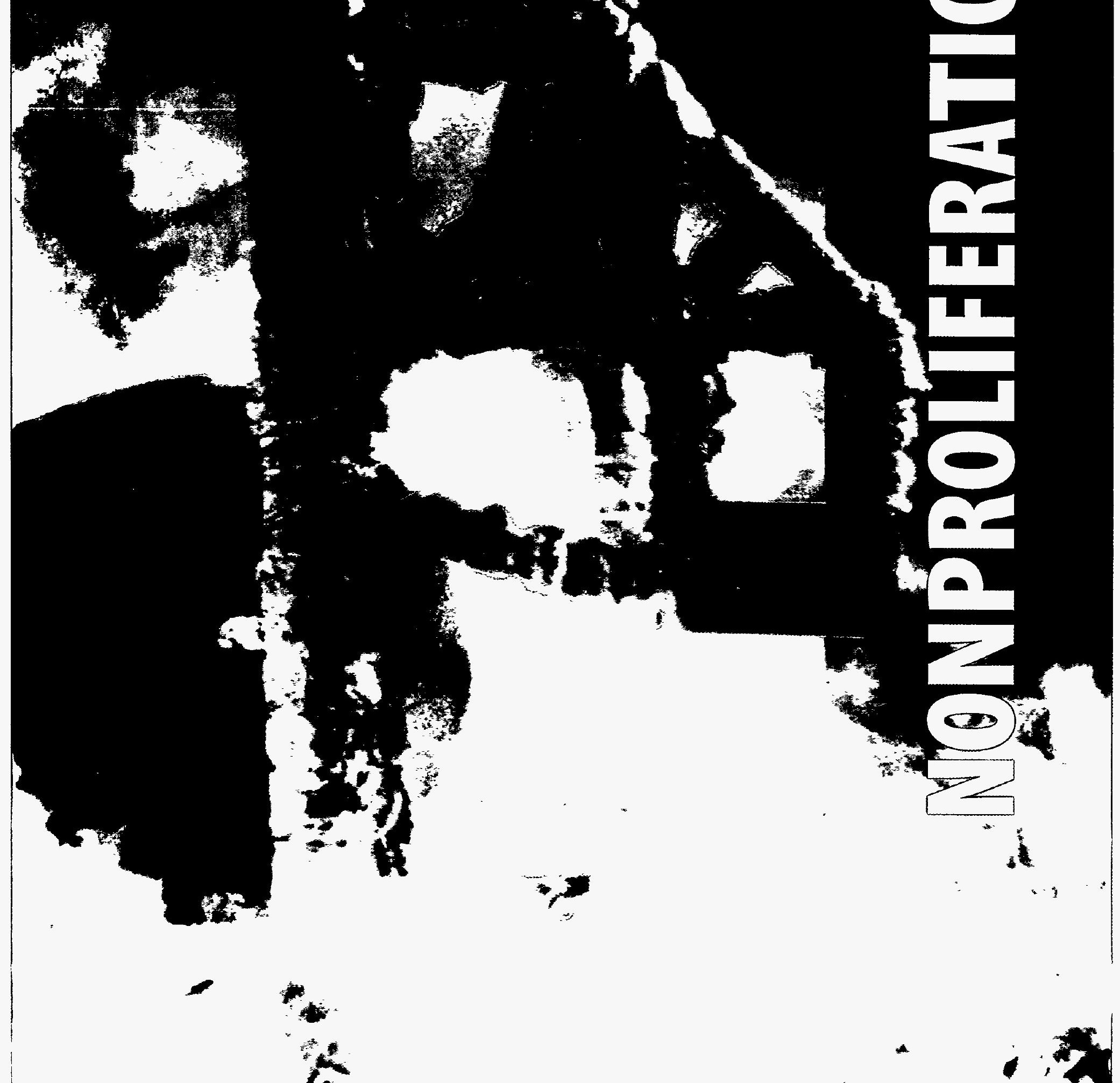


Formore information, call Michael Chiesa SolidMechanics (510) 294-2103

\section{Robert Monson} Systems Engineering (510) 294-2258

\author{
Protective \\ containers help \\ prevent \\ dismantlement \\ disaster
}

W

Thile the prospect

of nuclear arms reductions promises to enhance the safety of all the world's

inhabitants, dismantling nuclear warheads is not a simple matter. As weapons of mass destruction, they must be handled with great care.

To help meet this need especially for weapons transported over long distances, the Energy Department has directed Sandia to design containers to protect nuclear weapons in the event of an aircraft crash and a subsequent fuel fire. The program supports nuclear disarmament and also protects the environment and avoids the cleanup costs that would accompany any dispersal of nuclear material.

These protective vessels, called Transportation Accident Resistant Containers, are designed to survive a minimum 225-feet-per-second impact on a hardened concrete target, such as a runway, followed by a 2-hour fuel fire of $1,800^{\circ} \mathrm{F}$. The containers must also protect warheads from shock loads that could potentially scatter nuclear materials. Sandia's extensive testing facilities make it possible to evaluate the effects of such conditions and design components to withstand them.

To date, Sandia has designed and tested three basic containers that can transport seven different nuclear weapons. "These weapons range from small artillery projectiles to large, laydown bombs," says engineer Robert Monson, at Sandia's California facility.

Each vessel consists of an inner and outer container. The outer container is made of a thin, stainless steel skin, chosen for its great ductility, that can withstand considerable deformation without rupturing. Inside the container is a redwood material that can absorb considerable kinetic energy and provide thermal insulation. In extreme 


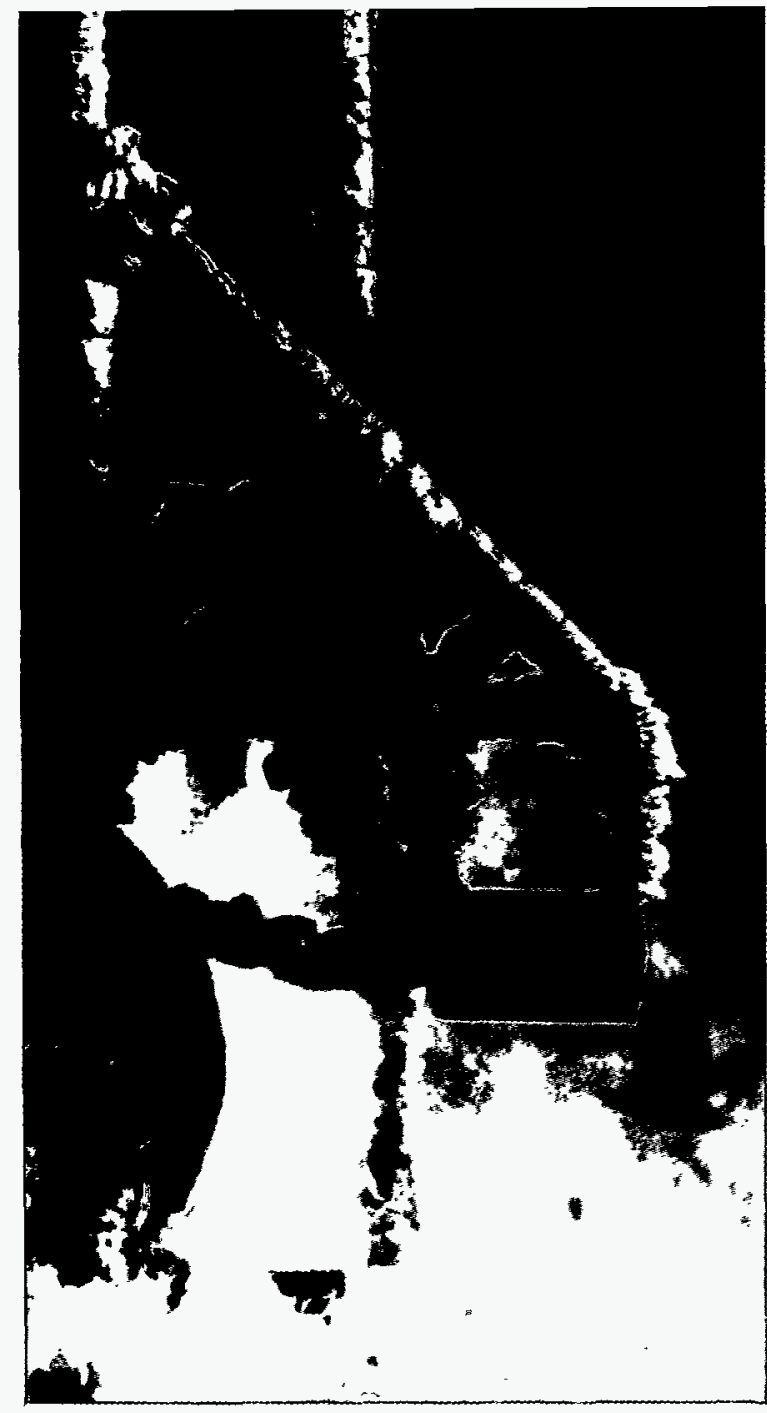

heat, as long as there are no large ruptures, the redwood will char instead of burn because of a lack of oxygen, continuing to provide thermal protection.

Inside the redwood layer is a thick, aluminum inner container designed to protect warheads from possible punctures and deformation, and serve as a backup container to prevent dispersal. Special inserts designed to fit each weapon limit shocks during transportation and provide added protection in the event of a crash.

Three-dimensional computer modeling, one of Sandia's major areas of expertise, simulated many of the accident scenarios and reduced the time and cost that would be required to conduct full-scale impact tests.
Large, finite-element models were used to predict the response of the container and the warhead. These calculations predicted the behavior of the outer stainless steel skin, the impact magnitude at various velocities, the effect of various container orientations, and even the behavior of door bolts joining container parts.

Such calculations enabled engineers to optimize the design of the inserts for the weapons being transported and maximize the accident conditions each warhead could survive, says Sandia engineer Mike Chiesa. The computer models also calculated the response of the redwood shielding and the effect of the concrete target or runway on the crash vehicle and its cargo. In addition, actual testing of components, such as drop tests, burn tests, and vibration tests, validated the predictions of the computer models.

Sandia first began designing Accident Resistant Containers for the Energy Department to prevent dispersal of plutonium from warheads in the early 1970s. In the mid-1970s, Sandia designed a smaller container to be carried on helicopters. By the late 1980s, Sandia began modifying and converting container designs to accommodate other weapons. Today, the containers accommodate the W79, W70,W48, B57, and B61 warheads.

Soon, the containers will also accommodate the W62 and W78 warheads. 固

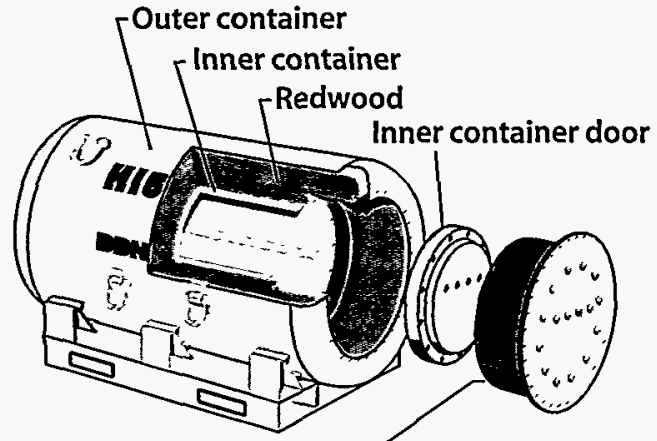

Outer container door

A protective container for carrying nuclear weapons (left) is subjected to intense fire at a Sandia test facility in Albuquerque, New Mexico. $A$ cross section (above) shows protective layers that can withstand deformation and heat. 


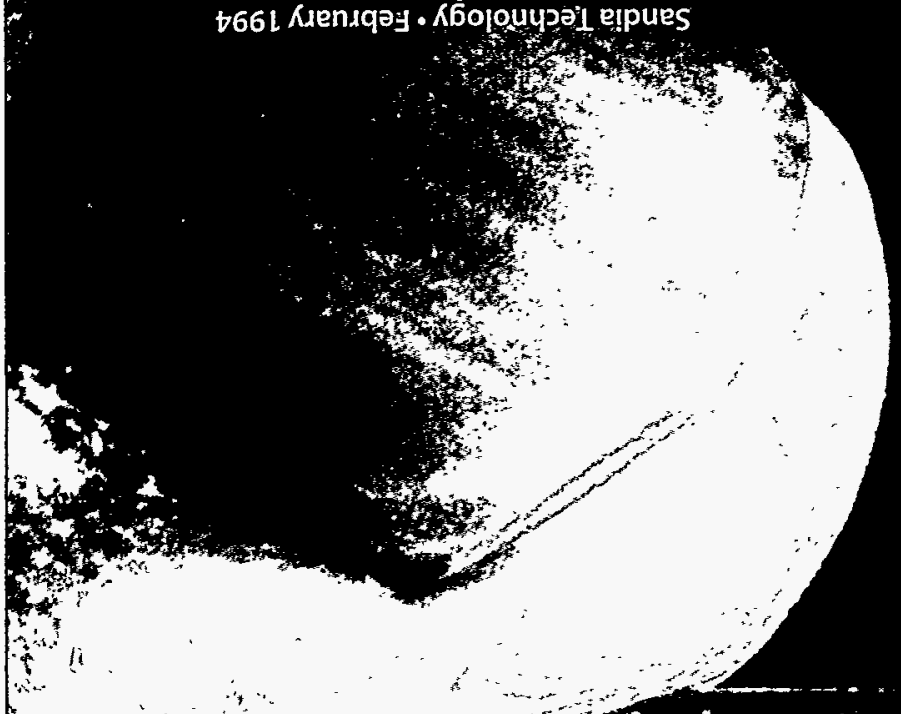

\section{suo!feכ|jdde Kueu} әлеч Keu

s|е!.әұеш ұчб!әмұчб!า

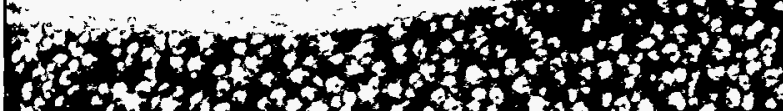
(2)

4.

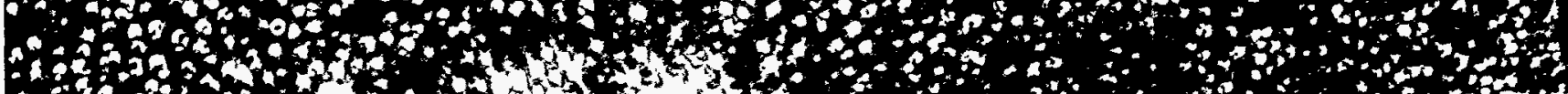

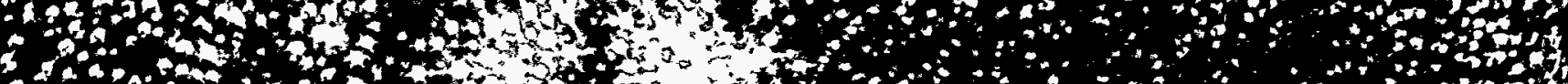
a

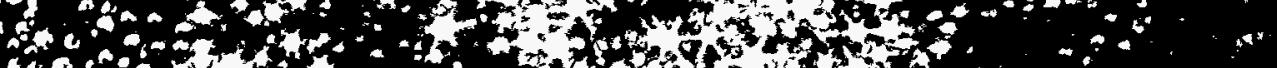

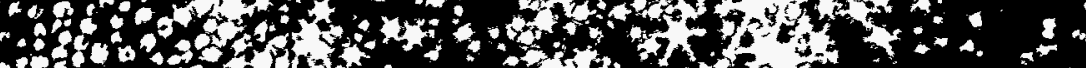

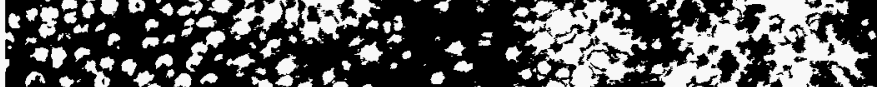

$\Leftrightarrow$

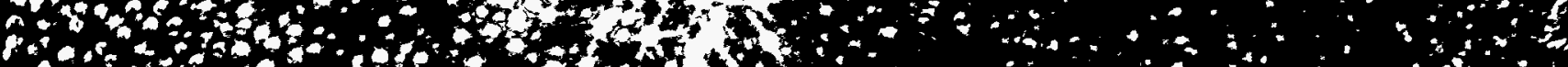
net

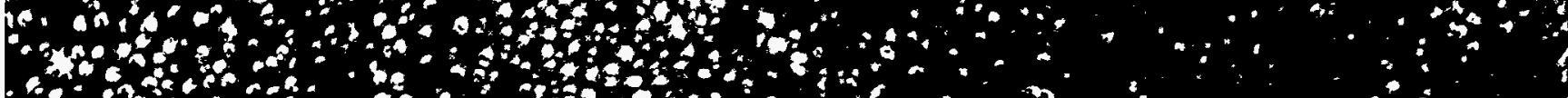

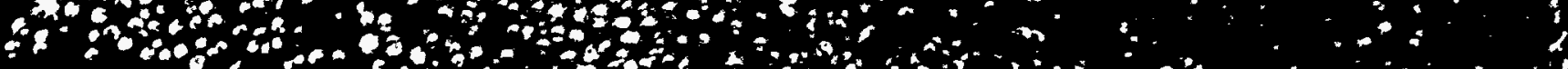
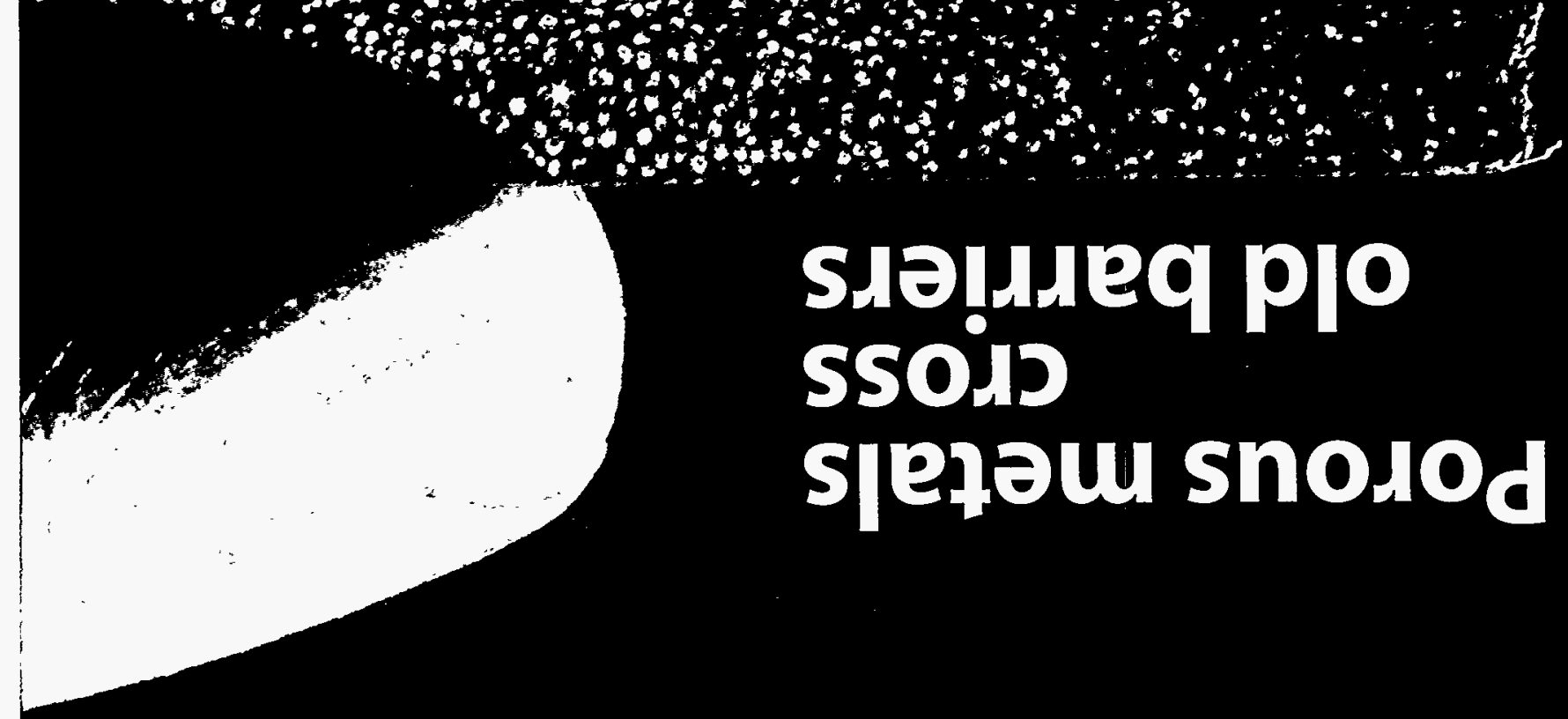


\section{Old enemies, new partners}

\section{Working with the FSU to ensure nuclear safety}

W

hen the strategic arms reduction treaties were signed

with the Soviet Union, nobody in the U.S. foresaw the imminent collapse of the Communist government and the emergence of several nations with nuclear weapons on their soil. Now Sandia is working with the former Soviet Union (as are other U.S. labs and government agencies) to help ensure that, as the treaties are implemented, safety and accountability are maintained over the scattered FSU stockpile.

Several projects are under way to help the FSU (primarily Russia) transport weapons safely and maintain control over all nuclear weapons. In one effort, 2,500 armored blankets were delivered to Russia to provide small arms protection during

A stainless steel container designed by Sandia holds radioactive material from Russian nuclear weapons. Sandia is helping the FSU dismantle and store the components of nuclear weapons eliminated under arms reduction treaties.

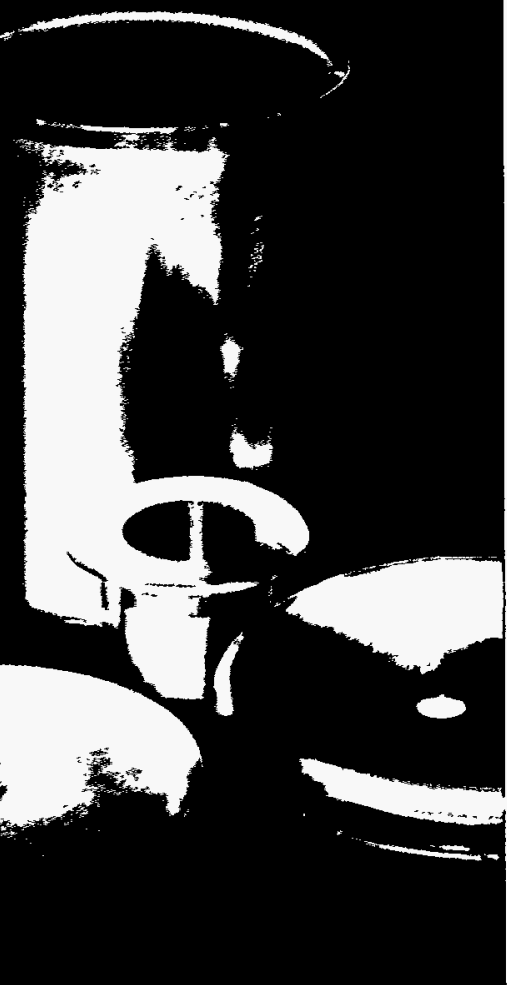

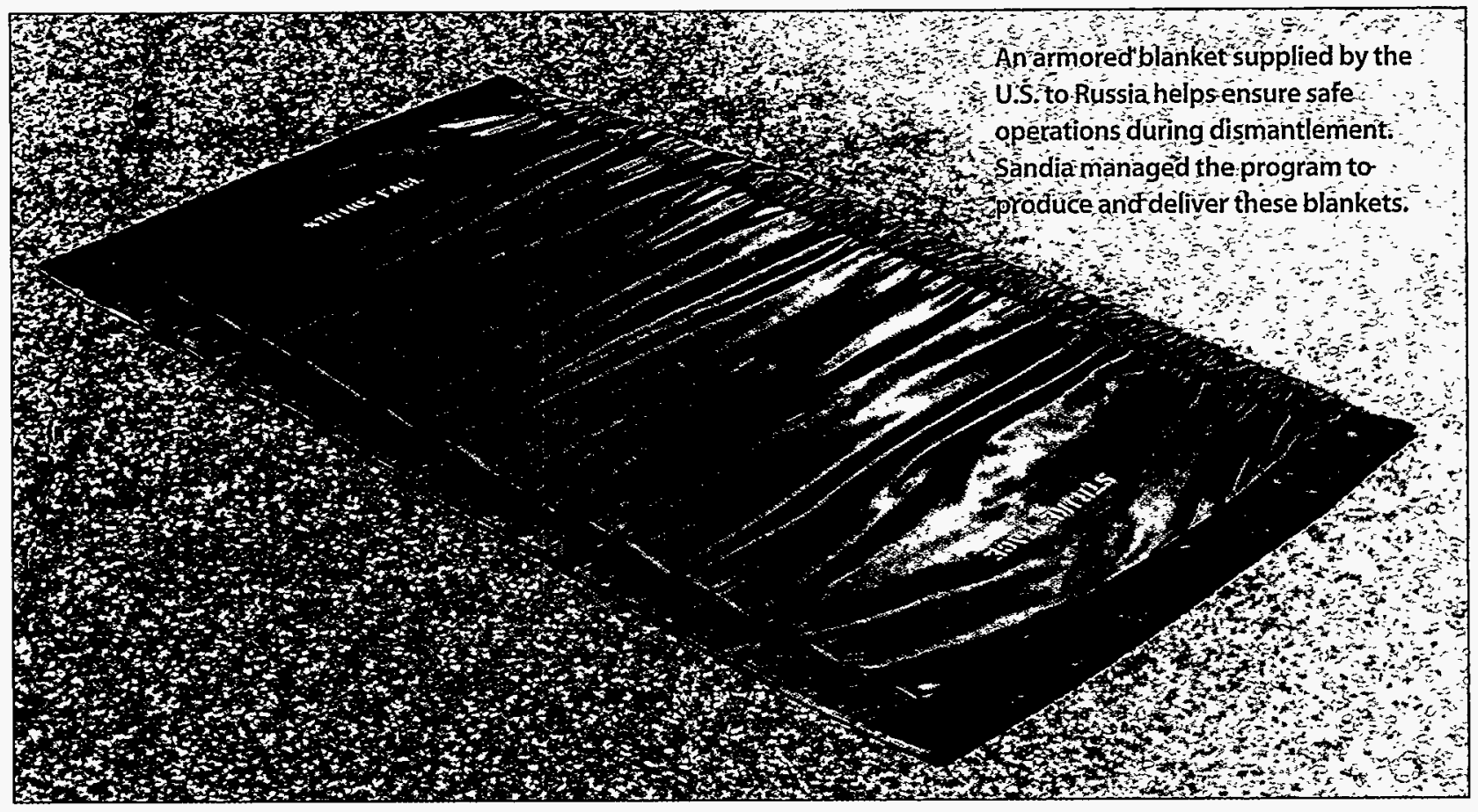




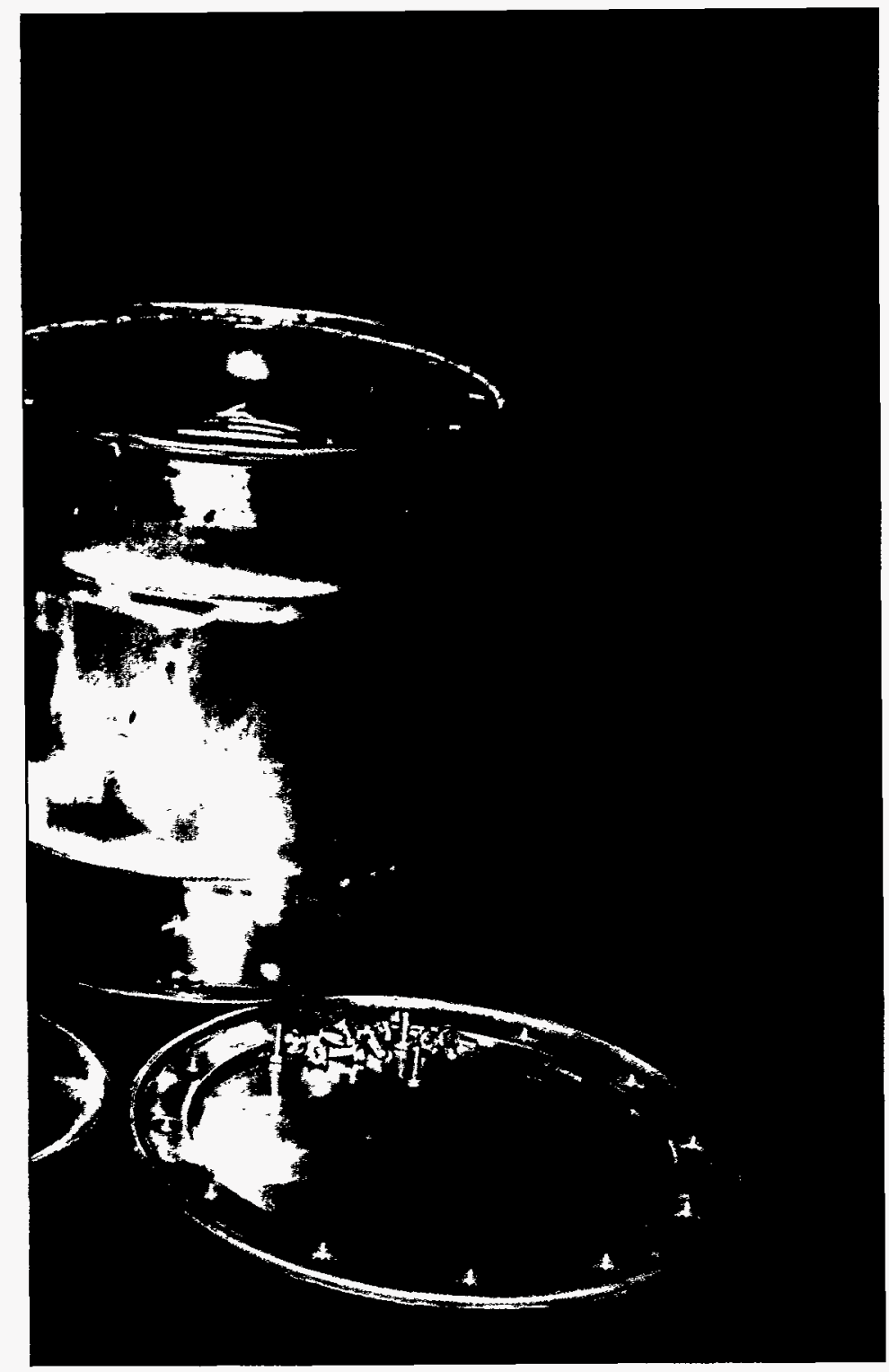

operations associated with dismantlement. Sandia managed this work and received a commendation from DOE for coming in ahead of schedule and under cost.

Sandia engineers are also designing and testing containers for radioactive material from Russian weapons to ensure safe storage and transportation. The Defense Nuclear Agency will procure the containers, and Sandia will provide quality evaluation for fabrication processes. Sandians are involved in the design of a facility to store radioactive materials after they are removed from weapons. They are also involved in other projects to ensure that the reduced Russian stockpile will be safe and secure.

"We want to make sure that they know where everything is all the time," is the way Dave Nokes puts it. Nokes is manager of Sandia's Surety Program Office and has been involved in many of the projects with the FSU. His words reflect the view that, with the reduced tensions between the U.S. and the FSU, the greatest nuclear danger in this area is the theft or diversion of nuclear weapons in the new states of the FSU.

To ensure that this does not happen, Sandians have been working with Russian counterparts on transportation and surety issues. "It is in our interest to diminish some of the folklore on their side about what we're like, and diminish the folklore on our side about them," Nokes said. Sandia weapons experts have visited some of the Russian weapons facilities that were impenetrable a few years ago and are proposing projects with Russian labs to keep Russian weapons personnel employed.

As cooperation continues between the two former enemies, Sandians will be helping Russians keep their weapons under firm control, accountable to treaty requirements, and out of the hands of terrorists. 因 


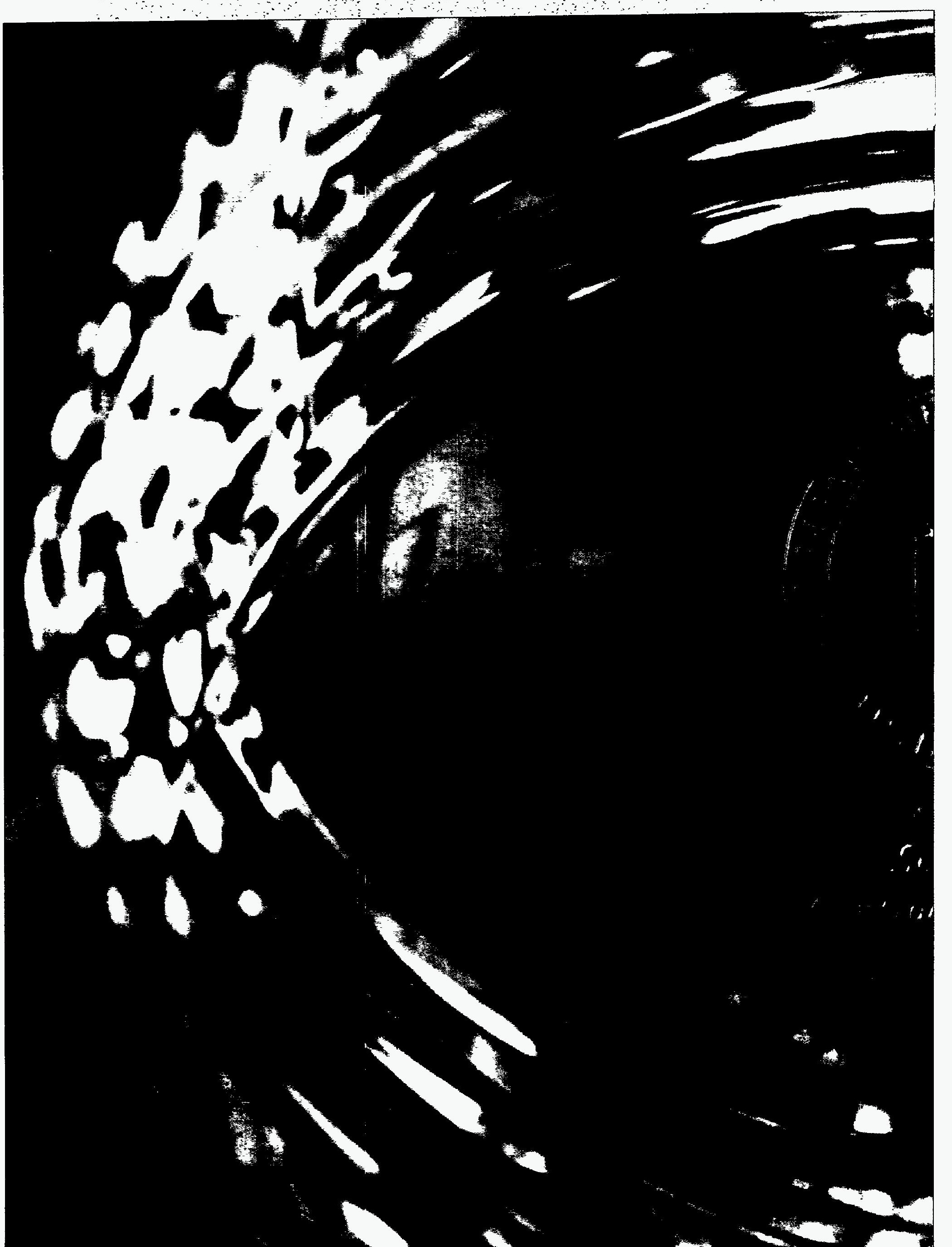




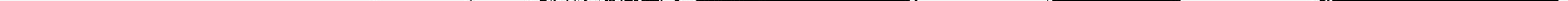




\section{Awards}

\section{Professional society and prestigious awards}

Mike Cieslak

Robert Graham

Walter Herrmann

Gary Kellogg

Al Narath

Gordon Osbourn

Carl Peterson

\section{Other prestigious awards}

Keith Almquist

\section{Carol Ashby \\ David Ginley \\ Jon Martens \\ Tom Plut}

Ted Blacker

Ray Meyers

John Biffle

Michael Stephenson (BYU)

Roger Cass (BYU)

Don Cook

Rich Diver (SNL)

Cummins Power Generation, Inc.

Sunpower, Inc.

Thermacore, Inc.

David Haaland

David Melgaard

Thomas Niemczyk (UNM)

Bob Hughes

Jose Rodriguez

Wayne Corbett

Paul Klarer

Jim Purvis

Kent Biringer

Mike Maguire
American Welding Society Professor Masubuchi/Shinso Corporation Award

American Physical Society 1993 Shock Compression Award

Academy of Engineering fellow

American Physical Society fellow

American Association for the Advancement of Science fellow

American Physical Society International Prize for New Materials

American Institute of Aeronautics and Astronautics fellow

Central Intelligence Agency National Intelligence Meritorious Unit Citation for his role as a member of the Nuclear Weapons Security and Logistics Working Group

$R \& D 100$ Award for development of a family of water-based chelating etches for the photolithographic processing of metal-oxide thin films used in the development of microelectronic devices

R\&D 100 Award for development of a mesh-generation algorithm called "paving" that enhances computer-aided design of numerous industrial products

Fusion Power Associates 1993 Leadership Award

R\&D 100 Award for development of a solar parabolic dish system for converting sunlight into electricity

Semiconductor Research Corporation, Durham, NC, 1992 Technical Award of Excellence for research of methods for measuring the quality of microelectronic circuits using infrared spectroscopy and chemometrics

R\&D 100 Award for development of a microsensor that can detect hydrogen in a wide array of industrial applications

Design Engineering magazine monthly international design competition with the Robotic All-Terrain Lunar Exploration Rover (RATLER)

American Welding Society Charles H. Jennings Memorial Award 


\author{
Sandia Labs \\ Annette Sobel \\ Jim Sweet \\ Dave Peterson \\ Melanie Tuck \\ Larry Teufel (Sandia) \\ Douglas Rhett and \\ Helen Farrell (Phillips Petroleum) \\ Margie Whipple
}

\section{DOE/DoD awards}

\section{Bob Bradley}

Dick Brodie

Dick Craner

Mark Dickinson

Wil Gauster

Orval Jones

Al Narath

Heinz Schmitt

Wendell Weart
Society of Manufacturing Engineers Citation for Economic Development

Aerospace Medical Association 1993 Julian E. Ward Memorial Award

R\&D 100 Award for development of a family of integrated circuits used to test semiconductor assembly and packaging processes

1993 U.S. National Committee for Rock Mechanics Case History Award for work described in the paper "Effect of reservoir depletion and pore pressure drawdown on in-situ stress and deformation in the Ekofisk Field, North Sea"

Society of Women Engineers Distinguished New Engineer Award for 1993

Secretary of Defense Federal Advisory Committee on Nuclear Failsafe and Risk Reduction (FARR) Award for Excellence for contributions to FARR's Remote Destruct Study Group

Department of Energy Distinguished Associate Award for distinguished and unique contributions to the surety of nuclear weapons and nuclear weapon systems, and for outstanding leadership in an area of utmost importance to the security of the United States

1993 Department of Energy Classification Award for Excellence

Secretary of Defense Federal Advisory Committee on Nuclear Failsafe and Risk Reduction (FARR) Award for Excellence for contributions to FARR's Positive Control Materials and Devices Study Group

Department of Energy Distinguished Associate Award for outstanding contributions to the nation's fusion energy program, particularly in the areas of fusion plasma materials interactions and high heat flux components, and continuing efforts to further international collaboration in fusion

Department of Energy Distinguished Associate Award for distinguished and unique contributions to nuclear weapon safety and security and for outstanding leadership in establishing programs of utmost importance to the security and economic well-being of the United States

Secretary of Energy Outstanding Contractor Manager Award for 1992

Secretary of Defense Federal Advisory Committee on Nuclear Failsafe and Risk Reduction (FARR) Medal for Outstanding Public Service for serving as Chairman of FARR's Technology Working Group from 5/91 through 10/92

Secretary of Energy Outstanding Contractor Program Manager Award for 1992 


\section{Patents}

Advanced motor-driven clamped borehole seismic receiver B.P. Engler, G. E. Sleefe, R. P. Striker

Patent \#5,189,262

Apparatus and method for laser velocity interferometry L. L. Bonzon, O. B. Crump Jr., P. L. Stanton, W. C. Sweatt Patent \#5,245,473

Apparatus and method for measuring and imaging surface resistance

J. S. Martens, V. M. Hietala, G. K. G. Hohenwarter

Patent \#5,239,269

Apparatus and method to enhance $X$-ray production in laser-produced plasmas

A. L. Augustoni, J. B. Gerardo, T. D. Raymond

Patent \# 5,175,757

Chloromethyl chlorosulfate as a voltage delay inhibitor in lithium cells

F.M.Delnick

Patent \#5,202,203

Crystalline titanate catalyst supports

R. G. Anthony, R. G. Dosch, B. Tex

Patent \#5,177,045

Digitally controlled distributed-phase shifter

V. M. Hietala, S. H. Kravitz, G. A. Vawter

Patent \#5,237,629

Electrically controlled polymeric gel actuators

D. B. Adolf, D. J. Segalman, M. Shahinpoor, W. R. Witkowski

Patent \#5,250,167

Hybrid sol-gel optical materials

J. M. Ziegler

Patent \#5,204,381

Method for forming hermetic coatings for optical fibers

T. A. Michalske, R. R. Rye, W. L. Smith

Patent $\# 5,246,746$

Integrated optical tamper sensor with planar waveguide

R.F. Carson, S. A. Casalnuovo

Patent \#5,177,352

Method and apparatus for acoustic plate mode liquid-solid phase transition detection

D. S. Blair, G. C. Frye, R. C. Hughes, S. J. Martin, A. J. Ricco

Patent \#5,187,980
Method of producing strained-layer semiconductor devices via subsurface patterning

B.W. Dodson

Patent \#5,225,368

Method for simultaneous measurement of mass loading and fluid property changes using a quartz crystal microbalance

V.E. Granstaff, S. J. Martin

Patent \#5,201,215

Method and split-cavity oscillator/modulator to generate pulsed particle beams and electromagnetic fields

P. D. Coleman, M. C. Clark, B. M. Marder

Patent $\# 5,235,248$

Micromachined resonator

N. A. Godshall, D. R. Koehler, A. Y. Liang, B. K. Smith

Patent \#5,198,716

Multiple-frequency acoustic wave devices for chemical sensing and materials characterization in both gas and liquid phase

S. J. Martin, A. J. Ricco

Patent \#5,235,235

Planar photovoltaic solar concentrator module

C. J.Chiang

Patent \# 5,167,724

Process for making solid state radiation-emitting composition

C. S. Ashley, C. J. Brinker, S. T. Reed, R. J. Walko

Patent \#5,240,647

Quantitative method for measuring heat flux emitted from a cryogenic object

R.V.Duncan

Patent \# 5,193,909

Reflection mass spectroscopy technique for monitoring \& controlling composition during molecular beam epitaxy T. M. Brennan, B. E. Hammons, J. Y. Tsao

Patent \# 5,171,399

Sequencing and fan-out mechanism for causing a set of at least two sequential instructions to be performed in a dataflow processing computer

V. G. Grafe, J.E. Hoch

Patent \#5,226,131 
Published by Sandia National Laboratories

Sandia is a multiprogram engineering and science Department of Energy with major facilities at Albuquerque, New Mexico, and Livermore, California, and a test range near Tonopah, Nevada. We have major research and development responsibilities for nuclear weapons, arms control, energy, the environment, economic competitiveness, and other areas of importance to the nation. Our principal mission is to support national defense policies by ensuring that the nuclear weapon stockpile meets the highest standards of safety, reliability, security, use control, and military performance. laboratory operated by Martin Marietta Corporation for the

Laboratory Communications, Sandia National Laboratories

Writing and Editing Linda Doran (lead) H.L. Floyd Bob Goetsch Colleen Keane (TRI) Jim Leonard Lori Parrott Dan Scott (TRI)

Graphic Design and Illustration Jim Bolton (TRI)

Toby Dickey Carl Hamberg (TRI) Janet Jenkins Kay Rivers-Stroup

Photography Wayne Gravning Lynda Hadley Bob McInteer Randy Montoya Mark Nohl, NM Economic Development \& Tourism

Send change of address (include old address) and requests for additional copies to the address below, or telefax to (505) 844-1392.

Publications Administrator Debbie Johnson (505) 844-4902

Sandia National Laboratories Laboratory Communications Dept.

P.O. Box 5800

Albuquerque, New Mexico 87185-0129

SAND93-2687

DOE Distribution Category UC900
Printed in the United States of America Available from

National Technical Information Service U.S. Department of Commerce 5285 Port Royal Road Springfield, Virginia 22161

(703) $487-4600$ 